University of Tennessee Health Science Center

UTHSC Digital Commons

$12-2008$

\title{
Predictors of Depressive Symptoms and Obesity in African American Women Transitioning from Welfare to Work
}

\author{
Mayola Rowser \\ University of Tennessee Health Science Center
}

Follow this and additional works at: https://dc.uthsc.edu/dissertations

Part of the Behavior and Behavior Mechanisms Commons, and the Mental and Social Health Commons

\section{Recommended Citation}

Rowser, Mayola, "Predictors of Depressive Symptoms and Obesity in African American Women Transitioning from Welfare to Work" (2008). Theses and Dissertations (ETD). Paper 356. http://dx.doi.org/ 10.21007/etd.cghs.2008.0269.

This Dissertation is brought to you for free and open access by the College of Graduate Health Sciences at UTHSC Digital Commons. It has been accepted for inclusion in Theses and Dissertations (ETD) by an authorized administrator of UTHSC Digital Commons. For more information, please contact jwelch30@uthsc.edu. 


\title{
Predictors of Depressive Symptoms and Obesity in African American Women Transitioning from Welfare to Work
}

\author{
Abstract \\ Depression and obesity are significant public health problems that adversely affect the health and quality \\ of life of women in the United States, particularly female African American welfare recipients transitioning \\ to work. African American women are twice as likely to experience depressive symptoms as women of \\ other races. Fifty percent of African American women are obese. The prevalence of depression and \\ depressive symptoms and obesity is higher among African American women who receive welfare \\ benefits. These health conditions jeopardize their health status, ability to work, and chances to become \\ self-sufficient. To ensure the successful transition of recipients to work, health care providers and \\ researchers must better understand how depression and obesity affect the overall health status of \\ African American women on welfare. It is imperative that factors that predict these disorders in this \\ population are identified and used to guide risk reduction interventions. Few studies have examined risk \\ factors for depressive symptoms and obesity and the relationships among these variables in African \\ American women welfare recipients moving into the workforce. Thus, the purposes of this study were to \\ describe the prevalence of depressive symptoms, obesity, and health risk behaviors among African \\ American women transitioning from welfare to work. Additionally, the investigator explored the \\ associations among health risk behaviors (physical inactivity, poor nutrition, smoking, and alcohol \\ consumption), personal demographic risk factors (age and education), one biological risk factor (BMI), \\ perceived health, depressive symptoms, and obesity in this population. This descriptive, correlational \\ study utilized a secondary data source to examine the health assessments of 162 African American \\ women aged 18 to 55 years, enrolled in welfare to work program at a large research university in the mid- \\ southern region of the United States. Three instruments were used to assess study variables: the \\ Healthier People Network Health Risk Appraisal (HPN-HRA), the Perceived Health Status Appraisal, and \\ the Center for Epidemiological Studies Depression Scale (CESD). Thirty-five percent of the participants \\ reported moderate levels of depressive symptoms (CES-D score 21-30). Twelve percent of participants \\ reported severe levels of depressive symptoms (CES-D score $\geq 30$ ). Forty-eight percent of the \\ participants had body mass index (BMI) scores $\geq 30 \mathrm{~kg} / \mathrm{m}^{2}$. The average BMI was $33.6 \pm 6.7 \mathrm{~kg} / \mathrm{m}^{2}$ which is \\ indicative of obesity. Despite the high rates of depressive symptoms and obesity found in this sample, \\ there were no statistically significant relationships indicated between depressive symptoms and obesity. \\ Findings warrant further investigation to improve health outcomes of African American women \\ transitioning from welfare to work. Long term retention in the workforce and economic independence are \\ closely linked to the health status of recipients. More prospective studies are needed to determine the \\ pathways by which depressive symptoms and obesity interact in this population in order to develop \\ tailored effective prevention strategies.
}

\section{Document Type}

Dissertation

\section{Degree Name}

Doctor of Philosophy (PhD)

\section{Program}

Nursing

Research Advisor

Muriel Curry Rice, Ph.D. 


\section{Keywords}

Depressive symptoms, obesity, African American women, welfare, health risk behaviors, personal risk factors

\section{Subject Categories}

Behavior and Behavior Mechanisms | Medicine and Health Sciences | Mental and Social Health |

Psychiatry and Psychology 


\title{
PREDICTORS OF DEPRESSIVE SYMPTOMS AND OBESITY IN AFRICAN AMERICAN WOMEN TRANSITIONING FROM WELFARE TO WORK
}

\author{
A Dissertation \\ Presented for \\ The Graduate Studies Council \\ The University of Tennessee \\ Health Science Center
}

\author{
In Partial Fulfillment \\ Of the Requirements for the Degree \\ Doctor of Philosophy \\ From The University of Tennessee
}

By

Mayola Rowser

December 2008 
Copyright (C) 2008 by Mayola Rowser

All rights reserved 


\section{DEDICATION}

This dissertation is dedicated to my parents, Hubert R. and Mary L. Barbry, my little brothers David and Jeffrey Barbry and my husband, DeJuan Rowser, whose memories serve as my source of inspiration and motivation. 


\section{ACKNOWLEDGEMENTS}

I would like to thank my dissertation advisor, Dr. Muriel C. Rice, for her assistance in helping me reach this professional milestone. Additionally, I would like to express my gratitude to the other members of my dissertation committee: Drs. Patricia Cowan, Patricia Cunningham, Mona Wicks, and Hossein Yarandi for their support and guidance through this journey. I would also like to acknowledge the support and mentoring I received from Dr. Nadine Coudret, Dr. Faye Gary, Ms. Janet Jackson, Dr. Ann White, Dr. Catherine Ehlman, and the encouragement from my colleagues at the University of Southern Indiana. Most importantly, words cannot express how grateful I am for the love and support of my children DeJuan and Darius and my soul mate, Steve. I also would like to thank my sister, Deborah, my brothers, Ray and Al, my mother in law, Ethel, and my nieces, Deirdre and Teresa for their understanding and continuous encouragement. I have the best friends in the world and I would like to extend my sincere gratitude to Sharon Marie, Sharon Elaine, Arlinda, Donnita, Dr. Jan Collins McNeil, Dr. Lois Bolden, Winnetta, Ella, and Pam for their encouragement and support during this process. Funding for this research was provided by a fellowship from the Ethnic Minority Fellowship from Substance Abuse Mental Health Services Administration (SAMHSA). 


\begin{abstract}
Depression and obesity are significant public health problems that adversely affect the health and quality of life of women in the United States, particularly female African American welfare recipients transitioning to work. African American women are twice as likely to experience depressive symptoms as women of other races. Fifty percent of African American women are obese. The prevalence of depression and depressive symptoms and obesity is higher among African American women who receive welfare benefits. These health conditions jeopardize their health status, ability to work, and chances to become self-sufficient. To ensure the successful transition of recipients to work, health care providers and researchers must better understand how depression and obesity affect the overall health status of African American women on welfare. It is imperative that factors that predict these disorders in this population are identified and used to guide risk reduction interventions. Few studies have examined risk factors for depressive symptoms and obesity and the relationships among these variables in African American women welfare recipients moving into the workforce. Thus, the purposes of this study were to describe the prevalence of depressive symptoms, obesity, and health risk behaviors among African American women transitioning from welfare to work. Additionally, the investigator explored the associations among health risk behaviors (physical inactivity, poor nutrition, smoking, and alcohol consumption), personal demographic risk factors (age and education), one biological risk factor (BMI), perceived health, depressive symptoms, and obesity in this population. This descriptive, correlational study utilized a secondary data source to examine the health assessments of 162 African American women, aged 18 to 55 years, enrolled in welfare to work program at a large research university in the mid-southern region of the United States. Three instruments were used to assess study variables: the Healthier People Network Health Risk Appraisal (HPN-HRA), the Perceived Health Status Appraisal, and the Center for Epidemiological Studies Depression Scale (CESD). Thirty-five percent of the participants reported moderate levels of depressive symptoms (CES-D score 21-30). Twelve percent of participants reported severe levels of depressive symptoms (CES-D score $\geq 30$ ). Fortyeight percent of the participants had body mass index (BMI) scores $\geq 30 \mathrm{~kg} / \mathrm{m}^{2}$. The average BMI was $33.6 \pm 6.7 \mathrm{~kg} / \mathrm{m}^{2}$ which is indicative of obesity. Despite the high rates of depressive symptoms and obesity found in this sample, there were no statistically significant relationships indicated between depressive symptoms and obesity. Findings warrant further investigation to improve health outcomes of African American women transitioning from welfare to work. Long term retention in the workforce and economic independence are closely linked to the health status of recipients. More prospective studies are needed to determine the pathways by which depressive symptoms and obesity interact in this population in order to develop tailored effective prevention strategies.
\end{abstract}




\section{TABLE OF CONTENTS}

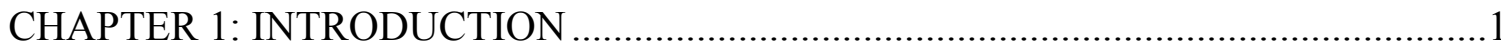

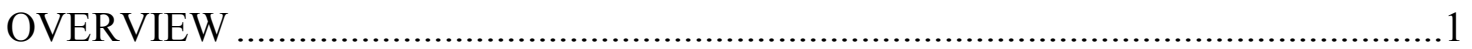

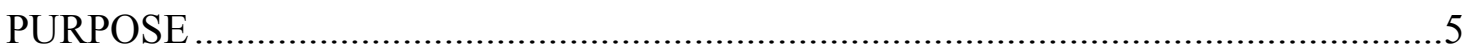

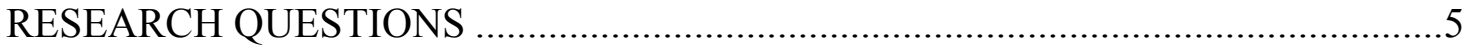

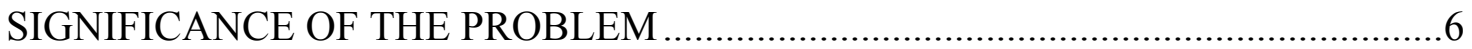

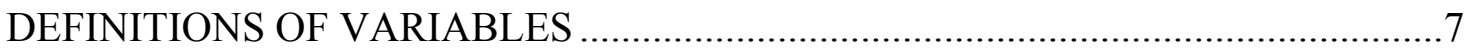

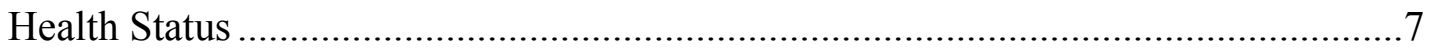

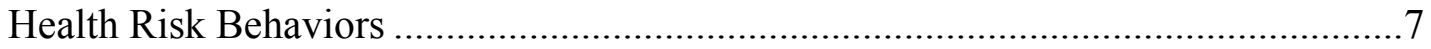

Physical inactivity …………………..................................................

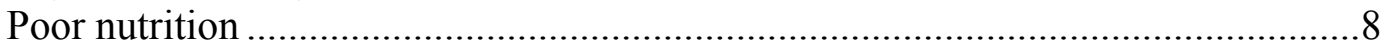

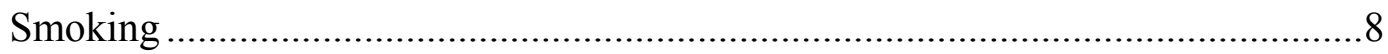

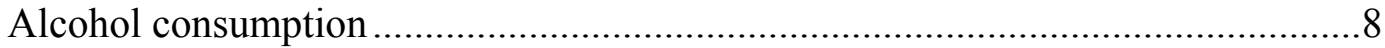

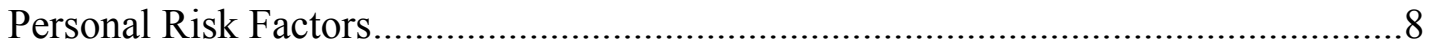

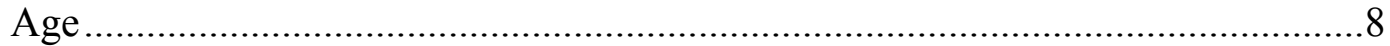

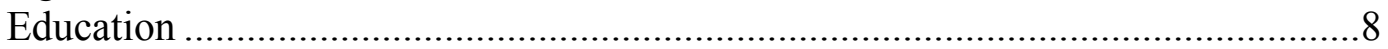

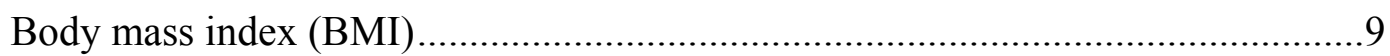

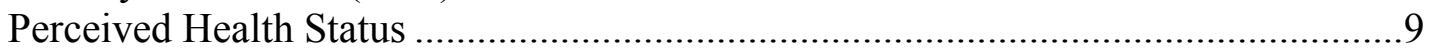

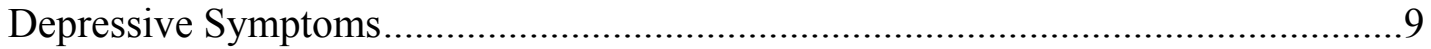

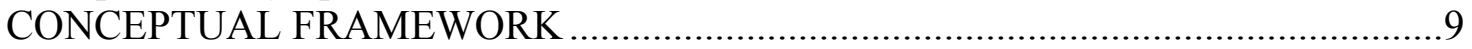

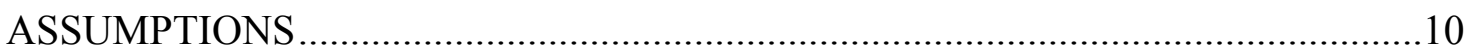

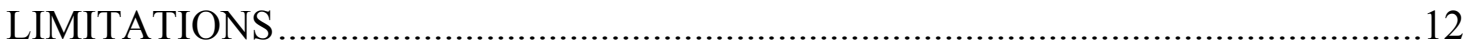

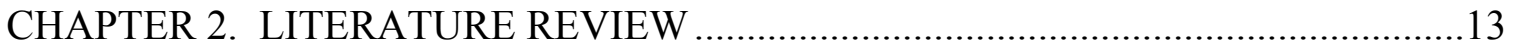

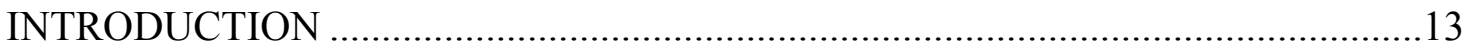

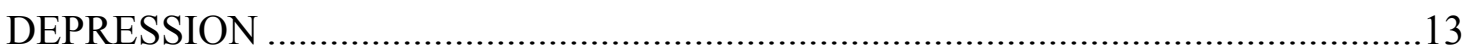

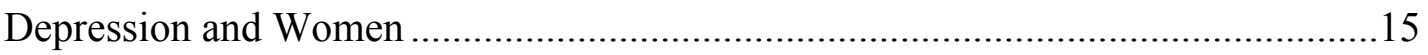

Depression and Women on Welfare …………………....................................15

Depression and African American Women .........................................................16

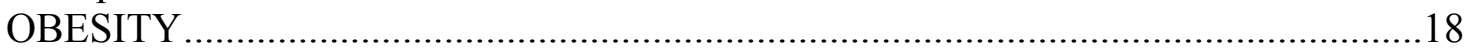

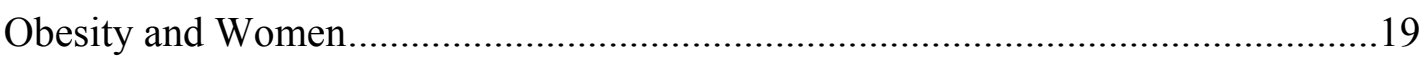

Obesity and Women on Welfare

Obesity and African American Women...........................................................20

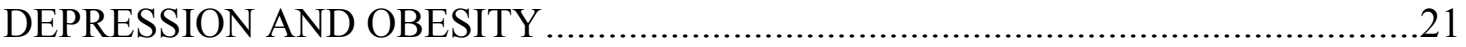

Health Risk Behaviors and Depression..............................................................24

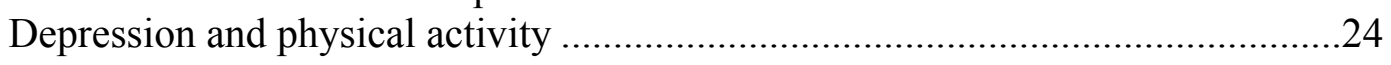

Depression and nutritional intake ....................................................................25

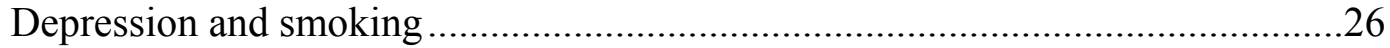

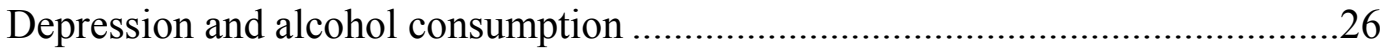

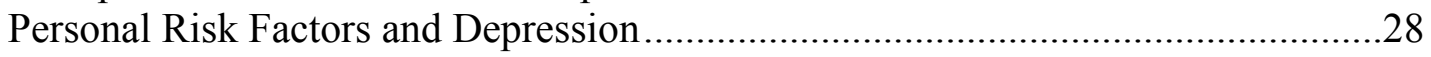

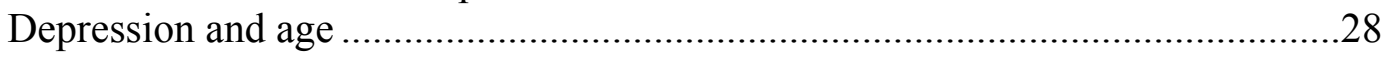

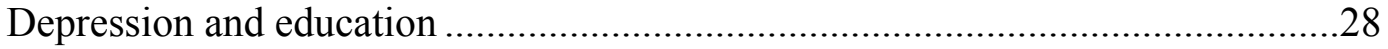

Depression and body mass index ..................................................................29

Depression and Perceived Health Status.................................................................29 
Health Risk Behaviors and Obesity ..........................................................................30

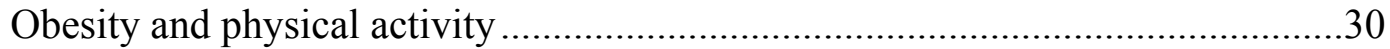

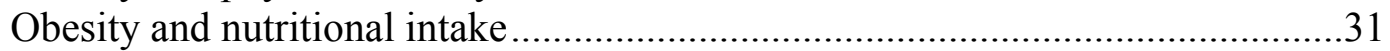

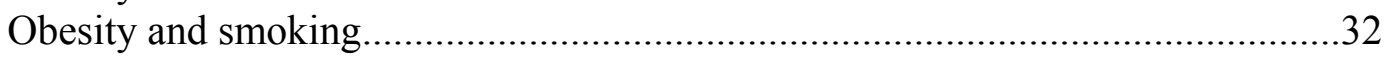

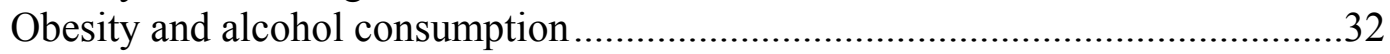

Personal Risk Factors and Obesity ………………...............................................33

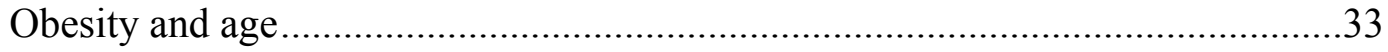

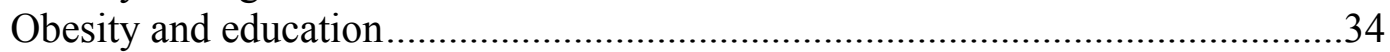

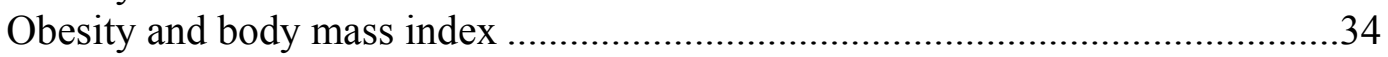

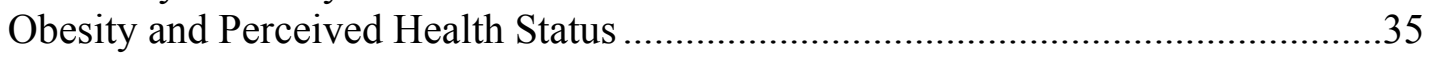

SUMMARY OF THE REVIEW OF LITERATURE.................................................36

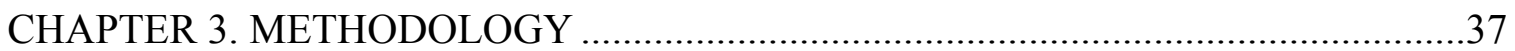

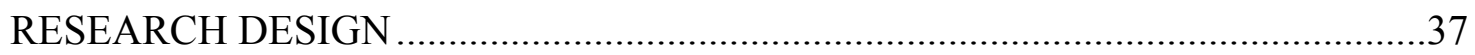

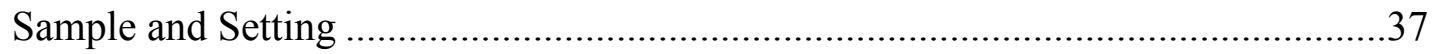

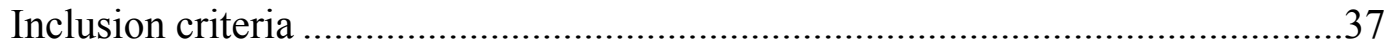

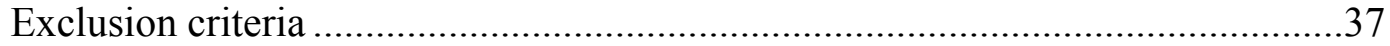

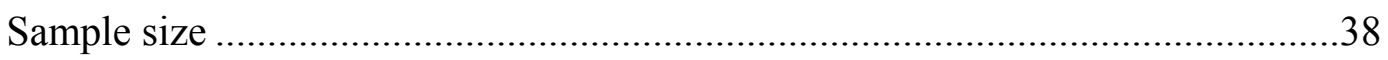

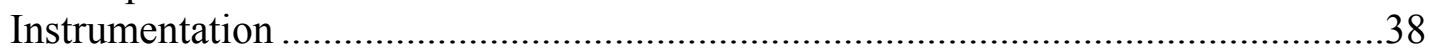

Healthier People Network Health Risk Appraisal (HPN - HRA, Version 6.0) .....38

Health Self Report Appraisal ............................................................................39

Center for Epidemiologic Studies Depression Scale (CES-D) ................................39

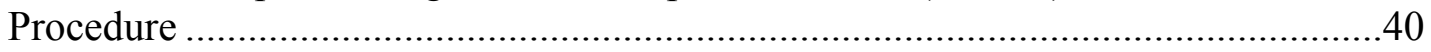

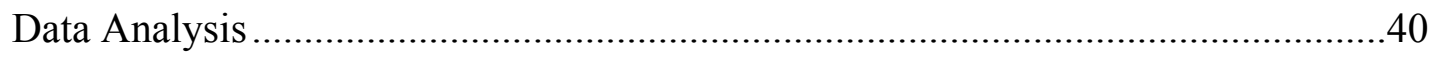

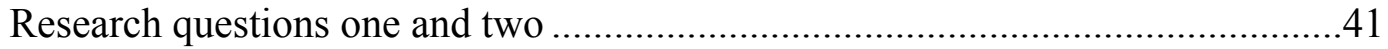

Research question three ............................................................................ 41

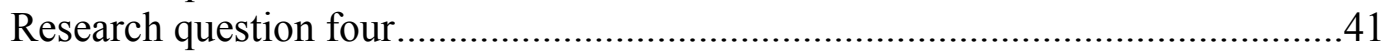

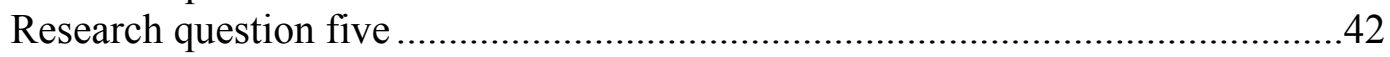

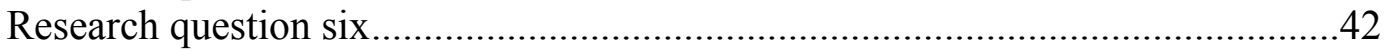

CONSIDERATION OF HUMAN SUBJECTS ........................................................43

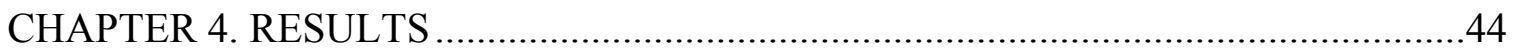

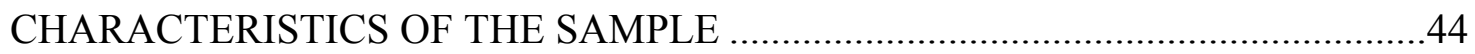

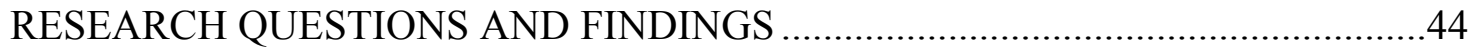

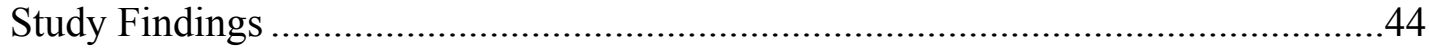

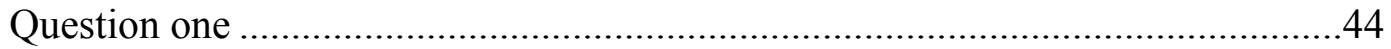

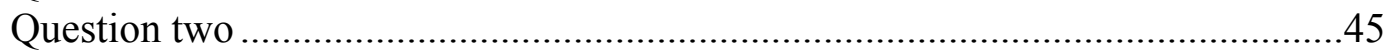

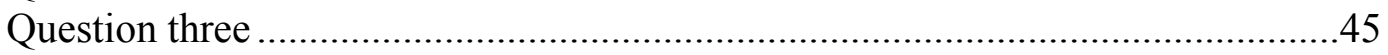

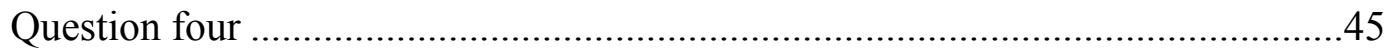

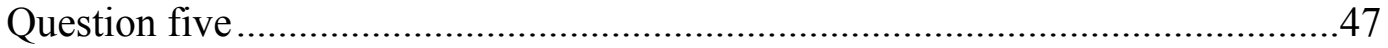

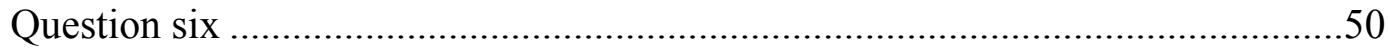

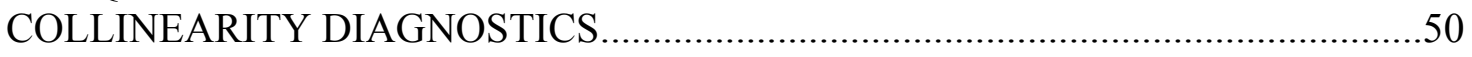


CHAPTER 5. DISCUSSION AND IMPLICATIONS …………....................................53

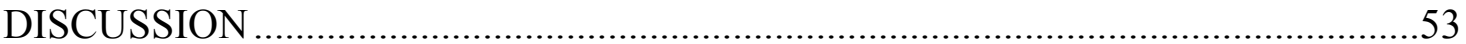

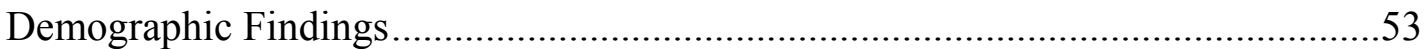

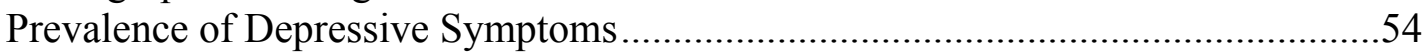

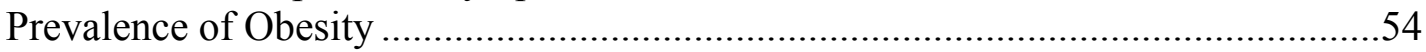

Relationship between Depressive Symptoms and Obesity ........................................54

Prevalence of Health Risk Behaviors ...................................................................55

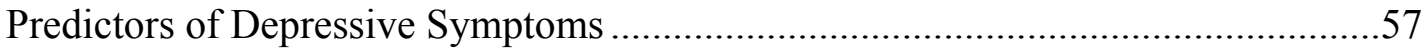

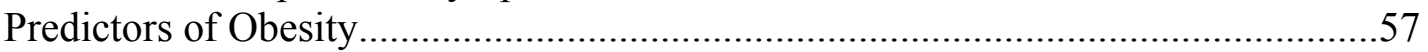

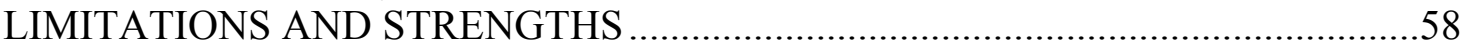

Implications for Practice and Policy ………………….......................................59

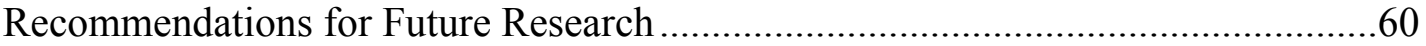

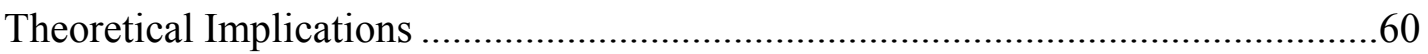

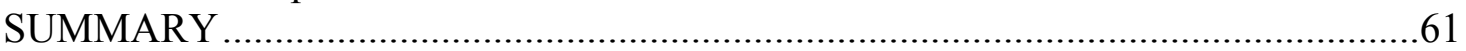

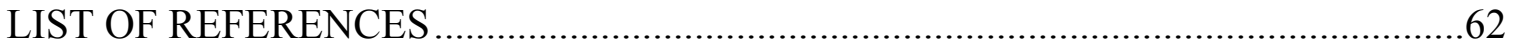

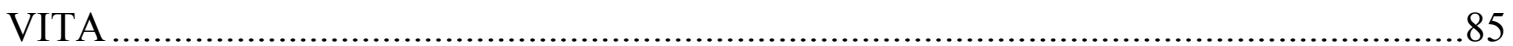




\section{LIST OF TABLES}

Table 1. Body Mass Index of African American Women Transitioning from

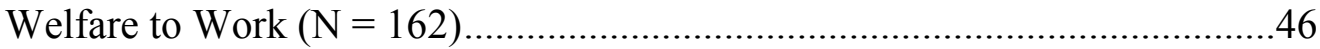

Table 2. Health Behaviors Reported by African American Women Transitioning from Welfare to Work $(\mathrm{N}=162)$.................................................................48

Table 3. Correlation Analysis between Sample Characteristics and Depressive

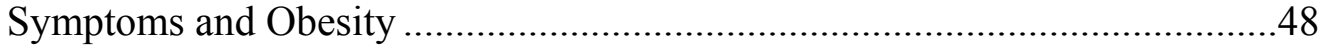

Table 4. Optimal Regression Results of Depressive Symptoms................................49

Table 5. Dummy Coding of the Nominal Variables ..............................................49

Table 6. Optimal Regression Results of Obesity ...................................................51

Table 7. Odds Ratio Estimates .............................................................................. 51

Table 8. Collinearity Diagnostics for the Model of Depressive Symptoms $(\mathrm{N}=$

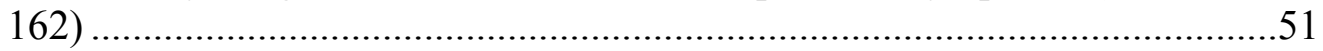

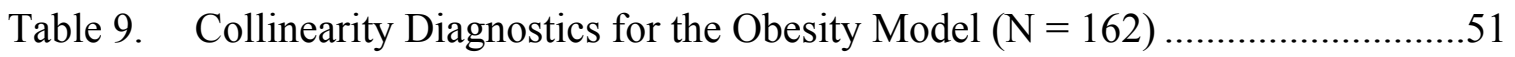




\section{CHAPTER 1: INTRODUCTION}

\section{OVERVIEW}

Depression and obesityy are significant public health indicators that threaten the health status and quality of life of women in the United States, particularly African American women moving from welfare to work. Women on welfare represent one of the most disadvantaged segments of our society; 39\% of are single African American women with children (Parvez, 2002). The prevalence of mental and physical health problems, depression, and obesity, is higher among welfare recipients than other populations (Romero, Chavkin, Wise, Smith, \& Wood, 2002). Moreover, African American women reportedly have more mental and physical health problems than women of other races (Corcoran, Danziger, \& Tolman, 2003). Thus, African American women who are also welfare recipients face significant health risk.

Depression and its related symptoms are the primary cause of disability and increased mortality among women. The prevalence of depression is $1.5 \%$ to $3.0 \%$ higher among women than in men (Lennon et al., 2001). Approximately $20 \%$ of all women will experience depressive symptoms or depression in their lifetime (Danziger \& Seefeldt, 2002). Several studies indicate that African American women are twice as likely to suffer from depression as Caucasian women (de Groot, Auslander, Williams, Sherraden, \& Haire-Joshu 2003; Lennon et al., 2001); however, other studies do not support this finding (McCoy, 2003; Poleshuck, Guiles \& Tu, 2006).

The rates of depression range from $12 \%$ to $36 \%$ among women on welfare (Lennon et al., 2001). Chronic illness or disability and involvement in an abusive or violent relationship (common findings among welfare recipients) significantly increase the risk for depression among welfare recipients (Lennon et al., 2001). Findings from the only longitudinal study conducted to assess the impact of welfare on psychological health, indicated that mood disorders such as depression, are a risk factor for and outcome of receiving welfare (Danziger et al., 2000). Furthermore, depression, and the associated sequelae, interferes with the ability of women to leave welfare for work (Siefert, Bowman, Heflin, Danziger, \& Williams, 2000).

The impact of depression on quality of life is far-reaching. The pervasive symptoms of depression affect sleep and eating patterns, energy levels, the desire to participate in leisure activities, and the ability to fulfill work-related responsibilities. The direct and indirect cost associated with depression, depends upon the severity of symptoms and impairment; however, costs estimates exceed $\$ 83$ billion annually (Lerner et al., 2004). The cost associated with untreated depression and loss of productivity typically surpasses the cost of treatment (Sipkoff, 2006).

Depression is a progressive disorder and is known to precipitate many other chronic health problems including asthma, arthritis, and obesity (Chapman, Perry, \&

Strine, 2005). Furthermore, while a significant number of persons who are obese are not 
depressed, studies have demonstrated a connection between obesity and an increase in depressive symptoms among women (Rumpel, Ingram, Harris, \& Madans, 1994).

The rate of obesity has reached epidemic proportions among women in the United States. Data obtained from the 2003-2004 National Health and Nutrition Examination Survey (NHANES) indicated that $33 \%$ of women in this country are obese (Ogden et al., 2006). The highest rates of obesity are among African American women (Ogden et al., 2006; York et al., 2004). The prevalence of obesity is especially high among women receiving welfare benefits. In one study, welfare recipients were twice as likely to be obese as non-recipients (Kaplan et al., 2005). This finding is particularly problematic as obesity is a barrier for women leaving welfare for work. Obesity in Caucasian women was associated with a $12 \%$ decrease in employment possibilities and in African American women obesity was associated with extended periods of time and dependence on welfare (Cawley \& Danziger, 2005).

Obesity is one of the leading causes of morbidity and mortality among women (Lemay et al., 2003). Persons who are obese are at a greater risk of dying from obesity related causes (50\% to 100\%) compared to persons not obese (Salinsky \& Scott, 2003). More than $80 \%$ of obese persons have coronary artery disease, hypertension, elevated lipids, and osteoarthritis (Partnership for Prevention, 2005), and obesity is the primary risk factor in the development of type II diabetes (Hu, 2003).

Obesity is also associated with increased utilization of health care resources, decreased work force participation, low earning potential, and unfavorable employment outcomes (Cawley \& Danziger, 2005; Wyatt, Winters, \& Dubbert, 2006). In the context of the transition from welfare to work, this risk-profile is particularly problematic. Medical expenses and lost wages associated with obesity were estimated at $\$ 117$ billion in 2000 (Salinsky \& Scott, 2003) and the cost are expected to increase as the prevalence of obesity increases. Moreover, at least one-half of medical related cost associated with obesity will be financed by the public through Medicaid and Medicare funding (Salinksy $\&$ Scott, 2003); obese African American women receiving welfare (e.g. Medicaid) are likely included in this cost estimate.

A growing number of researchers have investigated the relationship between depression and obesity. Depression and obesity share common health problems such as hypertension, dyslipidemia, diabetes, cardiovascular disease, and increased mortality rates although a causal link has not been established between these two disorders. Surveys conducted in the U.S. have found positive associations between depression and obesity among women but not among men (Carpenter, Hasin, Allison, \& Faith, 2000; Istvan, Zavela, \& Weidner, 1992; Palinkas, Wingard, \& Barrette-Connor, 1996). Some researchers have suggested that the association between depression and obesity occurs through multiple mechanisms rather than a single or unidirectional pattern of association (Faith, Matz, \& Jorge, 2002). In contrast, other investigators contend that depression and obesity likely co-occur by chance given the high prevalence of both of these disorders (McElroy et al., 2004). 
Researchers also speculate that depression may precipitate obesity and obesity may increase symptoms of depression (Chapman, Perry, \& Strine, 2005). Findings from studies have demonstrated that weight gain is a common side effect of treatment for depression (Devlin, Yanovski, \& Wilson, 2000) and, furthermore, medications used to treat obesity related complications frequently exacerbate depressive symptoms (Brown \& Stoudemire, 1998). Most studies examining the association between depression and obesity have been conducted with Caucasian samples; thus these findings may not be relevant for other populations such as African American women transitioning from welfare to work.

Although there is a lack of consensus on the exact nature of the relationship between depression and obesity, researchers agree that low socioeconomic (SES) status is a risk factors in the development of both depression and obesity. The rates of depression range from $12 \%$ to $36 \%$ among women on welfare (Lennon et al., 2001). Chronic illness or disability and involvement in an abusive or violent relationship (common findings among welfare recipients) significantly increase the risk for depression among welfare recipients (Lennon et al., 2001). Findings from the only longitudinal study conducted to assess the impact of welfare on psychological health, indicated that mood disorders, such as depression, are a risk factor for and outcome of receiving welfare (Danziger et al., 2000). Furthermore, depression and the associated sequelae interfere with the ability of women to leave welfare for work (Siefert et al., 2000).

Despite the abundance of evidence available on the prevalence of depression and obesity in the general population and among low income and poor persons, few studies have specifically investigated the influence of depressive symptoms and obesity on the health status and economic independence of African American women transitioning from welfare to work. In the proposed study, the investigator will examine the relationship between depressive symptoms and obesity and explicate risk factors that predict the development of these disorders in female African American welfare recipients moving into the workforce. It is crucial to identify recipients who are at increased risk for developing depressive symptoms and obesity to prevent the adverse health and economic outcomes associated with these disorders.

There are multiple factors that may influence the association between depressive symptoms and obesity in African American women leaving welfare for employment. These factors include health risk behaviors, personal risk factors, perceived health status, and situational influences. These factors were derived from Muriel Rice's Health Assessment Status model, which served as the conceptual framework for the current study. Rice's model was influenced by her experience with women on welfare, current literature, and Nola Pender's Health Promotion model (Pender, 1996). This framework is described in detail in the conceptual framework section of this chapter.

Health risk behaviors are harmful activities that lead to adverse health outcomes including depressive symptoms and obesity (National Center for Chronic Disease Prevention and Health Promotion, 2006). Health risk behaviors included in this study were: physical inactivity, poor nutrition, smoking, and alcohol consumption. Physical 
inactivity is more common among persons of low socioeconomic status, women, African Americans, and Hispanics (Haskell et al., 2007). Similarly, poor nutrition is present in $35 \%$ of low income households and is more common among ethnic minorities (Leff, 2002) and is positively associated with depression (Beardsley, 2000) and obesity (Brownell, 2002; Crawford, 2004). Overeating is a common manifestation of depression especially among African American women, resulting in unintended weight gain and obesity (Marano, 2003).

Smoking and alcohol consumption are also problematic in the study population. Recent prevalence data indicate that $24 \%$ of African American women are current smokers and poor African Americans have the lowest smoking cessation rates in the United States (National Cancer Institute, 2005). Moreover, women who smoke are more likely to have depressive symptoms or clinical depression (Morbidity and Mortality Weekly Review, 2002) and smoking is associated with central obesity in poor African American women (Office on Women's Health, 2001). Researchers estimate that $6 \%$ to $10 \%$ of women on welfare consume alcohol (Jayakody, Danziger, \& Pollack, 2000). Also, women employed while receiving welfare (e.g. transitioning from welfare to work) were more likely to report heavy drinking than unemployed women on welfare (Rodriguez \& Chandra, 2006). This drinking pattern could be the result of work-related stressors encountered by welfare recipients.

Personal risk factors are individual characteristics or traits that may influence the development of depressive symptoms and obesity. Personal risk factors that were examined in this study included demographic data (age and education) and one biological variable (body mass index). While age has been positively correlated with the onset of depression and obesity (McElroy et al., 2004), high rates of depression have been reported among African American women 20 to 29 years of age (Brown, Ahmed, Gary, \& Milburn, 1995). In a study of current and former welfare recipients $(\mathrm{N}=705), 46 \%$ of the recipients 25 to 34 years of age met the criteria for clinical depression. These findings are critical because most female welfare recipients are 18 to 35 years of age (Health Resources and Services Administration [HRSA], 2004). The prevalence of obesity also increases with age (Kushner, 2003; Office of Disease Prevention and Health Promotion, 2001), especially among African Americans (Burke et al., 1992).

In one study, education was inversely associated with the co-existence of depression and obesity in women on welfare (Division of Nutrition and Physical Activity, 2004). While obesity rates decline with increasing education among Caucasian women, this pattern has not been observed in African American women (Rosenberg, Palmer, Adams-Campbell, \& Rao, 1999). The reason for this inconsistency may reflect sociocultural influences related to perceptions about body image and beauty within African American communities. While depression has been linked to increased body mass index in women on welfare (McElroy et al., 2004), other investigators have not found a significant correlation between these variables.

Perceived health status was also measured in the current study and is a widely used measure of general health. Researchers report that a "fair to poor" perception of 
health was a predictor of depression in African American women on welfare (Brown, Ahmed, Gary, \& Milburn, 1995). This perception of "fair to poor" health is common among welfare recipients as $40 \%$ of African American women in one study described their health as fair to poor (Levin-Epstein, 2003). Although obese individuals in one study were more apt to report lower levels of perceived health than non-obese individuals (Kushner, 2003), perceptions of health were not influenced by obesity for some African American women in another study (Averett \& Korenman, 1999), perhaps because of differences in body image perceptions.

Situational influences are reflected in the chronic economic and environmental stressors faced by women on welfare, particularly African American women. Situational influences are marked by personal and family stressors associated with poverty and are also a consequence of the mandatory transition from welfare to work. Women on welfare are often forced to take low-paying, low-skill jobs with few or no benefits, and inflexible work schedules while struggling with child care responsibilities, few resources, and inadequate social support. Because the study sample was limited to African American women who shared the situational influence of receiving welfare benefits and its associated complexities, this variable was not measured in the current study.

\section{PURPOSE}

Depression and obesity are major public health issues that significantly threaten the independence of African American women receiving welfare (Carpenter et al., 2000). The health and economic welfare of this population will remain in jeopardy unless risk factors are identified. Therefore, the purposes of this study were to describe the prevalence of depressive symptoms, obesity, and health risk behaviors among African American women transitioning from welfare to work. Additionally the investigator explored the associations among health risk behaviors (physical inactivity, poor nutrition, smoking, and alcohol consumption), personal demographic risk factors (age and education), one biological risk factor (BMI), perceived health, depressive symptoms, and obesity in this population.

\section{RESEARCH QUESTIONS}

To address the above purposes, the following research questions were addressed in this study.

- What is the prevalence of depressive symptoms in African American women transitioning from welfare to work?

- What is the prevalence of obesity in African American women transitioning from welfare to work?

- What is the relationship between depressive symptoms and obesity in African American women transitioning from welfare to work?

- What is the prevalence of health risk behaviors in African American women transitioning from welfare to work? 
- To what extent do the following predict depressive symptoms in African American women transitioning from welfare to work:

- health risk behaviors (physical inactivity, poor nutrition, smoking, and alcohol consumption)

- personal demographic risk factors (age, education)

- personal biological risk factor (BMI)

- perceived health status

- To what extent do the following predict obesity in African American women transitioning from welfare to work:

- health risk behaviors (physical inactivity, poor nutrition, smoking, and alcohol consumption)

- personal demographic risk factors (age and education)

- personal biological risk factor (BMI)

- perceived health status

\section{SIGNIFICANCE OF THE PROBLEM}

In 1996, the Temporary Assistance to Needy Families (TANF) program replaced the Aid for Dependent Children program and reformed the welfare system. Reauthorization of the original TANF programs became effective as of July 2007. The new guidelines are more stringent and benefits will be further restricted. Reauthorization legislation focused on reducing welfare caseloads with work-first mandates, thus, many current recipients will no longer be eligible for benefits and will be required to find jobs. According to the National Longitudinal Youth Survey (NLYS), 90\% of women leaving welfare have at least one or more barriers that could potentially hinder their efforts to work (Olson \& Pavetti, 1996).

The barriers to work most frequently discussed by researchers and policymakers are limited education and lack of previous work experience and training (Olson \& Pavetti, 1996). Welfare recipients experience more health problems than the general population (Corcoran et al., 2003), yet little consideration has been given to the mental and physical health problems like depressive symptoms and obesity or the effect of these barriers on their ability to obtain and retain jobs. In a five year (1997 -2002) study of the health of welfare recipients, $85 \%$ of the participants reported mental or physical health problems at one or more waves of the study (Corcoran et al., 2003). Mental and physical health problems are also barriers to sustained employment; only $11 \%$ of welfare recipients with one or more barriers are able to maintain employment for one year (Olson \& Pavetti, 1996).

The chronic nature of depressive symptoms and obesity especially threaten the health and financial independence of African American women receiving welfare (Carpenter et al., 2000). The medical cost alone associated with depression approaches \$26 billion per year (Ramsey \& Glenn, 2002) and the medical cost associated with obesity exceeded \$61billion in 2000 (Kushner, 2003). Approximately 2 million Americans receive welfare and an estimated 39\% are single, African American women with children (Parvez, 2002). Thus, these health problems and their associated risk 
require investigation to facilitate the development of appropriate and effective interventions to eliminate these potential barriers to work, self sufficiency, and quality of life. Study findings therefore are relevant for multiple stakeholders including policymakers, researchers, health care providers, community leaders, and African American women on welfare, who together must work to address these issues.

\section{DEFINITIONS OF VARIABLES}

Theoretical definitions for the major concepts within the conceptual model are presented. In addition, because there are a variety of published definitions available for the terms used in this study, the following theoretical and operational definitions for the variables are provided and used in this study.

\section{Health Status}

Health is usually measured in terms of the absence of physical problems or disabilities likely to cause imminent death, emotional problems, and social dysfunction. Health status was determined by participant self report of physical health, mental wellbeing, and overall perception of health. The Healthier People Network Health Risk Appraisal (HPN - HRA, Version 6.0) assessment tool (available from Healthier People Network, 1991), the Health Self Report (Rice, 2008), and the Center for Epidemiological Studies Depression Scale (CES-D) (available from West Publishing Company, 1977) were used in this study to obtain information regarding the participants' current health status.

\section{Health Risk Behaviors}

Health risk behaviors (physical inactivity, poor nutrition, smoking, and alcohol consumption) are harmful activities that lead to adverse health outcomes including depressive symptoms and obesity (National Center for Chronic Disease Prevention and Health Promotion, 2006). Theoretical and operational definitions for these behaviors are described below.

\section{Physical inactivity}

The HPN-HRA defines physical activity as 20 minutes of physical activity at least one to three times per week. Physical inactivity was defined by a negative response to the physical activity question on the HPN-HRA form. 


\section{Poor nutrition}

For the purpose of this study, nutritional intake consists of diets high in saturated fats, sodium, and sugar and high in fruits, vegetables, whole grains, calcium, and fiber Poor nutrition was determined by the self-reported regular ingestion of a diet high in saturated fats, sodium, and sugar, and low in fruits, vegetables, whole grains, and fiber as specified on the HPN-HRA form.

\section{Smoking}

Smoking is the current use of smoked tobacco. For the purpose of this study, smoking was defined by the participant's affirmative response on the HPN-HRA form of regular use of smoked tobacco.

\section{Alcohol consumption}

The current dietary guidelines recommend no more than one alcoholic beverage per day for women (Division of Adult and Community Health, 2006). Consumption of more than 14 alcoholic beverages per week is considered harmful drinking (Division of Adult and Community Health, 2006). For this study, alcohol consumption was defined by the self-reported number of alcoholic beverages consumed in one week as indicated on the HPN-HRA form.

\section{Personal Risk Factors}

Personal demographic risk factors (age and education) and personal biological risk factors (body mass index) are individual characteristics or traits that may influence the development of depressive symptoms and obesity.

Age

Age is defined as the length of time a person has lived. The participant's selfreported age in years at the time the assessment was administered was used for this study.

\section{Education}

Education is a program of instruction of a specified kind or level. The level of education was determined by participant selection of a category of schooling (grade school or less, some high school, high school graduate, some college, college graduate, post-graduate or professional degree) on the HPN-HRA. 


\section{Body mass index (BMI)}

The BMI correlates with the amount of body fat and is defined as the relative weight for height (National Center for Health Statistics, 2006). The National Institute of Health recommends BMI as the method for determining obesity (Bertakis \& Azari, 2005). For the purpose of this study, BMI was calculated as weight in kilograms divided by the square of the height in meters $\left(\mathrm{kg} / \mathrm{m}^{2}\right)$. BMI was categorized as underweight (less than $\left.18.5 \mathrm{~kg} / \mathrm{m}^{2}\right)$, normal weight $\left(18.5-24.9 \mathrm{~kg} / \mathrm{m}^{2}\right)$, overweight $\left(25-29 \mathrm{~kg} / \mathrm{m}^{2}\right)$, and obese $\left(30 \mathrm{~kg} / \mathrm{m}^{2}\right)$. The BMI was furthered categorized as obese I $\left(30-34.9 \mathrm{~kg} / \mathrm{m}^{2}\right)$, obese II $\left(35-39.9 \mathrm{~kg} / \mathrm{m}^{2}\right)$, and obese III $\left(\geq 40 \mathrm{~kg} / \mathrm{m}^{2}\right)$. The mean BMI score and standard deviation were also reported for the sample.

\section{Perceived Health Status}

Perceived health status is the personal evaluation of one's own health status. Perceived health status was defined by the participant's evaluation of her own health. The Health Self Report Appraisal (Rice, 2008), a ten point Cantrell ladder scale, was used to measure the participant's perception of her health for which "ten" indicated perfect health and "one" indicated lack of health.

\section{Depressive Symptoms}

Depressive symptoms are a constellation of symptoms that include the participant's self reported feelings of sadness, lack of interest in usual activities, changes in appetite and sleep patterns, guilt or shame, decreased concentration, decreased energy levels and increased or decreased motor activity (National Institute of Mental Health, 2004). The Center for Epidemiologic Studies (CES-D), a 20 item self report tool, was used to measure the frequency of depressive symptoms. Participants selected a response to the question asked that corresponded with the frequency of their depressive symptoms (i.e. less than one day per week, one to two days per week, three to four days per week, or five to seven days per week). The total score on CES-D scale was calculated with higher scores indicating high frequency of depressive symptoms and low scores indicating low frequency of depressive symptoms.

\section{CONCEPTUAL FRAMEWORK}

The conceptual framework outlines the relationship between the variables and provides direction for the study (Polit \& Beck, 2004). An adaptation of Muriel Rice's Health Status Assessment Model, 2004 served as the framework for this study. Rice's Health Status Assessment Model was influenced by Nola Pender's Health Promotion model, 1996. Rice's model was originally developed to describe the health status of African American women receiving welfare benefits while participating in a work-related training program. The major concepts of Rice's model are health risk behaviors, personal risk factors, perceived barriers to action, situational influences, and overall health status. 
For the purposes of this study, key concepts (health risk behaviors, personal risk factors, and situational influences) were extracted from Rice's model because of the reported link between these concepts and depressive symptoms and obesity. The independent variables in this study included the following health risk behaviors: physical inactivity, poor nutrition, smoking, and alcohol consumption; personal risk factors: age education and BMI; perceived health status; and situational influences (transition from welfare to work). Depressive symptoms and obesity were the dependent variables of interest in this study. A schematic depiction of this framework is provided (Figure 1).

Physical inactivity, poor nutrition, smoking, and alcohol consumption are health risk behaviors. Studies have shown that African American women on welfare do not engage in regular physical activity, have diets higher in saturated fats, sodium, and sugar and lower in fruits, vegetables, whole grain, and fiber, and have the lowest smoking cessation rates, than women in the general population (Siegel, Yancey, \& McCarthy, 2000). Additionally, while there is limited data on alcohol consumption in African American women moving from welfare to work, some researchers report that women on welfare in general consume more alcohol than women not on welfare (Siegel et al., 2000).

Personal demographic risk factors (age and education), and biological factors (e.g., BMI), are characteristics that significantly influence the association between depressive symptoms and obesity in this population. Studies have shown that African American women on welfare are more susceptible to depressive symptoms and obesity with increasing age (McElroy et al., 2004). Limited education has been associated with adverse health outcomes including depressive symptoms and obesity in women on welfare (Blazer, Moody-Ayers, Craft-Morgan, \& Burchett, 2002; Coiro, 2001).

Perceived health status influences mental and physical health outcomes (Jones, O'Connell, Gound, Heller, \& Forehand, 2004). Studies have demonstrated that African American women on welfare have a lower perception of their health status than other women on welfare (Levin-Epstein, 2003). The variable situational influences (e.g. the transition from welfare to work) is included in the model because all participants were African American women transitioning from welfare to work, however this variable was not measured in the current study.

\section{ASSUMPTIONS}

The following assumptions were influenced by the study framework and published literature.

- The participants will answer the questions on the health risk appraisal tool honestly.

- Data obtained from the study instruments will reflect the perceptions of the participants 


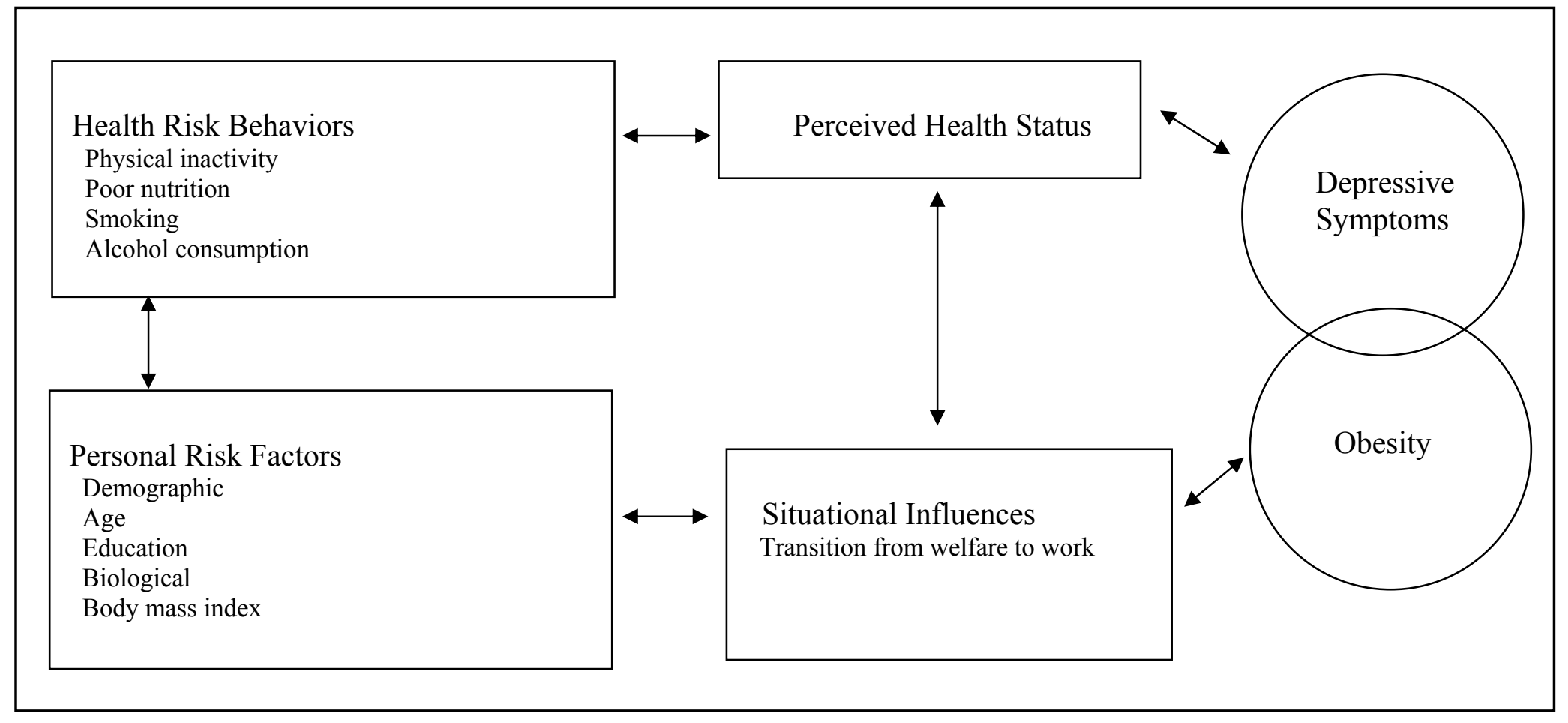

Figure 1. Conceptual model 
- The conceptual model is relevant for African American women on welfare, health care providers, and policy makers.

- The selected study instruments were relevant for the study population and valid and reliable indicators of the study variables.

\section{LIMITATIONS}

The Healthier People Network's health risk assessment tool used in this study is a self- report evaluation of the participants' current health status. This tool cannot be verified by objective measures and the probability that some participants may under report their symptoms is possible.

The Center for Epidemiological Studies Depression Scale (CES-D) has not been used extensively in African American women on welfare. However, it has been shown valid in African American populations and welfare recipients and will allow comparison of findings from this study to other published studies that have used the CES-D.

The CES-D is a 20-item, self-report tool designed to measure the number duration of depressive symptoms but does not diagnose depressive disorders.

This study will be conducted in one city and results may not be generalizable to welfare recipients in rural areas or non-African American welfare recipients.

Lastly, because this is a cross-sectional study, a causal relationship cannot be established between the variables. 


\section{CHAPTER 2. LITERATURE REVIEW}

\section{INTRODUCTION}

Depression and obesity rank among the most common chronic disorders in the United States (U.S.) (Dixon, Dixon, \& O'Brien, 2003). Approximately 14.8 million adults suffer from depression (World Health Organization, 2004), and more than 60 million persons age 20 and older are obese (Hitz, 2005). Differences in the rates of depression and obesity among gender and ethnic groups and the adverse health outcomes associated with both disorders are well documented. Additionally, a growing body of literature describes the impact of chronic disorders like depression and obesity on health-care costs and the financial well-being of persons affected by these disorders.

Despite the large amount of data available on these disorders, there is a lack adequate data on the prevalence of depressive symptoms and obesity in African American women on welfare. Known health disorders among minorities, poor and lowincome persons, and welfare recipients place African American women on welfare at high risk for poor health outcomes. The presence of depression and obesity in this population may further jeopardize their health and their ability to work and become selfsufficient. To ensure their successful transition to work, health care providers must better understand how depression and obesity affect the health of these women, and explore factors that predict such disorders in this population.

This review of literature begins with a discussion of the prevalence of depression and obesity in the U. S. population, and when information is available, among African American women transitioning from welfare to work. This review includes published studies on the association between depression and obesity and will explain and evaluate studies relevant to the predictor variables within the conceptual model and study aims. Moreover, because of the paucity of studies specific to African American women moving from welfare to the workforce, this literature review includes applicable studies on poor women, low-income women, and African American women.

\section{DEPRESSION}

Depression is one of the most pervasive psychiatric disorders in the world (Worley, 2006) and likely will rank second amongst global diseases by the year 2020 (Greden, 2001). According to Desai and Jann (2000) reports from the Global Burden of Disease Study have equated the disability associated with depression to blindness and paraplegia. Furthermore, officials from the World Health Organization have determined that disability associated with depression exceeds the disability associated with hypertension, diabetes, arthritis, and chronic back pain (Desai \& Jann, 2000). The economic impact of depression is enormous. The following figures represent the direct and indirect cost of depression: medical costs - \$26 billion; costs related to suicides - \$5 billion; and loss of productivity and absenteeism - \$52 billion (Greenberg et al., 2003). 
Depression, a complex disorder with a variety of symptoms, may affect a person's ability to sleep, eat, engage in pleasurable activities, and obtain and sustain employment. Prevailing symptoms of depression are sad mood, loss of interest in usual activities, increased or decreased appetite, changes in sleep patterns, decreased energy, difficulty concentrating, feelings of guilt or worthlessness, psychomotor agitation or retardation, and thoughts of suicide or death (American Psychiatric Association, 2000). Furthermore, depression affects other diseases (Chapman, Perry \& Strine, 2005). Depressed persons, for instance, are at greater risk for developing diabetes than those not depressed (Katon et al., 2004). In a longitudinal study of non-diabetic adults $(\mathrm{N}=$ $11,615)$, the risk of developing diabetes increased by $63 \%$ in persons with high levels of depressive symptoms compared to those with lower levels (relative hazard 1.63, CI: $95 \%$ 1.31 - 2.02) (Golden et al., 2004).

In addition, depression occurs in $50 \%$ of persons with multiple sclerosis (Siegert \& Abernethy, 2005) and about $40 \%$ of persons with cancer (Eli et al., 2007). Previous studies indicate, too, that depression influences response rates to chemotherapy and recovery in cancer patients (Eli et al., 2007) and is also associated with heart disease (Guck, Kavan, Elsasser, \& Barone, 2001). Furthermore, a growing body of evidence suggests that depression may lead to cardiac disease and a higher probability of death following myocardial infarction (Guck et al., 2001). Finally, depression contributes to high mortality rates - an estimated $15 \%$ of persons with severe depression commit suicide (Desai \& Jann, 2000).

Genetic, psychosocial, and biological factors may contribute to the development of depression although researchers have failed to reach consensus about exact causes (Bhatia \& Bhatia, 1999). Some research indicates, for example, that persons with a family history of depression may possess a genetic predisposition to depression, but not everyone with a family history of depression will develop depression (National Institute of Mental Health, 2007). In addition, psychosocial factors such as the death of a loved one, unemployment, homelessness, poverty, and welfare dependence may contribute to depression because of the increased stress associated with these events (Mazure, Maciejewski, Jacobs, \& Bruce, 2002).

Researchers have also reported that $50 \%$ of persons suffering from depression have increased levels of cortisol from stress-induced overstimulation of the hypothalamic-pituitary-adrenocortical (HPA) axis (Maes, Calabrese, \& Meltzer, 1994; Stokes, 1995). The increase in circulating cortisol is thought to disrupt neurotransmitter receptor-site activity which contributes to depression (Checkley, 1992; Rubin, 1989). In contrast, Strickland, Deakin, Percival, Dixon, Gater, and Goldberg (2002) contend that increased cortisol secretion is atypical in depression and that attempts to predict simultaneous depression and hypercortisolemia would be impractical in community based studies.

Alterations in metabolism of the neurotransmitters, particularly norepinephrine, dopamine, and serotonin, have also been suggested as contributing to development of depression because of their role in regulating mood (Kornstein, 1997). Consistent with 
this finding is the work of Nishizawa, Benkelfat, Young, Letyton, Mzengeza, DeMontigny, Blier, and Diksic, (1997), demonstrating differences in serotonin synthesis among women and men. In that study, men had higher levels of serotonin and were less likely to suffer from depression; decreased levels of serotonin reported in women were associated with depression (Nishizawa, et al., 1997). Hence, findings from this study suggest gender may be a key factor in developing depression.

\section{Depression and Women}

Psychiatric literature has consistently reported high rates of depression among women and found depression the leading cause of disability in women (Murray \& Lopez, 1997; Wilen \& Mounts, 2006). In fact, women are twice as likely to suffer from depression as men (Bhatia \& Bhatia, 1999; Blazer, Kessler, McGonagle, \& Swartz, 1994; Culbertson, 1997). The lifetime prevalence of depression varies from $10 \%$ to $25 \%$ in women compared to a 10\% lifetime prevalence among men (Desai \& Jann, 2000). Poor, single mothers of young children are particularly vulnerable to depression (Heneghan et al., 1998; Hobfoll, Ritter, Lavin, Hulsizer, \& Cameron, 1995) and the rates of depression are as high as $60 \%$ in this group (Hall, Gurley, Sachs, \& Kryscio, 1991).

Several theories seek to explain high rates of depression in women. According to one theory, women are more likely than men to seek mental-health services, which may account for the higher reports of depression among women (Kessler, McGonagle, \& Swartz, 1993). Other researchers contend that alterations in hormone levels influence the development of depression, and documented evidence reveals that changes in hormone levels directly affect chemical components of the brain that control emotions and mood (Mazure et al., 2002). Thus, variations in levels of estrogen, which occur during menses, pregnancy, and menopause, have been associated with an increased risk of depression in women (Joffe \& Cohen, 1998; National Institute of Mental Health, 2007).

Researchers have long suspected that women of childbearing age may be at greatest risk for depression because of heightened fluctuations in hormone levels (Bebbington et al., 1998; Jesse, Walcott-McQuigg, Mariella, \& Swanson, 2005). In support of this contention, a study by Bebbington et al., (1998) demonstrated that women in their study had a higher incidence of depression during reproductive years; an earlier study by Nazroo, Edwards, and Brown (1997), however, found no significant difference in the occurrence of depression among women with children and those without children. Furthermore, psychosocial factors including family responsibilities, high levels of stress, poor coping abilities, exposure to violence, and low socioeconomic status have all contributed to depression among women (Blazer, et al., 1994; Williams, Takeuchi, \& Adair, 1992).

\section{Depression and Women on Welfare}

Low socioeconomic status and poverty are undeniable predictors of depression, particularly among women (Siefert et al., 2000). Bruce, Takeuchi, \& Leaf (1991) 
reported an odds ratio of 2.29 for depression among poor persons compared to persons with higher incomes. Women and minorities are disproportionately represented among persons of low socioeconomic status and the poor (Siefert et al., 2000); 90\% of welfare recipients ( $>1.4$ million) are women (Levin-Epstein, 2003), and 39\% of these recipients are African American women (Rice \& Wicks, 2006). Lennon, Blome, and English (2001) contend that typically high rates of depression among women and constant stress associated with poverty place women on welfare at an even greater risk for depression than among women not receiving welfare benefits. Similarly, in a study of current and former welfare recipients, Danziger et al., (2000) found that gender, race, and low socioeconomic status were strong predictors of depression; and the one-year prevalence of depression was $25 \%$ in their follow-up study. Furthermore, women who were depressed were more likely to remain on welfare than women who were not depressed (Danziger et al., 2000).

Additionally, Lennon et al. (2001) report that $25 \%$ to $57 \%$ of women on welfare experience depressive symptoms, with a rate of depression ranging from $12 \%$ to $36 \%$ in this population. Consistent with these findings are results from a study of the health of welfare recipients transitioning to work conducted by Rice and Wicks (2006). Eightynine recipients participated in the study; $97 \%$ were females, and $31 \%$ of participants reported high levels of depressive symptoms (Rice \& Wicks, 2006). Likewise, Hildebrandt and Kelber (2005) explored perceptions of health among women participating in a welfare-related work program $(\mathrm{N}=34)$. Forty-four percent of participants in this study had severe depressive symptoms.

Depression has been associated with receipt of welfare benefits during childhood (Coiro, 2001). In a longitudinal study of current welfare recipients, women who reported receiving welfare benefits during childhood had higher rates of depressive symptoms than women who did not receive welfare benefits as children (Coiro, 2001). Furthermore, in a study of single, low-income women with young children $(\mathrm{N}=1602)$, depressive symptoms interfered with the ability of these women to engage in work-related activities, and their children were likely to have conduct problems in school (Rosman \& Yoshikawa, 2001).

Depression is the third leading barrier to employment (Danziger, et al., 2002) and is associated with failure to transition from welfare to work (Rice \& Wicks, 2006; Siefert et al., 2000). Yet, discussions of barriers to employment for women on welfare typically include sociodemographic barriers with little regard for psychiatric disorders, specifically depression, which may hinder their successful transition to work (Olsen \& Pavetti, 1996).

\section{Depression and African American Women}

Race, gender, and low socioeconomic status are highly correlated with depression (Belle \& Doucet, 2003; Heflin, Siefert, \& Williams, 2005; Krieger \& Zierler, 1995; Link \& Phelan, 1995; Poleshuck et al., 2006; Siefert et al., 2000; Siefert, Heflin, Corcoran, \& Williams, 2004; Williams, Yu, Jackson, \& Anderson, 1997). High rates of depression have been reported among African American women of low socioeconomic status 
(Blazer et al., 1994; Chung, McCollum, Elo, Lee, \& Culhane, 2004; McLennan, Kotelchuck, \& Cho, 2001; Williams, Takeuchi, \& Adair, 1992), although depression is often unnoticed and untreated in this population (Jackson, 2006). According to McGrath et al., (1990), African American women are more likely than Caucasian women to face a number of socioeconomic and sociodemographic factors placing them at increased risk for depression.

Similarly, a recent study by Siefert, Finlayson, Williams, Delva, and Ismail (2007) revealed significant socioeconomic and sociodemographic risk factors and high levels of depressive symptoms among African American mothers living in the poorest areas of a large Midwestern city $(\mathrm{N}=824)$. The annual income of $48 \%$ of the participants was less than $\$ 10,000$. The mothers who lived in homes that were poorly maintained and were unable to provide sufficient food for their children were $1.5-2.5$ times more likely to report high levels of depressive symptoms. Thirty-four percent $(\mathrm{N}=280)$ of participants scored 16 or higher on the Center for Epidemiological Studies Depression (CES-D) scale, and the CES-D scores of 19\% $(n=160)$ of these woman were greater than 23, indicating "probable depression" according to the researchers (Siefert, Finlayson, Williams, Delva, \& Ismail, 2007).

Moreover several studies have suggested that rates of depression may be higher among African American women because of racial discrimination (Kessler, Mickelson, \& Williams, 1999; Ren, Amick, \& Williams, 1999; Williams, Yu, Jackson, \& Anderson, 1997). According to these researchers, the perception of discrimination causes psychological distress, a precursor to depression (Siefert et al., 2000). Comparatively, studies of depression among African American and Caucasian women also found that African American women experienced more incidences of racial discrimination, events positively associated with depression (Kessler, et al., 1999; Ren, Amick, \& Williams, 1999; Williams, Yu, Jackson, Anderson, 1997). Results from a study by Siefert et al. (2000), on maternal depression among welfare recipients concur with these findings $(\mathrm{n}=$ 705). Fifty-six percent $(n=394)$ of participants were African Americans, 176 women met criteria for depression, and $38 \%$ of these women reported some form of racial discrimination.

Reports of the rates of depression among African American women conflict. Some studies have shown higher rates of depression among African American women of higher socioeconomic status compared to Caucasian women (Gazmararian, James, \& Lepkowski, 1995) while other studies have found higher rates of depression among African American women of lower socioeconomic status (Jones-Webb \& Snowden, 1993). In contrast, Poleshuck, Giles, and Tu (2006) directed a study of low income women seeking care in an urban women's clinic $(\mathrm{N}=242)$. Twenty-one percent of participants scored high on a depression inventory scale, and there were no significant differences in the rates of depression among African American and Caucasian women $(\mathrm{F}=0.18, \mathrm{p}>0.05)$ (Poleshuck et al., 2006).

These findings suggest that when socioeconomic factors are controlled, there are no differences in rates of depression among African American and Caucasian women. 
Additionally, results from the National Comorbidity Survey Replication Study (20012002) suggested that women, young people, and single persons were more likely to be depressed whereas African Americans and those with 0 to 11 years of education were less likely to be depressed (McCoy, 2003). Likewise, Jesse, Walcott-McQuigg, Mariella, and Swanson (2005), based on data from women enrolled in an urban prenatal clinic $(\mathrm{N}=$ 130), found that while the overall incidence of depression was high in this sample, African American women reported similar or lower rates of depression than Caucasian women.

Sociocultural experiences (e.g., religion and spirituality) play a significant in role in how African American women conceptualize, express, and manage depressive symptoms and depression (Waite \& Killian, 2007). Jesse et al. (2005) noted that the African American women in their study scored higher than Caucasian women on social support, spirituality, and strong religious beliefs; and these resources may have protected them from depressive symptoms and depression. Similarly, Dessio, et al. (2004) also found that religion and spirituality provided relief of depressive symptoms in $43 \%$ of African American women $(\mathrm{n}=812)$ participating in their survey.

Terms such as hopelessness, sadness, and depressed are rarely used by African American women when discussing depression (Barbee, 1994; Choi, 2002; Kohn \& Hudson, 2002; Waite \& Killian, 2007). Furthermore, African American women are more likely than Caucasian women to report somatic symptoms of depression such as changes in appetite and physical complaints (Frank, Matza, Revicki, \& Chung 2005). Fatigue is a cardinal symptom of depression in African American women. These symptoms are often not recognized as symptoms of depression by patients and providers and may result in underreporting of depression among African American women (Frank et al., 2005).

\section{OBESITY}

Obesity is a major health risk worldwide and has reached epidemic proportions in the United States (U.S.) (Deitel, 2003b). Officials from Healthy People 2010 have classified obesity as one of the ten leading health indicators (Hedley et al., 2004). Obesity has been associated with many disorders including depression, hypertension, heart disease, hyperlipidemia, gall bladder disease, arthritis, respiratory problems, diabetes, and certain cancers (Pi-Sunyer, 2002; Serdula, Khan, \& Dietz, 2003; York et al., 2004). Moreover, the medical cost associated with obesity account for more than $\$ 79$ billion of the total cost of health care in this country annually and the cost of absenteeism and lost productivity exceeds \$3.9 billion (Center for Disease Control and Prevention, 2007). Sixty-five percent of adults in the U.S. are overweight or obese (Martin, Dutton, \& Brantley, 2004; Wyatt, Winters, \& Dubbert, 2006), and researchers expect that more than $40 \%$ of the adults in the United States will be obese by the year 2025 if the current rate continues (York et al., 2004).

Furthermore, the Center for Disease Control and Prevention (CDC) has reported an increase in rates of obesity in 31 states, and no state has reported a decline in obesity (National Center for Health Statistics, 2006). The prevalence of obesity is highest in 
southern regions of the United States; in Tennessee for instance, 27\% (one in every seven persons) are obese (National Center for Health Statistics, 2006). Like depression, obesity is associated with high mortality rates. More than 300,000 adults die each year of obesity-related complications (Fontaine, Redden, Wang, Westfall, \& Allison, 2003).

Many factors may influence the development of obesity including lack of social support, race, ethnicity, education, and income (Goodman \& Whitaker, 2002; Mustillo et al., 2003; Onyike, Crum, Lee, Lyketsos, \& Eaton, 2003; Sammel et al., 2003). Another predictor in the development of obesity is genetics (Salinksy \& Scott, 2003). Scientists speculate that genetics contributes between $25 \%-70 \%$ of the variance in body-fat composition (Hill, Wyatt, \& Melanson, 2000).

Other researchers propose that gender plays a key role in the development of obesity. Men are more likely to be in the overweight range whereas women are more likely to be obese (Salinsky \& Scott, 2003). Findings from a study of the association between depressive symptoms and obesity $(\mathrm{N}=2431)$ express similar results. Forty-three percent of men participating in the study were overweight compared to $28 \%$ of women. In addition, $26 \%$ of the women respondents were obese compared to $23 \%$ of men. Ethnic minority populations in the United States are at a greater risk for obesity than Caucasians (Zhang \& Wang, 2004), and the prevalence of obesity is highest among ethnic minority women (Flegal, Carroll, Ogden, \& Johnson, 2002).

\section{Obesity and Women}

More than $50 \%$ of women in the United States are overweight, $30 \%$ are obese, and $6 \%$ of women are morbidly obese (BMI $>40$ ) (Deitel, 2003a). Rates of obesity are higher among African American and Hispanic-American women, with African American women having the highest rates (York et al., 2004). Researchers suggest that childhood overweight/obesity and a family history of overweight or obesity contribute to adult obesity in women (Allison, Edlen-Nezin, \& Clay-Williams, 1997; Kumanyika, 1987; Wolfe, Sobal, Olson, Frongillo, \& Williamson, 1997). A study by Davis, Rovi, and Johnson (2005) on mental health, family function, and obesity in African American women $(\mathrm{N}=113)$, supports this hypothesis. Twenty-eight percent of women who were obese reported being overweight as children, and $64 \%$ of these women had overweight parents or siblings (Davis et al., 2005). In addition to gender, obesity is positively associated with low socioeconomic status in women although it is unclear whether low socioeconomic status predicts obesity or obesity influences socioeconomic status (Paeratakul, White, Williamson, Ryan, \& Bray, 2002).

\section{Obesity and Women on Welfare}

Many studies have linked low socioeconomic status with adult obesity (Brunner, Shipley, Blane, Smith, \& Marmot, 1999; Langenberg, Hardy, Kuh, Brunner, \& Wadsworth, 2003; Lawlor, Ebrahim, Davey-Smith, 2002; Power, Manor, \& Matthews, 
2003). Moreover, empirical research has demonstrated that women of lower socioeconomic status (SES) are more likely to be obese than women of higher SES (Thurston, Kubzansky, Kawachi, \& Berkman, 2005; Wang, Monteiro, \& Popkin, 2002; Zhang \& Wang, 2004). The effect of higher SES on obesity however, is more pronounced in Caucasian women than in African American women (Office of Disease Prevention and Health Promotion, 2001).

In a study of the relationship between SES and obesity in African American women $(\mathrm{N}=760)$, incomes of $81 \%$ of women ranked in the lower SES range, and $43 \%$ of the respondents were obese (James, Fowler-Brown, Raghunathan, \& Van Hoewyk, 2006). Consistent with previously published studies, Rice and Wicks (2006) found high rates of obesity $(70 \%)$ in their sample of predominately African American women on welfare $(n=83)$. But in contrast to previous work, Chang and Lauderdale (2005) suggest that high rates of obesity are not specific to poor or low SES persons. In their analysis of data from the National Health and Nutrition Examination Surveys (1971-2002), Chang and Lauderdale (2005) observed an increase in rates of obesity at all income levels, and middle-income African American women experienced the largest gain (27\%) in rates of obesity during this period.

Obesity as a major barrier to employment has not been studied extensively in women on welfare (Cawley \& Danziger, 2005). Previous data suggest that overweight and obesity adversely affect employment among women more than men; and obese women earn less than women not obese (Cawley \& Danziger, 2005). Data from the 1997 -2003 Women's Employment Survey (WES) $(\mathrm{N}=753)$ indicated that obese Caucasian women had difficulty obtaining employment, worked fewer hours, and have lower monthly earnings than women of other races who participated in the study (Cawley \& Danziger, 2005). The WES consisted of interviews over a five-year period from single women on welfare living in Michigan; $49 \%$ of Caucasian women and $56 \%$ of African American women in the study were obese. By contrast, weight was not associated with employment or hours worked for African American women on welfare but did correlate positively with additional time on welfare (Cawley \& Danziger, 2005).

\section{Obesity and African American Women}

The prevalence of obesity is inexplicably higher among African American than among women of other races and men of all races (Averett \& Korenman, 1999; Davis et al., 2005; Sharp et al., 2002; Siegel et al., 2000). Seventy-eight percent of African American women in the United States are overweight, 50\% are obese, and $15 \%$ of African American are morbidly obese (American Obesity Association, 2002). African American and Hispanic women have the highest rates of central obesity $(60 \%)$, which is associated with higher health risk, compared to rates for Caucasian women $(40 \%)(\mathrm{Hu}$, 2003). Central obesity is associated with metabolic syndrome, polycystic ovarian syndrome, type 2 diabetes, coronary heart disease, and postmenopausal and ovarian cancer in women $(\mathrm{Hu}, 2003)$. 
Lower income, physical inactivity, and poor nutrition contribute to obesity in African American women (Siegel et al., 2000). In addition, findings from several studies suggest that high rates of obesity may be related to low metabolic rates in African American women (Foster, Wadden, \& Vogt, 1997; Jakicic \& Wing, 1998). Conversely, Kushner, Racettte, Neil, and Schoeller (1995) and Nicklas, Toth, Goldberg, and Poehlman, (1997) found no significance difference in metabolic rates among African American and Caucasian women.

African American women view weight differently than Caucasian women. In a study of perceptions of obesity in African American women, higher weights were perceived to signify power (Stearns, 1997), and African American women were more likely to associate obesity with being attractive than did women of other races (Allan et al., as cited in Davidson \& Knafl, 2006). Similarly, researchers have observed higher levels of self-esteem among obese African American women than among obese Caucasian women (Cawley \& Danziger, 2005). In addition, high levels of self efficacy and high rates of obesity were noted among African American women participating in a study about the health of women leaving welfare for work (Rice \& Wicks, 2006). Moreover, African American women participating in a qualitative study conducted by Baturka, Hornsby, and Schorling (2000) cited acceptance by family, friends, and significant others as a major influence in their perceptions about weight.

From a health perspective, African American study participants minimized the health risks associated with obesity (Baturka et al., 2000; Davidson \& Knafl, 2006; Kumanyika et al., 2005). For some study participants, health was influenced by obesity only when "Your legs and back hurt, when you can feel it, then you know you are overweight" (Gore, 1999). Respondents from other studies reported that family members encouraged them not to lose weight, stating "If you get sick, you won't have anything to fall back on" or "Have a healthy weight in case of illness" (Baturka et al., 2000). Researchers note that most data on obesity in African American women has been extracted from studies on Caucasian women (Siegel et al., 2000), but agree that low socioeconomic status, physical inactivity, poor nutritional intake, and cultural values contribute to obesity in African American women (Riley et al., 1998).

\section{DEPRESSION AND OBESITY}

Many studies have explored the relationship between depression and obesity (Bertakis \& Azari, 2005; Chapman, Perry \& Strine, 2005; Dixon, Dixon, \& O'Brien, 2003; Faith, Matz, \& Jorge, 2002; Stunkard, Faith, \& Allison, 2003), and several theories seek to explain this relationship. Dysregulation of the neurotransmitters serotonin and norepinephrine is a likely explanation in this association because of their effect on regulation of mood and appetite (McElroy et al., 2004).

In addition, some researchers have suggested that childhood depression is a predictor of obesity (DiPietro, Anda, Williamson, \& Stunkard, 1992; Goodman \& Whitaker, 2002; Richardson et al., 2003). A prospective study by Pine, Goldstein, Wolk, and Weissman (2001) ( $\mathrm{N}=177)$ demonstrated that childhood depression predicted 
increased body-mass index in adulthood (OR; 1.9; CI: 1.02 - 3.4). Likewise, Goodman and Whitaker (2002) found that depression during adolescence predicted the development of obesity over a one-year period (OR; 2.05; CI: 1.04 - 4.06).

Mounting evidence from epidemiological studies name genetics as a key component in the co-occurrence of depression and obesity (Kendler, Eaves, Walters, Neale, Health, \& Kessler, 1996; Sullivan, Neale, \& Kendler, 2000). The findings are consistent with a study by Stunkard, Faith and Allison, (2003). These researchers suggest that a genetic predisposition to both depression and obesity may be influenced by unpleasant experiences during childhood (Stunkard, Faith, \& Allison, 2003). Furthermore, initial results from a study by Dong, Sanchez, and Price, (2004) found the odds for depression were greatest among persons who were obese $(\mathrm{OR}=1.69$ for $\mathrm{BMI} \geq$ $30)$ and whose parents were depressed $(\mathrm{OR}=3.06, \mathrm{p}<0.0001)$, in other words, obesity predicted depression. Conversely, additional results indicated that depression was not a predictor of obesity in this sample (Dong, Sanchez, \& Price, 2004).

Divergent views exist however, among researchers about whether a relationship exists between depression and obesity (Faith, Matz, \& Jorge, 2002; Friedman \& Brownell, 1995). A positive relationship between depression and obesity was found in community-based studies (Carpenter et al., 2000; Istvan, Zavela, \& Weidner, 1992; Roberts, Kaplan, and Shema \& Strawbridge, 2000; Roberts, Strawbridge, Deleger, \& Kaplan, 2002). In contrast, studies with similar methodology conducted by Hallstrom and Noppa (1981); Palinkas, Wingard, and Barrett-Connor (1996); and Faubel (1989), found no significant associations between depression and obesity.

Some researchers have suspected the relationship between depression and obesity differs among women and men (Becker, Margraf, Turke, Soeder, \& Neumer, 2001). One study found that obese women experienced a $50 \%$ increase in the lifetime prevalence of depression in contrast to men who were obese (Becker, Margraf, Turke, Soeder, \& Neumer, 2001). Furthermore, analysis of data from the NHANES III survey conducted by Onyike, Crum, Lee, Lyketsos, and Eaton, (2003) revealed that obesity was related to a previous month history of depression in women (OR;1.82, CI: $1.01-3.3)$ but not men (OR;1.73, CI: 0.56 - 5.37).

Carpenter et al. (2000) observed a strong correlation in the co-occurrence of depression and obesity in women and an inverse relationship in the co-occurrence of depression and obesity in men. Results from this study showed a $37 \%$ increase in depression in obese women compared to a 37\% decrease in depression in obese men (Carpenter et al., 2000). On the other hand, central obesity and a high waist to hip ratio was associated with greater risk for depressive symptoms and increased use of antidepressants in men but not in women (Rosmond \& Bjorntorp, 2000). Contrary to findings from these studies are results from a study by Dong, Sanchez, and Price, (2004) which found a significant association between depression and obesity among women and men alike. 
Additionally, inconsistent findings have come from studies conducted primarily on women regarding the relationship between depression and obesity. A study directed by Sammel, Grisso, Freeman, Hollander, Liu, and Liu et al., (2003) of women in their reproductive years $(\mathrm{N}=336)$ found that depression was positively associated with weight increase. Another study conducted by Bertakis and Azari (2005), of obese $(\mathrm{n}=205)$ and non-obese patients $(\mathrm{n}=301)$ confirmed the hypothesis that depression and obesity were positively correlated in the female respondents. Rohrer and Rohland (2004), however, conducted a cross-sectional survey of low-income women attending a family planning clinic $(\mathrm{N}=274)$ and found no relationship between depression and obesity in this sample. The survey contained only one question about depression, and the researchers concluded that measurement error may have contributed to lack of significance between depression and obesity in this sample.

Few studies exist on the relationship between depression and obesity in African American women and even fewer studies exists on African American women on welfare transitioning to work. Much of the available data on African American women derives from studies include only a small sampling of African American women (Siegel et al., 2000). Nevertheless, data from a study of African American women participating in a pilot exercise program $(\mathrm{N}=429)$ showed a small, but significant association between depression and overweight in this sample $\left(\mathrm{R}^{2}=0.09, \mathrm{p}<0.001\right)$ (Siegel et al., 2000). Weight was categorized as "overweight or not overweight," and the correlation between depression and weight was explained in part by participant's current health status and the presence of co-morbidities.

Another study addressing depression and obesity in African American women $(\mathrm{N}=113)$ documented high rates of depressive symptoms among $39 \%$ of the women in the study and $47 \%$ were obese (Davis et al., 2005). Depressive symptoms were measured by the Center for Epidemiologic Studies Depression Scale in this study. Investigators in this study determined that scores of 27 or greater indicated positive for "probable depression" (rather than the customary cutoff of 16 or greater); thus rates may have been higher if cutoff score were 16. In a similar manner, to reduce the likelihood of false positives, recent studies have used higher cutoff points for the CES-D in populations with high rates of depression (Cook, Cohen, Burke, Grey, Anastos, Kirstein et al., 2002; Golub, Laka, Hagan, Havens, Hudson, Kapadia, et al.; McLennan, 2004; Perdue, Hagan, Thiede, \& Valleroy, 2003). Consistent with the previous studies, Rice and Wicks (2006) conducted a study on the health of African American women on welfare transitioning to work. Thirty-one percent of respondents reported depressive symptoms, and $70 \%$ of respondents were obese (Rice \& Wicks, 2006). Thus, results from these studies indicate that depressive symptoms and obesity may co-occur in this population although more research is needed to determine factors that may predict this co-occurrence.

Inconsistencies in previously published studies on the association between depression and obesity may arise because of variations in methodology (Carpenter et al., 2000). In fact, results from many aforementioned studies came from clinical trials without control groups or from community samples not representative of the population and subject to selection bias. These factors, therefore, may contribute to inconsistencies 
among studies associating depression and obesity (Carpenter et al., 2000). Onyike, Crum, Lee, Lyketsos, and Eaton, (2003) and Goodman and Whitaker, (2002) contend that depression and obesity may not always co-occur, which may account for inconsistencies in prior studies. Furthermore, these researchers propose studies to determine "when [does] an association occur between depression and obesity" (Onyike et al., 2003). Mental and physical health problems such as depression and obesity have been associated with short-term employment and, in general, are barriers to employment among welfare recipients and persons moving from welfare to work (Corcoran, Danziger, \& Tolman, 2003). It is imperative that researchers explore the impact of depression and obesity on the health status of persons affected by these disorders particularly African American women leaving from welfare for employment.

\section{Health Risk Behaviors and Depression}

Physical activity, nutritional intake, smoking behavior, and alcohol consumption were the health risk behaviors of interest for this study. Thus, the next sections describe the documented associations among these variables and depression.

\section{Depression and physical activity}

Early studies have shown that more than $60 \%$ of U.S. adults participate in little or no regular physical activity (Eaton et al., 1999). Researchers have demonstrated that physical inactivity increases with age and occurs more commonly among women, persons with lower incomes, and persons with limited education (Wise, AdamsCampbell, Palmer, \& Rosenberg, 2006). Data from the National Center for Health Statistics reveal that $39 \%$ of Caucasian women and $57 \%$ of minority women do not exercise regularly (Bedinghaus, Leshan, \& Diehr, 2001), and some researchers have reported that among U.S. women, African American women are least likely to engage in regular physical activities (Crespo, Keteyian, Heath, \& Sempos, 1996; Crespo, Smit, Andersen, Carter-Pokras, \& Ainsworth, 2000). Moreover, in a national survey on physical activity and prevention of coronary disease, 34\% of African American women reported no routine physical activity compared to $22 \%$ of Caucasian women (Morbidity and Mortality Weekly Report, 2005). Contrasting with these findings are results from a study by Davis et al., (2005) wherein $45 \%$ of the African American women reported engaging in regular physical activity more than three times per week.

Reports conflict about the relationship between depression and physical inactivity. Evidence from several population-based studies demonstrates a positive relationship between depression and physical inactivity (Backmand, Kaprio, Kujala, \& Sarna, 2003; Strawbridge, Deleger, Roberts \& Kaplan, 2002; Wyshak, 2001). No relationship between depression and physical inactivity was found in studies conducted by Cooper-Patrick, Ford, Mead, Chang, and Klag (1997) and Kritz-Silverstein, Barrett-Connor, and Corbeau (2001). Currently, there are few studies on the relationship between depression and physical inactivity among African American women (Wise, Adams-Campbell, Palmer, \& 
Rosenberg, 2006) and no known studies examining this relationship in African American women leaving welfare for employment.

Studies in which African American women were enrolled found no significant relationship between depression and physical activity (Farmer, Locke, Mosicicki, Dannenberg, Larson, \& Radloff, 1988; Strawbridge, Deleger, Roberts, \& Kaplan, 2002) included African American women and no significant relationships were found. Sample sizes were small however and data not stratified by race. By contrast, results from a large, retrospective study on the relationship between depression and physical inactivity in African American women $(\mathrm{N}=35,224)$ concluded that only $11 \%$ of women in the sample engaged in regular, "vigorous" physical activity (Wise, Adams-Campbell, Palmer, \& Rosenberg, 2006). The odds ratio for participants in the study engaging in vigorous activity was (OR; 0.76 95\% CI: 0.71 - 0.82), indicating an inverse relationship between depression and physical activity.

In one of the few studies examining the health status of African American women moving from welfare to work, Rice and Wicks (2006) found high rates of depressive symptoms and physical inactivity among participants (31\% and $62 \%$ respectively). These studies, thus, indicate a plausible relationship between depression and physical activity. More research can perhaps determine the impact of physical activity on the development of depression particularly in African American women on welfare who are transitioning to work.

\section{Depression and nutritional intake}

Poor nutrition may play a vital role in the onset and severity of depressive symptoms and depression (Beardsley, 2000). Depressed persons may suffer loss of appetite and may choose unhealthy foods resulting in vitamin deficiencies, particularly the $\mathrm{B}$ vitamins, those vitamins instrumental in producing neurotransmitters that regulate mood (Beardsley, 2000). Some depressed persons have low levels of B vitamins, possibly because of decreased appetite or ingestion of foods high in carbohydrates and low in vitamins (Beardsley, 2000). In addition, persons with low carbohydrate intake may feel sad or depressed (Wurtman, 1993).

Recent research has documented a strong association between depression and food insecurity among female welfare recipients (London \& Scott, 2004). Food insecurity is defined as having limited access to food, particularly food that is nutritionally adequate (Gibson, 2003). London and Scott (2004) conducted a qualitative study over two years (1999-2000) among women on welfare living in Cleveland $(\mathrm{N}=36)$ to determine the relationship between mental health and food insecurity. Findings indicated that $80 \%$ of women in the study who scored high on the Center for Epidemiologic Study Depression Scale (CES-D) in 1999 also reported food insecurity in 2000,2001 , or both years (London \& Scott, 2004). These researchers argue that debilitating effects of depression may affect these women's ability to secure food for their families, which results in food insecurity. 
Likewise, data from a 1997 survey of women on welfare in an urban Michigan county $(\mathrm{N}=753)$ demonstrated a significant relationship between depression and food insecurity (Heflin, Siefert \& Williams, 2005). Thirty-five percent of participants in the study who reported food insecurity also met diagnostic criteria for depression (Heflin, Siefert, \& Williams, 2005). Hence, although evidence from these studies demonstrates a relationship between nutritional intake and food insecurity, further studies might determine if depression impairs the ability to obtain adequate and appropriate food or if food insecurity causes stress which influences the development of depression.

\section{Depression and smoking}

According to results from the United States (U.S.) National Institute of Health Study, $70 \%$ of adults with psychiatric disorders are cigarette smokers (Grant, Hasin, Chou, Stinson, \& Dawson, 2004). In addition, studies suggest that adults living below poverty level have the highest rates of cigarette smoking in the U.S. population (Morbidity \& Mortality Weekly Report, 2007). Approximately 25\% of depressed adults are addicted to nicotine (Grant, Hasin, Chou, Stinson, \& Dawson, 2004), and in depressed persons, nicotine may stimulate neuromodulators in the brain that improve mood (Benowitz, 2008).

Women are more likely than men to smoke to relieve depressive symptoms (Bedinghaus, Leshan, \& Diehr, 2001). A recent study Vander, Ward, Scarinci et al. (2006) reported a strong connection between depression and cigarette smoking in lowincome women. Webb and Carey (2008) examined cigarette smoking among low-income African American women ( $\mathrm{N}=263)$, and found $70 \%$ of women in the study smoked cigarettes. In fact, the odds of smoking were greater for older women with limited education who used alcohol frequently and who had higher levels of perceived stress than the younger women in the study.

Yet, data from the (1997-2003) Women Employment Survey Health Supplement $(\mathrm{n}=299)$ indicated that African American women on welfare were less likely than Caucasian women to smoke or ever to have smoked (Kaplan, Siefert, Ranjit, Raghunathan, Young, Tran, et al., 2005). In contrast, Rice and Wicks (2006) discovered high rates of depressive symptoms (31\%) with high rates of current smokers (30\%) in their health-risk assessment of women leaving welfare for work. Of the 89 women in this study, 93\% were African American. There remains, however, a gap in the literature of studies specifically addressing smoking among African American women leaving welfare for work.

\section{Depression and alcohol consumption}

Data are limited on depression and alcohol consumption in women on welfare, specifically in African American women on welfare transitioning to work. Studies that examined the association between depression and substance use (which includes alcohol consumption) will be discussed. When available, data on depression and alcohol use in 
welfare recipients and African American women will be presented. Researchers have discovered widespread co-occurrence of alcohol consumption and depression in the U.S. population (Conway, Compton, Stinson, \& Grant, 2006). One study proposed that the presence of genetic factors common to depression and alcohol dependence accounted for this co-occurrence (Hasin, Goodwin, Stinson, \& Grant, 2005). Results from the (2001 2002) National Epidemiologic Survey of Alcohol and Related Conditions (NESARC) demonstrated a strong relationship between depression and alcohol-use disorders (Hasin, Goodwin, Stinson, \& Grant, 2005). Indeed, according to this study, $14 \%$ of depressed persons suffer a co-occurring alcohol-use disorder (Hasin, Goodwin, Stinson, \& Grant, 2005). Research on the link between depression and alcohol-use disorders, however, has yet to determine a common causal factor.

Substance use has been difficult to quantify in women on welfare because of inconsistencies in both measurement scales and definitions of substance use. Substance use has been associated though, with mental-health problems and limited education among welfare recipients (Montoya, Bell, Atkinson, Nagy, \& Whitsett, 2002). Estimates of substance use range from $10 \%$ to $30 \%$ among welfare recipients (Montoya et al., 2002), and high rates of substance abuse have been reported in $15 \%$ of welfare recipients between ages 18 and 34 (American Psychological Association, 2006). In contrast, according to Rodriguez and Chandra (2006), reports that welfare recipients abuse alcohol may be inflated. One study found $7.5 \%$ of welfare recipients met criteria for alcohol dependence compared to $4.6 \%$ of participants not receiving welfare (Pollack, Danziger, Jayakody, \& Seefeldt, 2002),

Although the relationship between alcohol consumption and welfare dependency has been documented in several studies, the exact nature of the association remains to be explored thoroughly (Rodriguez \& Chandra, 2000; Schmidt \& McCarty, 2000). In their study on employment status and alcohol use, Rodriguez and Chandra (2000) discovered that women who worked part-time while on welfare were more likely to drink than were women working full-time (OR; 3.37, CI: 1.44 - 7.56), and African American women in their study were less likely to drink than Caucasian women (OR; 0.64 , CI $0.43-0.92$ ) (Rodriguez \& Chandra, 2000). These researchers contend that alcohol use among working welfare recipients may arise from stress associated with poverty, low wages, and child-care issues (Rodriguez \& Chandra, 2000).

Results from the National Longitudinal Survey of Youth $(n=3600)$ indicated that depression and alcohol consumption influenced women's entry into the welfare system, but was not a barrier to the transition from welfare to work (Dooley \& Prause, 2002; Pollack, Danziger, Jayakody, \& Seefeldt, 2002). Indeed, women on welfare who were substance users reported more barriers to work than did welfare recipients who were not substance users (Metsch \& Pollack, 2005). Similarly, one study revealed that only $15 \%$ of welfare recipients who were substance users worked full-time in contrast to $22 \%$ of all welfare recipients in the study (Olson \& Pavetti, 1996). 


\section{Personal Risk Factors and Depression}

Age and education, as correlates of depression, were the demographic risk factors of interest in the current study. Published research related to these variables as correlates of depression is presented. Body mass index (BMI) was the sole personal risk factor included as a correlate of depression in the current study. A synthesis of relevant published research is described.

\section{Depression and age}

Age is an independent risk factor for depression (Desai \& Jann, 2000). Approximately $2 \%$ of children and $5 \%$ of teenagers suffer some form of depressive disorder; before the onset of puberty, rates are similar for girls and boys (Zahn-Waxler, 2004). But the prevalence of depression increases in girls around ages 13-15 (Hankin, et al., 1998; Zahn-Waxler,et al., 2004), and girls are twice as likely as boys to suffer depression by ages 15-18 (Hankin, Abramson, Moffitt, Silva, McGee, \& Angell,1998; Zahn-Waxler, et al., 2004). Childhood depression typically continues throughout adulthood, and studies have revealed that a large number of new cases of adult depression originated in childhood or adolescence (Kessler et al., 2005). The highest prevalence rates of depression occur among minority women on welfare of childbearing or childrearing age (Heneghan, Silver, Bauman, Westbrook, \& Stein, 1998; Weissman \& Olfson, 1995). According to the National Comorbidity Survey, African American females, ages 35-44 have the highest lifetime prevalence of depression (Blazer et al., 1994).

\section{Depression and education}

Limited education has been cited as a predictor of one-year and lifetime prevalence of depression (Desai \& Jann, 2000). Blazer et al. (1994) noted that persons with limited education experienced higher rates of depression than did persons with higher levels of education; and Blazer et al., noted further that persons who did not complete high school were seven times more likely to suffer from another psychiatric disorder co-occurring with depression than were persons with a college education. Likewise, data from a large epidemiological study $(\mathrm{N}=7000)$ about the relationship between socioeconomic status (SES) and depression revealed that $21 \%$ of participants with high levels of depression had less than a high-school education compared to $11 \%$ of participants with similar depressive symptoms and a high-school education (Everson, Maty, Lynch, \& Kaplan, 2002).

Studies reveal that lack of education and limited work experience are often cited as barriers to successful transition to work (Cancian \& Meyer, 2000; Murry, et al., 2002). Women on welfare remain trapped in a cycle where they must participate in work-related activities rather than education in order to comply with welfare-reform mandates (American Psychological Association, 2006). Between 10\% and 30\% of welfare recipients have only earned a grade-school education (Olson \& Pavetti, 1996) and less 
than $50 \%$ of women on welfare completed high school (Metsch \& Pollack, 2005). Lack of high-school diploma and depression typically are the second and third barriers to employment, respectively (Danziger, et al., 2002). Furthermore, $40 \%$ to $50 \%$ of women with a high-school diploma or less return to welfare within two years because lack of education reduces their earning power (DeAngelis, 2001).

\section{Depression and body mass index}

The relationship between depression and body mass index (BMI) is not clear and study results remain inconsistent (Anderson, Cohen, Naumova, \& Must, 2006). Nevertheless, Pine, Goldstein, Wolk, and Weissman (2001) found a positive association between childhood depression and increased BMI scores in adults. Participants with a history of childhood depression had higher BMIs $(26.1 \pm 5.2)$ as adults, compared to persons not depressed $(24.2 \pm 4.1 ; \mathrm{t}(175)=2.7)$ (Pine, Goldstein, Wolk, \& Weissman 2001).

From their study of women and men with anxiety and depressive disorders $(\mathrm{N}=310)$, Anderson, Cohen, Naumova, and Must, (2006) reported that 32\% $(\mathrm{n}=98)$ of depressed women had higher BMI scores and were more likely to have yearly increases in BMI scores than did women who were not depressed $(n=93)$. In their study of the relationship between depression and BMI, Onyike, Crum, Lee, Lyketsos, and Eaton (2003) discovered a stronger association between depression and higher BMI scores $(\geq 40)$ compared to depression and lower BMI scores $(<40)$. Unlike the previous studies, Ross (1994) found depression associated with increased BMI only among well-educated persons. While inconsistencies exist among studies on the relationship between depression and BMI, there is plausible evidence that an association between depression and elevated BMIs exists.

\section{Depression and Perceived Health Status}

According to Peden, Rayens, Hall, and Grant (2004), depressed persons have lower self-esteem and poorer perceptions of their health than do persons who are not depressed. Those persons who are poor often have low perceptions of health, and welfare recipients have a lower perception of health than do both persons who are poor and those who are not. According to a study conducted by Heneghan, Silver, Bauman, Westbrook, and Stein (1998), low income mothers living in the inner city self-reports of poor health and meager finances were more likely to predict depression than were other sociodemographic risk factors.

Researchers from Manpower Demonstration Research Corporation (1998 -1999) conducted a survey of health status among current and former welfare recipients $(\mathrm{N}=3771) ; 75 \%$ of these women reported at least one health problem, including depression, and $25 \%$ perceived their health as "fair to poor" (Polit, London, \& Martinez, 2001). Similarly, high rates of depressive symptoms (31\%) and poor perceptions of health $(48 \%)$ were reported in a sample of female welfare recipients $(\mathrm{N}=89)$ leaving 
welfare for work (Rice \& Wicks, 2006). Thus, these studies indicate that depression affects perceptions of health particularly among poor women and women on welfare.

\section{Health Risk Behaviors and Obesity}

As with depression, obesity has been associated with physical activity levels, nutritional intake, smoking behavior, and alcohol consumption. Published research documenting the nature of these associations is described in the sections that follow.

\section{Obesity and physical activity}

According to data from the Center for Disease Control and Prevention (CDC), $50 \%$ percent of U.S. adults do not engage in regular physical activity (Morbidity and Mortality Weekly, 2007). Moreover, minorities and poor women are less likely to engage in physical activity than are Caucasians and women of higher socioeconomic status (Bedinghaus, Leshan, \& Diehr, 2001). Rates of physical inactivity are highest in the southern states where data indicate that $30 \%$ of adults living in Mississippi, Louisiana, Kentucky, and Tennessee do not engage in regular physical activity (Department of Health and Human Services, 2008).

Consistent with these findings are high rates of physical inactivity among participants in a study by Rice and Wicks (2006). Participants in this study were welfare recipients residing in Tennessee; health-risk assessment findings indicated that $61 \%$ of participants "exercised less than three times per week" (Rice \& Wicks). In contrast, 45\% of women participating in a study of mental health and obesity among African American women $(\mathrm{N}=113)$ reported regular physical activity (exercise $>3$ times per week) compared to the national average of $31 \%$ of African American women (Davis et al., 2005). Data for this study were obtained by self report, and researchers acknowledged that "perception bias and a desire to give the right answer" might have influenced responses (p. 481).

Additionally, Blair and LaMonte (2005) found sufficient evidence linking obesity associated morbidity and mortality to physical inactivity. Additionally, a growing body of evidence reveals that obesity likely results from decrease in energy output rather than increase in energy intake, supporting the role of physical inactivity in the development of obesity (Sparling, Owen, Lambert, \& Haskell, 2000). In contrast, data from other studies determined that the relationship between physical activity and obesity was not statistically significant in community samples (Samuel, Grisso, Freeman, Hollander, Liu, Liu, et al., 2003). Moreover, other researchers have argued that obesity may be either a precursor or an outcome of physical inactivity (DiPietro, Dziura, \& Blair, 2004; Petersen, Schnohr, \& Sorensen, 2004).

Researchers have proposed lack of leisure time, physical health problems, and lack of access to exercise programs, particularly among poor women, as barriers to physical activity (Bedinghaus, Leshan, \& Diehr, 2001). Women on welfare cited child- 
care responsibilities, fatigue, and inclement weather as barriers to physical activity (Fahrenwald \& Walker, 2003). In addition, African American women reported "feeling tired," child care responsibilities, access to exercise facilities, personal safety when exercising outdoors, and weather as factors that influenced their ability to participate in physical activities (Sanderson, Littleton, \& Pulley, 2002).

\section{Obesity and nutritional intake}

Researchers agree that poor nutrition combined with other risk factors contributes to obesity (Brownell, 2002; Crawford, 2004; James, 2002). Poor nutrition includes diets low in fruits, vegetables, and fiber and high in fats, sodium, and sugar (American Medical Association, 2000). According to Healthy People 2010, 75\% of Americans do not eat the recommended daily allowance of fruits and vegetables and $64 \%$ consume more saturated fat than the daily allotment - both habits contribute to obesity (MMWR, 2007). A study by Rice and Wicks (2006) supported these findings; 70\% of the participants in their study were obese and 89\% reported diets high in saturated fats (Rice \& Wicks, 2006).

Limited access to healthy food choices could directly affect nutritional intake (Salinsky \& Scott, 2003). Consistent with this observation are results from one study which found that the intake of fruits and vegetables increased by $32 \%$ with an increase in the number of supermarkets in predominately African American neighborhoods (Moreland, Wing, \& Diez, 2002). Furthermore, some researchers have discovered that nutrition may be influenced by social and cultural traditions (Henderson, 2002), particularly among African American women (Owens, 2003). In one study, African American women reported less restraint in food choices and fewer restrictions in eating patterns than did Caucasian women in the study (Sanchez-Johnson, Dymek, Alverdy \& Le Grange, 2003). Consistent with the previous study, a small but positive correlation $(\mathrm{r}=0.20)$ occurred between obesity and less food restraint in a study of African American women participating in a diet and exercise program $(n=429)$ (Siegel et al., 2000).

Studies have demonstrated moreover, that food insecurity may cause poor nutritional intake in low income women (Gibson, 2003; Leff, 2002). Food insecurity affects more than 30\% of low-income households (Leff, 2002), (food insecurity is defined as having limited access to food, particularly food that is nutritionally adequate) (Gibson, 2003). In a study of current and former welfare recipients participating in the Women's Employment Survey $(n=753), 35 \%$ percent of participants reported food insecurity at various points during the study (Siefert, Corcoran \& Heflin, 2000). Food insecurity was reported most often amongst women who had been welfare recipients for seven or more years, were over age 35, worked fewer than 20 hours per week, and had earned less than a high school education (Siefert, Corcoran, \& Heflin, 2000).

Food insecurity may also indicate increased risk of obesity and recent data suggests that approximately $73 \%$ of food insecure women are likely to be obese (Rector, Warner, Liu, Hinton, Sun, Cox, et al., 2007). Data from the 1998 and 1999 California Women's Health Survey revealed that obesity was more prevalent in households with 
food insecurity than in households with adequate food. Furthermore, highest rates of food insecurity occurred among poor, single, African American and Hispanic mothers (Siefert, Corcoran, \& Heflin, 2000).

Participation in the food-stamp program has also been linked to food insecurity and obesity in women with low incomes - but not to men (Gibson, 2003). Lowincome women participating in food-stamp programs had a $9.1 \%$ increase in the predicted probability of obesity (Gibson, 2003). The relationship between food-stamp participation, food insecurity, and obesity remains "paradoxical" according to some researchers (Townsend, Peerson, Love, Achterberg, \& Murphy, 2001). Food stamps are intended to fight hunger and ensure an adequate food supply. Yet, even with food stamp assistance, food-insecure households more likely purchase cheaper, less nutritious food high in calories, fats, and starches, all of which contribute to obesity, rather than nutritious, though costly food items such as fruits, vegetables and lean meats (Drewnowski \& Specter, 2004). Although research on the relationship between poor nutrition and food insecurity as risk factors for obesity continues, more research might clarify the relationship between poor nutritional intake and obesity in African American women leaving welfare for employment.

\section{Obesity and smoking}

Obesity was inversely associated with smoking in a cross-sectional survey of lowincome persons receiving care from three community clinics $(n=747)$ (Rohrer, Rohland, Denison, \& Way, 2005). The adjusted odds ratio (AOR) of being obese was low for persons who smoked 1-20 cigarettes per day (AOR: 0.56) and for persons who smoked more than 20 cigarettes per day (AOR: 0.33) compared to nonsmokers (Rohrer, Rohland, Denison, \& Way, 2005). Similar findings occurred in a cross-sectional survey of mental health and obesity among African American women receiving care in three ambulatory clinics $(n=113)$ (Davis et al., 2005). Fifty-three women met criteria for obesity, and $28 \%$ of these women were smokers. The relationship between obesity and smoking, however, proved not statistically significant $(\mathrm{p}=0.49)$ in this sample.

Additionally, Patt, Yanek, Moy and Becker (2004) observed a decrease in rates of smoking as obesity increased (16.4\% versus $9.9 \%)$, particularly in the obese II range ( $>35$ $\left.\mathrm{kg} / \mathrm{m}^{2}\right)$. Contrary to results obtained from the aforementioned studies, high rates of obesity $(70 \%)$ and a high number of current smokers $(30 \%)$ were reported in the sample of female welfare recipients preparing for employment $(n=89)$ (Rice \& Wicks, 2006). Although correlations were not conducted in this study, high rates of obesity and smoking in the sample validate the need for further research on the health status and health-risk behaviors of African American women preparing to leave welfare for employment.

\section{Obesity and alcohol consumption}

Risk factors contributing to obesity also relate to other high-risk behaviors such as alcohol consumption even when no causal relationship exists between these risk factors 
(Rohrer, Rohland, Denison, \& Way, 2005). Previous studies have reported an inverse relationship between alcohol consumption and body mass index in women (Colditz, Giovannucci, Rimm, Stampfer, Rosner, Speizer, et al., 1991; Fisher \& Gordon, 1985; Gruchow, Sobocinski, Barboriac, \& Sheller, 1985). In their study of obesity and frequency of alcohol consumption among low income women $(\mathrm{n}=747)$, Colditz, et al., found that obesity most often occurred with abstinence from alcohol as opposed to frequent consumption of alcohol (Rohrer, Rohland, Denison, \& Way, 2005).

\section{Personal Risk Factors and Obesity}

Literature that describes the associations between obesity and age and education are presented next. Both variables are important demographic risk factors associated with obesity. The biological risk factor of interest in the current study was body mass index (BMI). Obesity reflects the accumulation of excess body fat and is characterized by an increased BMI.

\section{Obesity and age}

Obesity often increases with age (Onyike, Crum, Lee, Lyketsos, \& Eaton, 2003; Sammel, Grisso, Freeman, Hollander, Liu, Liu, et al., 2003; Serdula, Ivery, Coates, Freedman, Williamson, \& Byers, 1993). Previous studies demonstrated that adolescent obesity strongly predicts adult obesity (Guo, Roche, Chumlea, Gardener, \& Siervogel, 1994; Haas, Lee, \& Kaplan, Sonneborn, Phillips, \& Liang, 2003; Whitaker, Wright, Pepe, Seidel, \& Dietz, 1997). Similar findings derived from the National Longitudinal Study of Adolescent Health (Gordon-Larsen, Adair, Nelson, \& Popkin, 2004). This study reported a substantial increase in prevalence and maintenance of obesity from adolescence to adulthood (Gordon-Larsen, Adair, Nelson, \& Popkin, 2004). According to some researchers, rates of obesity are similar among African American and Caucasian children, but higher rates of obesity occur in African American women beginning in late adolescence and extending into adulthood (Burke, Savage, Manolio, Sprafka, Wagenknecht, Sidney, et al., 1992).

Although prevalence of obesity is increasing among all age groups, the fastest increase involves persons aged $18-29$ in all races (Goodman \& Whitaker, 2002). A study by McTigue, Garrett, and Popkin, (2002) suggested that 20 to 30 year-old African American and Hispanic women become obese sooner than Caucasian women. Among African American women, the highest rates of obesity occur in women ages 40 and older (Liburd, 2003). Data from the 2003 -2004 National, Health and Nutrition Examination (NHANES) Survey indicated that $58 \%$ of African American women ages $40-59$ were obese in contrast to $38 \%$ of Caucasian women of the same age (Ogden, Carroll, Curtin, McDowell, Tabak, \& Flegal, 2006). Similar findings were reported in a survey assessing mental health, family function, and obesity among African American women $(n=113)$ (Davis et al., 2005). In this survey, age correlated positively with obesity $(\mathrm{p}=0.02)$ among women with a mean age of $44.6(\mathrm{SD} \pm 10)$ (Davis et al., 2005). 


\section{Obesity and education}

Published literature on obesity has demonstrated that prevalence of obesity varies with changes in socioeconomic status (SES) - and education is a common measure of SES (Yoon, Oh, \& Park, 2006). Studies have shown that women who were obese during childhood completed fewer years of education than did women who were not obese (Dietz, 1998). Results from a large community study $(n=7000)$ of psychosocial factors and the health status of Alameda County residents indicated that rates of obesity were higher for persons with low levels of education (15\%) than for persons with moderate levels of education (11\%) (Everson, Maty, Lynch, \& Kaplan, 2002). Similarly, high levels of obesity occurred among $60 \%$ of obese, low-income women (in a study about personal stressors associated with obesity) $(n=274)$ who had earned less than a high school education and were obese (Rohrer \& Rohland, 2004).

Based on a study of the demographics of obesity in the U.S., York, Rossner, Caterson, Chen, James, Kumanyika, et al., (2004) observed an inverse relationship between obesity and education. The increase in educational levels and the subsequent decline in obesity rates proved more pronounced in Caucasian women (York et al., 2004). Yet, education does not appear to influence rates of obesity among African American women (Burke, Savage, Manolio, Sprafka, Wagenknecht, Sidney, et al., 1992). Higher rates of obesity occurred among African American women in a previous study of obesity in African American and Caucasian women $(n=2801)$ aged 18-30 regardless of education (Burke, et al., 1992).

Similar findings resulted from data extracted from the Black Women's Health Study (Rosenberg, Palmer, Adams-Campbell \& Rao, 1999). A total of 18,653 women participated in this study. Thirty-four percent of the college- educated women under age 40 years were overweight or obese, and 45\% of women aged 50-69 were overweight or obese (Rosenberg, Palmer, Adams-Campbell \& Rao, 1999). Furthermore, obesity occurred in $42 \%$ of high school graduates and in $51 \%$ of women with fewer than 12 years of education (Rosenberg, Palmer, Adams-Campbell, \& Rao, 1999).

\section{Obesity and body mass index}

The National Heart, Lung, and Blood Institute (NHLBI) recommends use of the body mass index (BMI) to classify weight (Wyatt, Winters, \& Dubbert, 2006), and the Center for Disease Control regards the BMI as the best measure for assessing weight status in the population (Division of Nutrition and Physical Activity, 2004). Though the $\mathrm{BMI}$ is easy to calculate and inexpensive to use, it does not take into account variables such as age, gender, race, physical activity, and body type - all of which can affect composition of body fat (Deurenberg, Yap, \& van Staveren, 1998; Gallagher, Visser, Sepulveda, Pierson, Harris, \& Heymsfield, 1996; Prentice \& Jebb, 2001). Moreover, some researchers have suggested that minorities, particularly African Americans, may have higher body fat composition than other races (Bennett \& Wolin, 2006). 
When, Gallagher, Visser, Sepulveda, Pierson, Harris, \& Heymsfield, (1996) conducted a study on the influence of age, gender, and race on BMI and body-fat composition, they discovered that BMI correlated with body fat composition in female and male African Americans and Caucasians, but that, higher body fat compositions occurred in older females (Gallagher et al., 1996). Contrary to these results, Deurenberg, Yap, and van Staveren (1998) found the BMI overestimated body fat percentage in African Americans.

Indeed, studies have shown that African American women experience body image dissatisfaction (BD) at a higher body mass index (BMI) than do Caucasian women (Fitzgibbon, Blackman, \& Avellone, 2000). Baturka et al. (2000) noted that misperceptions regarding weight among African American women suggest that even when these women were overweight, they did not identify themselves as overweight. Bennett and Wolin (2006) validated these misperceptions in their study for which all of the participants were overweight or obese $(n=3437)$. African American women were two to three times more likely to describe themselves as being "about the right weight" than were other women in the study (Bennett \& Wolin, 2006).

Incongruencies between obesity and body-mass index exist in persons with different body types. Those with muscular bodies usually have higher BMIs because of higher muscle mass. Those with leaner body types may have normal BMIs when the body mass percentage is high because they have lower muscle mass. Moreover, persons of short stature may have false, low BMIs scores -- as in the cases of children and the elderly with lower bone density (Division of Nutrition and Physical Activity, 2004). Thus, we can identify limitations of the current BMI rating scale; various cutoff points may be required to allow for higher body fat composition.

\section{Obesity and Perceived Health Status}

Studies examining the association between obesity and perceptions of health status, indicate that obese participants were more likely to report their health status as poor than were participants who were not obese (Bertakis \& Azari, 2005; Dixon, Dixon, \& O'Brien, 2003; Faith, Matz, \& Jorge, 2002). In a study by Patt, Yanek, Moy, and Becker (2004), the General Well-Being Scale (GWB) was used to assess cardiovascular risk factors in African American women $(n=496)$. Since a subscale of the GWB includes a measure of perceived health or "freedom from health concern", researchers contend that higher BMIs were associated with lower perceived health scores (Patt, Yanek, Moy, \& Becker, 2004).

Kaplan, Siefert, Ranjit, Raghunathan, Young, Tran, et al., (2005) studied health perceptions of welfare recipients from the Women Employment Survey (WES) (1997 2001), and women similar in age and race from the National Health and Nutrition Examination Survey $(1999-2000)$. Women in the WES sample $(n=299)$ were more likely to be obese than those in the NHANES sample $(\mathrm{n}=359)$ predictive risk $(\mathrm{PR})=1.78$; CI: $95 \%, 149,2.08)$ and were three times as likely to report their health as fair to poor $(\mathrm{PR}=2.79, \mathrm{CI}: 95 \%, 2.10,3.49)$. Similar findings occurred in a study of the 
health status of women leaving welfare for work; approximately $70 \%$ of women in the study were obese, $48 \%$ perceived their health as poor, and $68 \%$ percent reported dissatisfaction with their lives (Rice \& Wicks, 2006).

\section{SUMMARY OF THE REVIEW OF LITERATURE}

African American women on welfare face an inordinate number of barriers that may hinder their successful transition to work including mental and physical health problems, both of which are major predictors of a person's ability to secure and maintain employment (Earle \& Heyman, 2002). This chapter reviewed seminal and current research on depressive symptoms and depression and obesity among African American women on welfare and explored factors that may affect their ability to move from welfare for work.

African American women preparing to leave welfare for work share many healthrisk factors related to socioeconomic status with poor and low-income women and women on welfare; and they share similar cultural influences with African American women not receiving welfare benefits. Therefore, because of the paucity of literature related to this population, relevant studies on poor women, low-income women, women on welfare, and African American women were reviewed.

Despite an abundance of information on the prevalence of depression among women and persons of low socioeconomic status, inconsistencies occur, within the literature, about the prevalence of depression among African American women generally. Nevertheless, most researchers agree that socioeconomic status is highly predictive of depression; and because of their socioeconomic status, African American women leaving welfare for work are at great risk for depressive symptoms and depression.

Convincing evidence reveals higher prevalence rates of obesity among African American women, and a growing body of literature suggests that high rates of obesity in this population persist regardless of socioeconomic status. Though the relationship between depression and obesity has been described in many cross-sectional and clinical studies, inconsistencies remain partly because of differences in methodology (e.g. assessment of depression, calculation of BMI). Furthermore, since we lack longitudinal data on the relationship between depression and obesity, researchers can draw no conclusions about the exact nature of this association.

Based upon published research, relationships between depression and obesity and physical activity, nutritional intake, smoking, alcohol consumption, age, education, BMI, and perceived health status are influenced by gender, race, and socioeconomic status. Few studies have examined the association of these variables specifically in African American women transitioning from welfare to work. This study therefore, will add to the literature by investigating (1) the prevalence of depression and obesity, (2) the association between these two disorders and (3) the relationship of these disorders to physical activity, nutritional intake, smoking, alcohol consumption, age, education, BMI, and perceived health status in this population. 


\section{CHAPTER 3. METHODOLOGY}

This chapter provides a detailed description of the study design, sample, setting, and the instruments. Procedures for data collection and statistical analyses as well as protection of human subjects are discussed.

\section{RESEARCH DESIGN}

The study was a retrospective, descriptive, correlational, study of data obtained from the health-risk assessments of women participating in the University of Tennessee Health Science Center (UTHSC) Health Works program. Retrospective data were chosen for this study because of the availability of the data and the probability that an adequate sample size could be extracted from the existing data for the study. The study was conducted to determine if significant relationships existed among physical activity, nutritional intake, smoking, alcohol consumption, age, education, body mass index (BMI), and perceived health status (the independent variables) and depressive symptoms and obesity, (the dependent variables) in the study.

\section{Sample and Setting}

The sample data were obtained from completed health risk assessments of welfare recipients enrolled in the UTHSC Health Works program from June 2006 through December 2007. This program provides health risk assessments, career assessments, personal counseling, occupational skills training, and job placement services for eligible Shelby County welfare recipients transitioning from welfare to work. A detailed description of the sample is provided in chapter 4 .

\section{Inclusion criteria}

The data were limited to health risk assessments from African American women who were18 years of age or older and able to speak and read English. Data were extracted from 162 nonrandomized health risk assessments meeting the inclusion criteria.

\section{Exclusion criteria}

The health risk assessments of non African Americans were excluded from the study. All of the instruments included in the study were prepared in English therefore; the health risk assessments of persons unable to speak or read English were excluded from this study. Health risk assessments from persons less than 18 years of age were also excluded from the study because minors are unable to give legal consent. 


\section{Sample size}

There are many methods of determining sample size. The most common methods use a fixed effect size, alpha and power, and include the number of predictors in the model. Cohen's (1998) criterion was used to determine the effect size for this study. A power analysis was performed to determine the number of subjects needed to ensure a significant $\mathrm{p}$-value $(<.05)$ The GPOWER computer software program was used to calculate the required sample size for this study (Erdfelder, Faul, \& Buchner, 1996). Based on a medium effect size (0.15), an alpha of 0.05 , a power formulation of $80 \%$, and five predictors (alcohol consumption, age, education, body mass index [BMI], and perceived health status), a sample of 98 subjects was deemed sufficient to address the research questions. To ensure an adequate sample size and external validity of the study, the sample size was increased to 162 health risk assessments from 162 women.

\section{Instrumentation}

Data were extracted from the Healthier People Network Health Risk Appraisals, the Health Self Report Appraisal (Rice, 2008) and the (CES-D) depression screening tools of women enrolled in the UTHSC Health Works program. The reliability and validity of the selected instruments are well documented.

\section{Healthier People Network Health Risk Appraisal (HPN - HRA, Version 6.0)}

The Healthier People Network Health Risk Appraisal (HPN - HRA, Version 6.0, The Healthier People Network Inc., 1992) a 20-item, self-report questionnaire, was used to identify health risk behaviors (physical activity, nutritional intake, smoking, and alcohol consumption) and personal risk factors (age, education, and body mass index). The HPN-HRA has face and content validity, and is useful in categorizing health risk behaviors. Health risk appraisals are used to objectively assess health risk behaviors, lifestyle choices and physiological measures (i.e. blood pressure, height, weight). In addition, HRAs are frequently used as a component of health promotion activities. Health risk appraisals typically consist of a questionnaire, a formula for estimating health risks based on existing epidemiological data, a method for generating reports and a means to provide participants with feedback.

The goals of HRAs are to assess health risks behaviors and lifestyle choices and health-promotion. Health risk appraisals can provide a summary of group data including major health problems and modifiable risk factors and a mechanism for disseminating preventive health information. Furthermore, interventions can be developed to reduce or eliminate health risks based upon the data retrieved from the HRA.

The HPN-HRA defines physical activity as thirty minutes of physical activity at least one to three times per week. Physical activity was defined by a positive or negative response to the physical activity question on the HPN-HRA form. Nutritional intake was determined by the self -reported, regular ingestion of a diet high in saturated fats, sodium 
and sugar and high in fruits, vegetables, whole grain, and fiber as specified on the HPNHRA form.

Smoking was defined by the participant's affirmative response on the HPN-HRA form of regular use of smoked tobacco. Alcohol consumption was defined by the number of alcoholic beverages consumed in a one-week period as noted on the HPN-HRA form. Age is the length of time a person has lived and the participant's self-reported age at the time the assessment was administered was used for this study. The level of education was determined by participant selection of a category of schooling (grade school or less, some high school, high school graduate, some college, college graduate, post graduate or professional degree) on the HPN-HRA.

Body mass index correlates with the amount of body fat and was defined by the relative weight in kilograms divided by the square of the height in meters $\left(\mathrm{kg} / \mathrm{m}^{2}\right)$. BMI was calculated and categorized as underweight (less than $18.5 \mathrm{~kg} / \mathrm{m}^{2}$ ), normal weight $\left(18.5-24.9 \mathrm{~kg} / \mathrm{m}^{2}\right)$, overweight $\left(25-29 \mathrm{~kg} / \mathrm{m}^{2}\right)$ and obese $\left(30 \mathrm{~kg} / \mathrm{m}^{2}\right.$ and higher $)$

(National Center for Health Statistics, 2006). Obesity was furthered categorized as obese I $\left(30-34.9 \mathrm{~kg} / \mathrm{m}^{2}\right)$, obese II $\left(35-39.9 \mathrm{~kg} / \mathrm{m}^{2}\right)$ and obese III $\left(\geq 40 \mathrm{~kg} / \mathrm{m}^{2}\right)$. The National Heart, Lung, and Blood Institute (NHLBI) recommend the use of stages (i.e. I, II, III) because these terms are less deprecating (Kushner \& Roth, 2005).

\section{Health Self Report Appraisal}

Perceived health status was defined by the participant's evaluation of her own health. The Health Self Report Appraisal (Rice, 2008), a ten point Cantrill ladder scale, has face and content validity. The Health Self Report Appraisal (Rice, 2008) was used to measure the participant's perception of her health for which "ten" indicates perfect health and "one" indicates lack of health.

\section{Center for Epidemiologic Studies Depression Scale (CES-D)}

The CES-D is a 20 item, Likert-type, self-report screening tool that measures the frequency of depressive symptoms. Radloff (1977) developed the CES-D to detect the levels of depressive symptoms in the population. The CES-D has been used extensively in urban and rural populations (Roberts, 1980). This instrument has proven useful in identifying study participants at risk for depression and for analysis of the association between depressive symptoms and other variables.

The 20 items on CES-D were selected from valid instruments and encompass many of the major symptoms of depression including sad or depressed mood, feelings of guilt and worthlessness, loss of appetite, sleep disturbances and energy levels however it does not measure the full range of depressive symptoms such as suicidality. Previous studies have demonstrated good internal consistency among subgroups including African Americans. The coefficient alpha for these subgroups is 0.85 (Auslander, Haire-Joshua, Houston, Rhee, \& Williams, 2000).Content, construct, and criterion validity have been 
well documented (Radloff, 1977). Validity was established by correlation of this instrument with other self-report depression screening tools (Cho, Moscicki, Narrow, Rae, Locke, \& Regier, 1993), and cases and non-cases of depression (Radloff, 1977).

Responses are rated from zero or none to four. A score of zero indicates the person has no symptoms or rarely has symptoms; a score of four means the person has experienced symptoms "all of the time" during the past week. Individuals are asked to rate such items as "I felt everything I did was an effort", "I felt depressed", "I felt I was just as good as other people', "I felt happy". Positive and negative questions are included in the scale to counterbalance any potential problems with response sets. Scores range from zero to sixty with higher scores indicative of increased symptomatology. Scores of 15 and less generally indicate no depressive symptoms are present, scores from 16 - 20 indicate mild distress, scores from 21 - 30 indicate a moderate level of depressive symptoms, and scores 31 and above indicate severe depressive symptoms (Radloff, 1977).

The cutoff score of 16 has a sensitivity of $80 \%$ and a specificity of $73 \%$ when compared to the standard interview type assessment of depression (Mulrow, Williams, Gerety, Ramirez, Montiel, \& Kerber, 1995). In addition, results from community based studies demonstrated that $>60 \%$ who scored $\geq 16$ on the CES-D met the criteria for depression (Boyd, Weisssman, Thompson, \& Myers, 1982). The Cronbach Alpha was 0.673 for this sample indicating good internal consistency. The CES-D was developed as a screening tool for depressive symptoms and not a diagnostic instrument which is a limitation of the instrument (Radloff). Furthermore, for the purpose of this study, the cutoff ranges should only be considered as an indicator of depressive symptoms rather than a diagnosis of depression.

\section{Procedure}

All of the participants in the study completed the HRA-HPN health assessment. Staff from the UTHSC Health Works program provided instructions for completion of the assessment. Heights and weights were measured by program staff and BMIs were calculated according to CDC recommendations. The assessments were completed on the site of the UTHSC Health Works program and collected by program staff. Data were entered into an Excel program file by graduate students trained on data entry. Numbers were assigned to each assessment in lieu of names and no other identifying information was included. Data were ultimately transferred to a Statistical Package for Social Sciences (SPSS) file by the researcher for the purpose of statistical analysis.

\section{Data Analysis}

The data were analyzed using SPSS version 16. A description of the variables used in a study is generally the first step in data analysis (Burns \& Groves, 2005). Descriptive statistics provided a manageable summary of the data and was useful during the initial inspection of the data for coding errors. Descriptive statistics were used to 
describe the frequency of health risk behaviors (physical activity, nutritional intake, smoking, and alcohol consumption), personal risk factors (age, education, and BMI), perceived health status, depressive symptoms and obesity in the sample. The number of observations associated with the scores in the data and any trends were extracted from frequency distributions.

In addition, the measures of central tendency and dispersion indicated the center point of the sample distribution along with the spread of the distribution. Furthermore, the mean and standard deviation served as a guide for choosing other types of statistical analysis appropriate for this study. The following statistical analyses were used to answer the study's research questions. The research questions are presented first, followed by the method chosen for analysis.

\section{Research questions one and two}

Question 1. What is the prevalence of depressive symptoms in African American women transitioning from welfare to work?

Question 2. What is the prevalence of obesity in African American women transitioning from welfare to work?

Prevalence was determined by the proportion of the sample who have depressive symptoms and/or obesity divided by the total number of participant health risk assessments in the sample.

\section{Research question three}

Question 3. What is the relationship between depressive symptoms and obesity in African American women transitioning from welfare to work?

Correlational analysis describes the relationship between and among variables. Pearson's Product Moment Correlation was used to determine the relationship between the variables measured on interval and ratio scales. Spearman Rho correlation was used to determine the relationship between the variables measured on an ordinal scale. Pearson's Product Moment Correlation was used to determine if a relationship existed among the dependent variables (depressive symptoms and obesity) in the study.

\section{Research question four}

Question 4. What is the prevalence of health risk behaviors among African American women transitioning from welfare to work? 
Prevalence was determined by the proportion of the sample that have health risk behaviors divided by the total number of participant health risk assessments in the sample.

\section{Research question five}

Question 5. To what extent do the following predict depressive symptoms in African American women transitioning from welfare to work?

- Health risk behaviors (physical activity, nutritional intake, smoking, and alcohol consumption),

- Personal demographic risk factors (age, education),

- Personal biological risk factors (body mass index), and

- Perceived health status

Multiple linear regression analysis was used to determine if the independent variables (physical activity, nutritional intake, alcohol consumption, smoking, age, education, body mass index, and perceived health status) could explain a significant proportion of the variance in the dependent variable (depressive symptoms) at a 0.05 level. The goal was to determine the best (most important or most valid) multiple regression model for describing the relationship between the dependent variable and a set of independent variables. The predictors were deleted in a stepwise and backward fashion in order to obtain a more parsimonious model.

\section{Research question six}

Question 6. To what extent do the following predict obesity in African American women transitioning from welfare to work?

- Health risk behaviors (physical activity, nutritional intake, smoking, and alcohol consumption),

- Personal demographic risk factors (age and education),

- Personal biological risk factors (BMI), and

- Perceived health status

Stepwise logistic regression analysis permitted the use of continuous and categorical variables. Stepwise logistic regression models were used to determine whether differences existed between obese and non-obese participants in terms of health risk behaviors (physical activity, nutritional intake, alcohol consumption, and smoking), personal risk factors (age, education, and body mass index), and perceived health status. The goal was to determine the best logistic regression model for describing the relationship between the dependent variables and a set of independent variables. 


\section{CONSIDERATION OF HUMAN SUBJECTS}

This study involved an analysis of secondary data; therefore, the risk to participants was minimal. Consideration for human subjects for this study primarily involved maintenance of confidentiality of the health information. Verbal and written explanation of the instruments was provided to each participant in the study simultaneously enrolled in the UTHSC Health Works program. Permission was obtained from the UTHSC Institutional Review Board (IRB) to conduct the study. Confidentiality of the data was maintained and no identifying information was used. Health risk assessments were coded and a master list of the participants will be maintained by the Director of the UTHSC Health Works program. The initial data is located in a locked file in the office of the program director. An electronic copy of data will be retained by the program director and the researcher.

Potential risks were minimal for the participants who completed the assessments. The assessments are related to health risk behaviors, personal risk factors, perception of health, and depressive symptoms. The only risk that were anticipated was minimal stress or uneasiness pertaining to self-disclosure or introspection from answering questions related to health status and depression. A letter of referral was provided to participants who scored 16 and over on the CES-D for depressive symptoms.

The aggregate data from this study will be disseminated in a manner that will not breach the confidentiality of the participant data in the study. The potential for the results of this study to impact the lives of other African women is an added benefit of this study. The UTHSC Institutional Review Board will have access to the identifying information in this study as part of their oversight activities. A master key that links the name and the code number will be maintained in a separate locked file cabinet in the office of the Director of Health Works at UTHSC. 


\title{
CHAPTER 4. RESULTS
}

The purpose of this study was to determine the predictors of depressive symptoms and obesity in a sample of African American women transitioning from welfare to work. Six research questions were developed to address this goal. The research questions are stated followed by the results of the statistical analysis. The data were analyzed using the Statistical Package for Social Science (SPSS) statistical program version 16.0. The initial discussion will begin with a description of the sample.

\section{CHARACTERISTICS OF THE SAMPLE}

The characteristics of the sample are reflected in the frequencies, percentages, means, and standard deviations. The total sample consisted of 162 welfare recipients. All of the recipients were African American females. The participants' ages ranged from 1855 with a mean age of 28.87 years $(\mathrm{SD}=7.79)$. Fifty-one $(32.1 \%)$ of the women in the sample graduated from high school, 38 (23.9\%) reported "some college", 8 women graduated from college, and one women obtained a post graduate or professional degree. One hundred sixty-one women rated their health on the Health Self Report (Rice, 2008) scale. Scores ranged from 1-10. The mean score was $7.34(\mathrm{SD}=1.89)$ and the majority of women $(n=102 ; 63.3 \%)$ rated their health from $7-10$, with 10 reflecting "perfect health". Frequencies, percentages, means, and standard deviations for participants' depressive symptom scores, body mass index, and health behaviors are presented as results for research questions 1,2 , and 3 .

\section{RESEARCH QUESTIONS AND FINDINGS}

\author{
Study Findings
}

Study findings are reported for each question in sequence followed by the results of the statistical analyses.

\section{Question one}

What is the prevalence of depressive symptoms in African American women transitioning from welfare to work?

Prevalence was defined as the number of participants in the sample with scores of 16 or greater on the Center for Epidemiological Studies Depression screening tool divided by the total number of participants in the sample. Scores on the CES-D were normally distributed, results are reported as means and the standard deviation, and all participants completed this instrument. The CES-D screening tool is a measure of the level of depressive symptoms. A score of 16 or greater on the CES-D indicates the need 
for further evaluation of depressive symptoms. Participants' total score on the CES-D ranged from zero (no depressive symptoms) to 50 (severe depressive symptoms). The mean score was $21.30(\mathrm{SD}=8.568)$ indicating a moderate level of depressive symptoms in this population. Forty-four (27\%) of the women reported depressive symptoms $<16$. Seventy-three percent of participants $(n=118)$ scored 16 or higher on the depression screening tool. Forty-two (26\%) reported depressive symptoms in the mild range (16-20). Fifty seven (35\%) reported depressive symptoms in the moderate range (21-30). Nineteen women (12\%) reported depressive symptoms $\geq 30$ indicating severe psychological distress.

\section{Question two}

What is the prevalence of obesity in African American women transitioning from welfare to work?

Obesity was defined as a body mass index greater than or equal to $30.00 \mathrm{~kg} / \mathrm{m}^{2}$. The prevalence of obesity was determined by the number of participants in the sample with a body mass index of $30 \mathrm{~kg} / \mathrm{m}^{2}$ or greater divided by the total number of participants in the sample. Body mass indexes (BMI) were obtained for all of the women in the sample $(\mathrm{N}=162)$. The body mass index of the participants ranged from $17.5-60.8 \mathrm{~kg} / \mathrm{m}^{2}$. The mean BMI score was $30.82 \mathrm{~kg} / \mathrm{m}^{2}(\mathrm{SD}=7.41)$ indicating a high prevalence of obesity in this population. Thirty-eight of the participants $(24 \%)$ were of normal weight and forty-five (28\%) were overweight. Seventy-seven (48\%) of participants in this study had BMI scores of $30 \mathrm{~kg} / \mathrm{m}^{2}$ or greater. Obesity was further categorized as "obese I (BMI $30-34.9 \mathrm{~kg} / \mathrm{m}^{2}$ ), obese II (BMI $35-39.9 \mathrm{~kg} / \mathrm{m}^{2}$ ), and obese III $\left(\right.$ BMI $\geq 40 \mathrm{~kg} / \mathrm{m}^{2}$ ) as summarized in Table 1.

\section{Question three}

What is the relationship between depressive symptoms and obesity in African American women transitioning from welfare to work?

The CES-D scores and BMI were tested for normality and the distributions were found to be normally distributed. Pearson's correlation coefficient was calculated to estimate the relationship between depressive symptoms and obesity in African American women transitioning from welfare to work. The results indicated that the relationship between depressive symptoms and obesity was statistically nonsignificant $(r=-0.114, p=$ $0.15)$.

\section{Question four}

What is the prevalence of health risk behaviors among African American women transitioning from welfare to work? 
Table 1. Body Mass Index of African American Women Transitioning from Welfare to Work $(\mathrm{N}=162)$

\begin{tabular}{|c|c|}
\hline Characteristic & n $(\%)$ \\
\hline $\begin{array}{l}\text { Categories of body mass index } \\
\text { Underweight } \quad\left(\leq 18.4 \mathrm{~kg} / \mathrm{m}^{2}\right) \\
\text { Normal weight } \quad\left(18.5-24.9 \mathrm{~kg} / \mathrm{m}^{2}\right) \\
\text { Overweight } \quad\left(25-29.9 \mathrm{~kg} / \mathrm{m}^{2}\right)\end{array}$ & $\begin{array}{rr}2 & (1.2) \\
38 & (23.5) \\
45 & (27.8)\end{array}$ \\
\hline $\begin{array}{l}\text { Obesity level } \\
\text { Obese I } \\
\text { Obese II } \\
\text { Obese III }\end{array}$ & $\begin{array}{ll}29 & (17.9) \\
28 & (17.3) \\
20 & (12.3) \\
\end{array}$ \\
\hline
\end{tabular}


Health risk behaviors (physical inactivity, poor nutritional intake, smoking, and alcohol consumption) are harmful activities that lead to adverse health outcomes including depressive symptoms and obesity (National Center for Chronic Disease Prevention and Health Promotion, 2006). Prevalence was determined by the number of participants in the sample that have health risk behaviors divided by the total number of participant health risk assessments in the sample (see Table 2). Thirty eight percent ( $\mathrm{n}=$ 60) of the participants engaged in physical activity at least three times per week however, $41 \%(n=65)$ engaged in physical activity only one or two times per week and $20 \%(n=$ 32) engaged in physical activity less than one time per week. The majority of the participants $(91 \%)(n=143)$ reported diets high in fiber while $72 \%(n=113)$ reported diets high in cholesterol. More than half of the sample (55\%) reported "never smoking" and $28 \%$ were still smoking at the time of data collection. Lastly, $68 \%(n=110)$ of the participants reported no alcohol consumption whereas $32 \%(n=32)$ reported alcohol consumption. In general, African American women transitioning from welfare to work were physically active, reported diets high in fiber but also high in cholesterol and most reported that they neither smoked nor used alcohol.

\section{Question five}

To what extent do the following variables predict depressive symptoms in African American women transitioning from welfare to work?

- Health risk behaviors (physical activity, nutritional intake, smoking, and alcohol consumption),

- Personal demographic risk factors (education and age),

- Perceived health status

- Personal biological risk factors (body mass index)

Pearson correlation analysis was used to determine the association between depressive symptoms, obesity, and the independent variables. A negative association was observed between perceived health status $(r=-0.302, p=0.0001)$ and depressive symptoms (Table 3). Step type regression (forward, backward, and stepwise procedure) was employed to determine the optimal model to predict depressive symptoms (Table 4). Prior to the regression analyses, residual analysis was conducted to identify sources of model misspecification, outliers, and possibly influential observations. Sensitivity analyses were performed to discern the impact of influential cases on the results. In addition, the nominal variables were dummy coded (Table 5), where the absence of a characteristic was coded as zero and the presence of a characteristic was coded as one.

The independent variables, physical activity, ingestion of foods high in fiber and cholesterol, smoking, alcohol consumption, level of education, age, perceived health status and obesity were regressed on the dependent variable, depressive symptoms. The final model consisted of the following variables perceived health status and BMI. Both of the variables in the optimal model had a significant effect on depressive symptoms. 
Table 2. Health Behaviors Reported by African American Women Transitioning from Welfare to Work $(\mathrm{N}=162)$

\begin{tabular}{lc}
\hline Characteristic & $\mathrm{n}(\%)$ \\
\hline Engage in physical activity & $32(20.4)$ \\
Less than one time per week & $65(41.4)$ \\
One to two times per week & $60(38.2)$ \\
At least three times per week & \\
Ingestion of foods high in fiber & $15(9.5)$ \\
No & $143(90.5)$ \\
Yes & \\
Ingestion of foods high in cholesterol & $43(27.4)$ \\
No & $113(72.0)$ \\
Yes & \\
Smoking History & $88(55.3)$ \\
Never smoked & $26(16.4)$ \\
Used to smoke & $45(28.3)$ \\
Still smoking & \\
Alcohol consumption & $110(68)$ \\
No & $32(32)$ \\
Yes &
\end{tabular}

Table 3. Correlation Analysis between Sample Characteristics and Depressive Symptoms and Obesity

\begin{tabular}{lcc}
\hline Variable (n) & Depressive Symptoms & Obesity \\
\hline Physical activity (157) & .150 & .009 \\
Ingestion of high fiber (158) & -.053 & .005 \\
Ingestion of high cholesterol (157) & .056 & .030 \\
Smoking (159) & .077 & -.042 \\
Alcohol consumption & .123 & .060 \\
Age & -.077 & $.167^{*}$ \\
Education (159) & .073 & .124 \\
Perceived health status (161) & $-.302^{* *}$ & -.114 \\
BMI & -.114 & .150 \\
Depressive symptoms & 1 & -.114 \\
\hline
\end{tabular}

Note: Sample size $=162$ except where noted. $* \mathrm{p} \leq .05, * * \mathrm{p} \leq .01$ 
Table 4. Optimal Regression Results of Depressive Symptoms

\begin{tabular}{lcc}
\hline Independent Variable & Beta & $\mathrm{p}$ \\
\hline Perceived health & -.335 & .000 \\
BMI $30 \mathrm{~kg} / \mathrm{m}^{2}$ or higher & -.153 & .049 \\
\hline
\end{tabular}

Note: Adjusted $\mathrm{R}^{2}=.122, \mathrm{~F}=10.41$, $\mathrm{df}=2, \mathrm{p}=.0001$ (model statistic) Excluded variables: physical activity, ingestion of foods high in fiber, ingestion of foods high in cholesterol, smoking, alcohol consumption, age, and education

Table 5. Dummy Coding of the Nominal Variables

\begin{tabular}{ll}
\hline Variables & Codes \\
\hline & \\
Engage in physical activity one or more times per week & 0 \\
No & 1 \\
Yes & \\
Ingestion of foods high in cholesterol & \\
No & 0 \\
Yes & 1 \\
Ingestion of foods high in fiber & \\
No & 0 \\
Yes & 1 \\
Current smoker & \\
No & \\
Yes & 0 \\
Alcohol consumption & 1 \\
No & \\
Yes & \\
Completed high school & 0 \\
No & 1 \\
Yes & \\
\hline
\end{tabular}


Eleven percent of the total variance in depressive symptoms was explained by perceived health status and BMI $(\mathrm{F}=10.41, \mathrm{p}=0.0001)$. These results indicate that women with higher levels of depressive symptoms had lower levels of perceived health status and lower BMI scores.

\section{Question six}

To what extent do the following predict obesity in African American women transitioning from welfare to work?

- Health risk behaviors (physical activity, ingestion of foods high in fiber and cholesterol, smoking, and alcohol consumption),

- Personal demographic risk factors (education and age),

- Perceived health status and

- Depressive symptoms

Pearson's correlation analysis was used to determine the association between obesity, depressive symptoms, and the independent variables. Participant age was the only variable that correlated with obesity $(r=0.167, p=0.034)$ (Table 3). Stepwise logistic regression was used to determine the optimal model to predict obesity in African American women transitioning from welfare to work (Table 6 and Table 7). Following the same principles as in the model for research question five, the independent variables, physical activity, ingestion of foods high in fiber and cholesterol, smoking, alcohol consumption, education, age, perceived health status, and depressive symptoms were entered in the model with obesity as the dependent variable. The results of logistic regression indicated that the variables perceived health status and depressive symptoms were statistically significant between obese and non-obese participants in the model (Table 6). Those participants who were obese were 0.798 times less likely to have positive perceptions of health and participants who were obese were 0.397 times less likely to have depressive symptoms (Table 7).

\section{COLLINEARITY DIAGNOSTICS}

Collinearity diagnostics were conducted to determine interrelatedness among the independent variables (Table 8 and Table 9). Collinearity or multicollinearity refers to the correlation among two or more independent variables within the regression model. Multicollinearity can falsely increase the variances of the predicted values and confound the effects or the contribution of the independent variables. In addition, multicollinearity can limit the strength of the coefficient of determination making predictions difficult to determine (Yarandi \& Gary, 2004). Correlations above .90 are typically an indication of multicollinearity. Other measures to assess for multicollinearity include tolerance, variance inflation factors, and the condition index. The tolerance measure is the amount of variability of an independent variable not explained by other independent variables. 
Table 6. Optimal Regression Results of Obesity

\begin{tabular}{lcccc}
\hline Parameter & Estimate & Standard Error & Wald Chi-Square & p-value \\
\hline Intercept & 1.055 & 1.401 & 0.567 & 0.452 \\
Perceived health & -0.225 & 0.101 & 4.963 & 0.026 \\
Depressive symptoms & -0.923 & 0.422 & 4.777 & 0.029 \\
\hline
\end{tabular}

Table 7. Odds Ratio Estimates

\begin{tabular}{lccc}
\hline Effect & Point Estimate & 95\% Wald Confidence Limits \\
\hline Perceived health & 0.798 & 0.655 & 0.973 \\
Depressive symptoms & 0.397 & 0.174 & 0.909 \\
\hline
\end{tabular}

Table 8. Collinearity Diagnostics for the Model of Depressive Symptoms $(\mathrm{N}=162)$

\begin{tabular}{lcccc}
\hline Variable & df & Tolerance & $\begin{array}{c}\text { Variance } \\
\text { Inflation }\end{array}$ & $\begin{array}{c}\text { Condition } \\
\text { Index }\end{array}$ \\
\hline Perceived health & 2 & 0.982 & 1.018 & 2.467 \\
BMI $\geq 30 \mathrm{~kg} / \mathrm{m}^{2}$ & 2 & 0.982 & 1.018 & 9.257 \\
\hline
\end{tabular}

Table 9. Collinearity Diagnostics for the Obesity Model $(\mathrm{N}=162)$

\begin{tabular}{lcccc}
\hline Variable & df & Tolerance & $\begin{array}{c}\text { Variance } \\
\text { Inflation }\end{array}$ & $\begin{array}{c}\text { Condition } \\
\text { Index }\end{array}$ \\
\hline Perceived health & 2 & 0.853 & 1.172 & 9.635 \\
Symptoms of depression & 2 & 0.862 & 1.160 & 19.600 \\
\hline
\end{tabular}


The value of tolerance should be one or less. The variance inflation factor (VIF) is the degree that one independent variable explains the other independent variables and the value of the VIF should be $\leq 10$. Another common measure of multicollinearity is the condition index. A condition index of $\geq 30$ indicates a linear relationship among the independent variables (Yarandi \& Gary, 2004). The tolerance measure for the models in this study ranged from 0.853 to 0.982 , the variance inflation factors were between 1.018 and 1.172 and the condition indexes for the models were between 2.467 and 19.600. Results of the collinearity diagnostics indicated the absence of multicollinearity for the models in this study. 


\section{CHAPTER 5. DISCUSSION AND IMPLICATIONS}

\section{DISCUSSION}

This study investigated the predictors of depressive symptoms and obesity in African American women transitioning from welfare to work. A summary of the study is presented in this chapter and the relationship of the study findings to the literature and previous research is also included. Limitations of this study are discussed however it important to note that much of the participant data included in the following sections were obtained by self report, which is a limitation of any study. Self report is a useful measure to obtain information about individual behavior nevertheless; there are many factors such as the physical and social environment, clarity of the instructions and the form, and response bias that may influence the accuracy of self report (Torabi \& Ding, 1998). These factors will be considered as the findings of this study are appraised. Lastly, implications for practice, policy and future research are explored.

\section{Demographic Findings}

Data from the health assessments of 162 African American women enrolled in the UTHSC Health Works program were analyzed for this study. Many of the findings in this study were comparable to findings in the literature and published research. The mean age of women in this study was 29 years, slightly less than the average age of 31 years of women on welfare in the population (Parvez, 2002). There was no correlation between depressive symptoms and age in this study although recent data suggests that depression often occurs in women ages 25 to 44 (Mental Health Resource Center, 2006) and among poor African American women ages 20 to 29 (Brown, Ahmed, Gary, \& Milburn, 1995). A small, but positive correlation was noted between obesity and age. This finding is consistent with previous research indicating an increase in the prevalence of obesity with increased age (Onyike, Crum, Lee, Lyketsos, \& Eaton, 2003; Sammel, Grisso, Freeman, Hollander, Liu, Liu, Nelson, et al., 2003).

High levels of education were noted among the women in this study in contrast to published reports indicating that less than $50 \%$ of welfare recipients complete high school (Metsch \& Pollack, 2005). Thirty-two percent of participants in this study completed high school, 24\% reported "some college", and 5\% were college graduates. Researchers have reported higher rates of depression among persons with limited education compared to persons with higher levels of education (Blazer et al., 1994). Results from the current study were incongruent with these findings. Women in this study reported high levels of depressive symptoms and high levels of education. High levels of depressive symptoms in this population are likely related to situational influences associated with being on welfare and mandated legislation requiring them to transition into the workforce.

Investigators have reported a positive correlation between obesity and limited education (Yoon, Oh, \& Park, 2006) however, findings from the current study are 
consistent with previous studies conducted by Burke et al., (1992) and Rosenberg, Palmer, Adams-Campbell, and Rao, (1999), wherein the prevalence of obesity was high among African American women regardless of level of education. A plausible explanation for the lack of association between obesity and education in this sample of African American women on welfare preparing for work is the influence of social and cultural factors on perceptions of weight. African American women are more likely to associate obesity attractiveness compared to Caucasian women (Allan et al., as cited in Davidson \& Knafl, 2006) and perceptions of their weight are influenced by friends and family members (Baturka et al., 2000).

\section{Prevalence of Depressive Symptoms}

Findings from this study are consistent with findings from previous studies which found high rates of depressive symptoms among welfare recipients (Hildebrandt \& Kelber, 2005; Lennon et al., 2001; Rice \& Wicks, 2006) and it is likely that these high levels of depressive symptoms are related to the chronic stress of being poor and on welfare. The large number of women experiencing moderate to severe levels of depressive symptoms warrants further attention. High levels of depressive symptoms place this population at an increased risk of experiencing clinical depression. Moreover, high levels of depressive symptoms threaten their overall health status and successful transition to work.

\section{Prevalence of Obesity}

The intent of the second research question was to determine the prevalence of obesity in this sample of African American women leaving welfare for work. Obesity was determined by a BMI of $30 \mathrm{~kg} / \mathrm{m}^{2}$ or greater. The mean BMI score for the sample was $30.82 \pm 7.41$ and $48 \%$ of the participants had BMI scores greater than $30 \mathrm{~kg} / \mathrm{m}^{2}$ indicating high rates of obesity among the participants. Findings from this study were not surprising given the high rates of obesity found among Tennessee residents. According to the Center for Disease Control and Prevention (CDC), 27\% of Tennessee residents are obese (Morbidity and Mortality Weekly, 2008). Additionally, results from the current study were consistent with previous studies wherein high rates obesity was found among poor women (James, Fowler-Brown, Raghunathan \& Van Hoewyk, 2006) and women on welfare (Rice \& Wicks, 2006).

\section{Relationship between Depressive Symptoms and Obesity}

The focus of the third research question was to determine if depressive symptoms were associated with obesity among participants in this study. Results from previous population based studies conflict on the relationship between depressive symptoms and obesity. Some investigators have found a positive association between depression and obesity (Carpenter et al., 2000; Istvan, Zavela, \& Weidner, 1992; Roberts, Kaplan, \& Shema, 2000) while others have found no relationship between the two disorders 
(Hallstrom \& Nopa, 1981; Faubel, 1989; Palinkas, Wingard, \& Barrett-Connor, 1996). High levels of depressive symptoms were reported among $73 \%$ of the participants in this study and $48 \%$ were obese yet the relationship between these two disorders was statistically nonsignificant. It is reasonable to assume however, that a significant number of women who were depressed were also obese and more research is needed to address the co-occurrence of depressive symptoms and obesity in this population.

\section{Prevalence of Health Risk Behaviors}

The aim of the fourth research question was to determine the prevalence of health risk behaviors (physical inactivity, poor nutritional intake, smoking, and alcohol consumption) among women in the sample. According to Haskell et al., (2007), physical inactivity is common among women and persons of lower socioeconomic status. Overall, high levels of physical activity were reported by the women in this study. Forty-one percent of the women reported physical activity one to three times per week, and 38\% reported physical activity at least three times per week. It is possible that participants in the current study reported levels of physical accurately, although it is conceivable that the levels may have been inflated through response bias.

There are conflicting reports in the literature regarding the relationship between depression and physical activity. Some investigators report a positive association between depression and physical activity whereas other investigators report no association between depression and physical activity (Cooper-Patrick, Ford, Mead, Chang, \& Klag, 1997; Kritz-Silverstein, Barrett-Connor \& Corbeau, 2001). There was no association observed between depressive symptoms and physical activity in this study suggesting that physical activity was not influenced by the level of depressive symptoms for women in this study. There is a widely held belief that physical inactivity contributes to obesity (Blair \& LaMonte, 2005; Sparling, Owen, Lambert, \& Haskell, 2000) however, physical activity was not associated with obesity in this study. These findings are consistent with a study conducted by Davis et al., 2005 on mental and obesity in African American women, $45 \%$ of the women reported regular physical activity more than three times per week. Thus, if participants in the study reported levels of physical activity accurately, it is reasonable to assume that depressive symptoms and obesity did not restrict the level of physical activity among the participants.

Poor nutritional intake was determined by reports of diets high in cholesterol. Seventy percent of respondents reported diets high in cholesterol similar to national data which demonstrated that $64 \%$ of Americans consume more saturated fat than the recommended daily allowance (USDHHS, 2000). Investigators have reported an association between depressive symptoms and poor nutrition (Beardsley, 2000) and obesity and poor nutrition (Brownell, 2002; Crawford, 2004; James, 2002). Unlike these reports, consumption of diets high in cholesterol was not associated with depressive symptoms or obesity in the current study.

According to recent data, 24\% of African American women smoke cigarettes and poor African American women have the lowest smoking cessation rates (National Cancer 
Institute, 2005). The majority of women in the current study (55\%) are non-smokers, $17 \%$ used to smoke and $28 \%$ are current smokers. Similar results were found in a study of welfare recipients conducted by Rice and Wicks, (2006) wherein 30\% of participants were current smokers. Depression has been linked to cigarette smoking in low income African American women (Vander et al., 2006) and investigators have reported that women are more likely to smoke to relieve depressive symptoms than men (Bedinghaus, Leshan, \& Diehr, 2001).

Unlike previous studies, while $73 \%$ of participants in this study reported mild to severe depressive symptoms and $28 \%$ were current smokers, smoking was not correlated with depressive symptoms in this study. An inverse relationship between obesity and cigarette smoking has been reported by a number of researchers (Davis et al., 2005; Patt, Yanek, Moy \& Becker, 2004; Rohrer, Rohland, Denison, \& Way, 2005). A large number of women in this study were obese (48\%) and a lesser number of the women were cigarette smokers $(28 \%)$; however, the relationship between obesity and cigarette smoking was not statistically significant, therefore an inverse relationship cannot be assumed.

Some researchers estimate that 6 to $10 \%$ of welfare recipients use alcohol (Jayakody, Danziger \& Pollack, 2000), although other researchers suggest that the rates of alcohol use among welfare recipients may be inflated. Data is limited on alcohol use in African American women on welfare. However, data from the USDHHS (2003) indicates that African American women in general drink less alcohol than Caucasian women (83\% and $68 \%$ respectively). Thirty-two percent of participants $(n=52)$ reported regular use of alcohol during a one week period. Results from this study however, cannot be compared to findings from previous studies because of probable differences in measurement scales and definitions of alcohol use.

Investigators have documented a strong relationship between depression and alcohol use in the U.S. population (Conway, Compton, Stinson, \& Grant, 2006; Hasin, Goodwin, Stinson, \& Grant, 2005). Seventy-three percent of women in the study reported moderate levels of depressive symptoms and $32 \%$ percent reported regular alcohol use. It is possible that some of the women with depressive symptoms also used alcohol although a significant relationship was not observed between depressive symptoms and alcohol consumption in this study. An inverse relationship has also been reported between obesity and alcohol consumption (Colditz et al., 1991; Fisher \& Gordon, 1985; Gruchow, Sobocinski, Barboriac, \& Sheller, 1985). The correlation between obesity and alcohol consumption in the current study was not significant.

It is important to note however, that substance use, including alcohol, has been cited as a barrier to employment by welfare recipients (Metsch \& Pollack, 2005). Furthermore, investigators have found that welfare recipients who were substance users were less likely to work than recipients who were not substance users (Olson \& Pavetti, 1996). The reported use of alcohol must be viewed with caution given the potential for response bias. Nevertheless, women in the current study should be evaluated further for alcohol and substance use disorders. 


\section{Predictors of Depressive Symptoms}

The aim of research question five was to explicate the predictors of depressive symptoms in this sample of African American women preparing for work. Results from the regression analysis indicated that perceived health and body mass index greater than $30 \mathrm{~kg} / \mathrm{m}^{2}$ contributed to $11 \%$ of the variance in depressive symptoms. Studies have shown that depression affects perceptions of health particularly among poor women and women on welfare (Heneghan, Silver, Bauman, Westbrook, \& Stein, 1998; Polit, London, \& Martinez, 2001). Moreover, other studies have demonstrated that fair or poor perception of health was a predictor of depression among African American women on welfare (Brown, Ahmed, Gary, \& Milburn, 1995). Similar to previous studies, women in this study reported lower perceptions of their own health as levels of depressive symptoms increased.

Many studies investigating the relationship between depressive symptoms and BMIs greater than $30 \mathrm{~kg} / \mathrm{m}^{2}$ (obesity) have suggested that persons who were obese were more likely to be depressed than persons not obese (Becker, Margraf, Turke, Soeder, \& Neumer, 2001; Dong, Sanchez, \& Price, 2004).. A study conducted by Dong, Sanchez and Price (2004) found the odds for depression were greater among persons in the study who were obese. Contrary to the results from the aforementioned studies, results from the current study indicated that the odds of depressive symptoms were low $(\mathrm{OR}=0.397$; $95 \% \mathrm{CI}=0.174-0.909$ ) among participants with body mass index greater than $30 \mathrm{~kg} / \mathrm{m}^{2}$ (obesity). Emerging evidence has demonstrated that while a positive relationship between depressive symptoms and obesity may not be observed in cross-sectional studies, a positive relationship may well appear in a prospective study among the same cohort of participants (Goodman \& Whitaker, 2002; Noppa \& Hällström, 1981; Ross, 1994;). This finding supports the need for more research to determine the cause of high rates of depressive symptoms and obesity in this population.

\section{Predictors of Obesity}

The focus of research question six was to explicate the predictors of obesity. Perceived health and depressive symptoms were predictors of obesity in the current study. Results from the logistic regression analysis indicated that women who were obese, were 0.798 times less likely to have positive perceptions of their own health. Similar findings were found in larger studies of welfare recipients (Bertakis \& Azari, 2005; Dixon, Dixon, \& O'Brien, 2003; Faith, Matz, \& Jorge, 2002). Women in these studies who were obese were more likely to report their health as poor compared to participants who were not obese. Results from the current study also indicated that participants who were obese were 0.397 times less likely to have depressive symptoms. This was an unexpected finding given the high rates of obesity and depressive symptoms among the participants in this study. This finding however, was consistent with a study conducted by Rohrer and Rohland, (2004) where a positive relationship between obesity and depressive symptoms was not observed. There is plausible evidence from other studies that a positive association between depressive symptoms and obesity exists. Longitudinal studies are needed to address the perceptions of health and the high rates of 
depressive symptoms and obesity in African American preparing to leave welfare for work.

\section{LIMITATIONS AND STRENGTHS}

There are several limitations and strengths of this study. Limitations of the study include instrumentation and sampling. Insight into the prevalence of depressive symptoms and obesity, health risk behaviors, personal risk factors, and perceptions of health among African American women transitioning from welfare of work are strengths of the study. Study limitations will be explored first followed by a discussion of the strengths of the study.

The instruments used in this study (HRA-HPN, CES-D, Health Self Report) were self report tools. Self report tools have many advantages and disadvantages. Self report tools typically measure what they are designed to measure (Baranowski, 1985), the data is easy to obtain and this method is relatively inexpensive. In addition, that participants report their own health status and behaviors is the main advantage of self report. The reliability and validity of self report however, must be considered (Baranowski, Dworkin, Cieslik, \& Hooks, 1984). The reliability and validity of self report may be influenced by the setting, the clarity of the instrument, the emotional state of the participant and response bias.

Response bias or the propensity to choose a socially acceptable response is a major threat to the accuracy of self report and is nearly impossible to control. Response bias must be considered when interpreting the self reported data from this study and anonymous self report may be an option for future studies. Additionally, although the CES-D tool has been used in many population based studies that include African Americans and welfare recipients, this tool has not been used extensively in African American women on welfare which is another limitation of the study. Moreover, the CES-D is a screening tool designed to measure the level of depressive symptoms and is not a diagnostic tool.

This study was a retrospective, descriptive, correlational design. The original data was obtained from a convenience sample of African American women preparing to leave welfare for work. Convenience sampling limits the generalizability of the findings thus results from this study may not be applicable to non-African American welfare recipients. Additionally, this study was conducted in an urban area and results may not generalizable to welfare recipients in rural areas. Lastly, because this is a cross-sectional study, causation cannot be established among the variables.

This study had several strengths despite the limitations noted. Many of the studies on the health status of welfare recipients were primarily conducted on Caucasian women with a small sampling of African American women. This study was one of the few studies conducted solely on African American women preparing to leave welfare for work. African American women are disproportionately represented among welfare

recipients and have more mental and physical health problems including depressive 
symptoms and obesity than women of other races. These findings add to the body of literature on the health status of African American women on welfare. In addition, few studies have examined the relationship between depressive symptoms and obesity among African American women on welfare transitioning to work which was an added strength of this study. Finally, this study explicated the predictors of depressive symptoms and obesity among participants which has not been previously addressed. Depressive symptoms and obesity are a threat to the health status and financial well being of African American women preparing to leave welfare to join the workforce. Findings from this study should be used to guide the development of tailored risk reduction interventions for these women to ensure their successful quest for self-sufficiency.

\section{Implications for Practice and Policy}

The high rates of depressive symptoms and obesity in this sample have generated important implications for practice and policy. African American women express somatic symptoms of depression thus, it is imperative that health care providers recognize that depressive symptoms in this population are often undetected which often leads to misdiagnosis and ineffective treatment. Furthermore, the high prevalence of depressive symptoms among African American women leaving welfare for work attests to the unmet need for mental health services. Additionally, African American women define obesity in more positive terms than do women of other races. Providers must be aware of the influence of sociocultural factors on the perception of obesity among these women. If the sociocultural factors are not acknowledged, preventative measures and interventions designed to address the high rates of obesity in this population may be misdirected.

The co-occurrence of depressive symptoms and obesity in this population can not be ignored. Therefore, measures are needed to promote frequent screening for early detection and treatment of depressive symptoms and obesity. Additionally, methods that focus on African American women on welfare with existing symptoms of depression and who are obese, are necessary to limit complications and disabilities associated with these two disorders.

Mental and physical health problems are major barriers to work for African American women transitioning from welfare to work. In light of the work-related mandates imposed by welfare reform, policy makers must provide funding for programs that address these barriers. Policies and programs that improve access to mental health services are essential in improving the mental health of African American women leaving welfare. Prevention of obesity must include public health initiatives that promote healthier diets and weight reduction activities among African American women leaving welfare for work Furthermore, policy makers must examine the effect of depressive symptoms and obesity on the ability of these women to leave welfare and obtain jobs. Findings from this study underscore the need for policies and programs that integrate treatment and work related programs to improve employment prospects for these women. 


\section{Recommendations for Future Research}

There are few studies on the health status of African American women on welfare or the health related barriers that prevent their successful transition to the workforce. This study provides evidence of a co-occurrence of depressive symptoms and obesity in African American women transitioning from welfare to work though more prospective studies are needed to determine causal relationships. Overall, high rates of depressive symptoms were observed among the participants in the sample yet there were some variations in the levels of depressive symptoms. Further research is needed to explore the variations in the levels of depressive symptoms in this population.

Consistent with previous studies, high levels of obesity were observed among the participants in the study regardless of education. Future studies are needed to determine why there are differences in the association between education and obesity in African American and Caucasian women; this may prove to be an important finding in designing interventions for African American women leaving welfare for work.

Lower perceptions of health were observed among women in the study who reported depressive symptoms and among those who were obese. Qualitative studies would help to elucidate how perceptions of health influence the development of depressive symptoms and obesity among African American women on welfare. Additionally, researchers should be cognizant of the impact that situational influences might have on the development of depressive symptoms and obesity.

Researchers have suggested that depressive symptoms and obesity may interfere with the ability of some of these women to obtain a job and remain employed. Further research is needed to determine the extent to which depressive symptoms and obesity affect employability among these women. While causality cannot be inferred from the cross-sectional data from this study, the findings indicate a need for a more comprehensive examination of the role of health risk behaviors, personal risk factors, perceived health status and situational influences in the development of depressive symptoms and obesity. Knowledge of these factors is necessary in developing interventions and strategies to prevent depressive symptoms and obesity in this population.

\section{Theoretical Implications}

The conceptual model for this study assumed a relationship among all of the independent variables and the dependent variables. Findings from this study revealed a lack of association between depressive symptoms and obesity; however, based upon the high rates of depressive symptoms and obesity in this population there was likely overlapping of these two disorders among some of the participants in the study. Perceived health and body mass index $30 \mathrm{~kg} / \mathrm{m}^{2}$ and above predicted depressive symptoms and perceived health and depressive symptoms predicted obesity which was consistent with the direction of influence of the variables in the conceptual model. The results from this 
study support some components of the conceptual model and demonstrate the applicability of this model in longitudinal studies of these variables.

\section{SUMMARY}

Our finding of high levels of depressive symptoms and high rates of obesity among this sample of African American women transitioning from welfare to work may in part reflect the normative nature of depressive symptoms and the socio-cultural influence on obesity in this population. Numerous theories have been proposed to explain the relationship between depressive symptoms and obesity yet no causal relationship has been established. More prospective studies are needed to determine the pathway by which depressive symptoms and obesity interact in order to develop effective strategies for prevention of depression and obesity. African American women express symptoms of depression differently and providers should be aware of this fact and screen for depression accordingly. In addition, African Americans view overweight and obesity differently and clinicians must also consider socio-cultural influences on perceptions of weight in this population. 


\section{LIST OF REFERENCES}

Allison, D. B., Edlen-Nezin, L., Clay-Williams, G. (1997). Obesity among African American women: prevalence, consequences, causes, and developing research. Women's Health, 3: 243-274.

American Medical Association, (2000). A healthy diet. Retrieved March 6, 2007 from

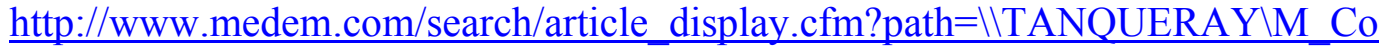
ntentItem\&mstr=/M ContentItem/ZZZG9QE5YAC.html\&soc=JAMA/Archives \&srch typ $=\mathrm{NAV}$ SERCH

American Obesity Association. (2005). Women and obesity. Retrieved December 1, 2006, from http://obesity1.tempdomainname.com/subs/fastfacts/obesity_women.shtml

American Psychiatric Association. (2000). Diagnostic \& statistical manual of mental disorders (4th ed., text revision). (pp.349-356). Washington, DC: American Psychiatric Association.

Anderson, S. E., Cohen, P., Naumova, E. N., \& Must, A. (2006). Association of depression and anxiety disorders with weight change in a prospective communitybased study of children followed up into adulthood. Archives Pediatric Adolescent Medicine, 160(3), 285-291.

Auslander, W., Haire-Joshu, D., Houston, C., Rhee, C., \& Williams, J. H. (2000). The short-term impact of health promotion program for low-income African American women. Research on Social Work Practice, 10, 78-97.

Averett, S., \& Korenman, S. (1999). Black-white differences in social and economic consequences of obesity. International Journal of Obesity Related Metabolic Disorders, 23(2), 166-173.

Backmand, H., Kaprio, J., Kujala, U., \& Sarna, S. (2003). Influence of physical activity on depression and anxiety of former elite athletes. International Journal of Sports Medicine, 24(8), 609-619.

Baranowski T. (1985). Methodologic issues in self-report of health behavior. Journal of School Health, 55, 179-182.

Baranowski, T, Dworkin, R., Cieslik, C. J., \& Hooks, P. (1984). Reliability and validity of children's self-report of aerobic activity: family health project. Research Exercise Report, 55(4), 309-317.

Barbee, E. L. (1994). Healing time: the blues and African American women. Health Care for Women International, 15(1), 53-60. 
Baturka, N., Hornsby, P. P., \& Schorling, J. B. (2000). Clinical implications of body image among rural African American women. Journal of General Internal Medicine, 15(4), 235-241.

Beardsley, B. (2000). Depression and Nutrition. Retrieved April 7, 2008, from http://www.healingwell.com/library/depression/beardsleyl.asp

Bebbington, P. E., Dunn, G., Jenkins, R., Lewis, G., Brugha, T., Farrell, M., et al. (1998). The influence of age and sex on the prevalence of depressive conditions: report from the National Survey of Psychiatric Morbidity. Psychological Medicine, 28(1), 9-19.

Becker, E. S., Margraf, J., Turke, V., Soeder, U., \& Neumer, S. (2001). Obesity and mental illness in a representative sample of young women. International Journal of Obesity and Related Metabolic Disorders, 25, Supplement 1, S5-9.

Bedinghaus, J., Leshan, L., \& Diehr, S. (2001). Coronary artery disease prevention: what's different for women? American Family Physician, 63(7), 1393-1400, 1405-1396.

Belle, D., \& Doucet, J. (2003). Poverty, inequality, and discrimination as sources of depression among U.S. women. Psychology of Women Quarterly, 27, 101-113.

Bennett, G. G., \& Wolin, K. Y. (2006). Satisfied or unaware? Racial differences in perceived weight status. International Journal of Behavioral Nutrition and Physical Activity, 3, 40.

Benowitz, N. L. (2008). Neurobiology of nicotine addiction: implications for smoking cessation treatment. American Journal Medicine, 121(4 Supplement 1), S3-10.

Bertakis, K. D., \& Azari, R. (2005). Obesity and the use of health care services. Obesity Research, 13(2), 372-379.

Bhatia, S. C., \& Bhatia, S. K. (1999). Depression in women: diagnostic and treatment considerations. American Family Physician, 60 (1), 225-234, 239-240.

Blair, S. N., \& LaMonte, M. J. (2005). Commentary: current perspectives on obesity and health: black and white, or shades of grey? International Journal of Epidemiology, 35(1), 69-72; discussion 81-62.

Blazer, D. G., Kessler, R. C., McGonagle, K. A., \& Swartz, M. S. (1994). The prevalence and distribution of major depression in a national community sample: the National Comorbidity Survey. American Journal of Psychiatry, 151(7), 979-986.

Blazer, D. G., Moody-Ayers, S., Craft-Morgan, J., \& Burchett, B. (2002). Depression in diabetes and obesity: racial/ethnic/gender issues in older adults. Journal of Psychosomatic Research, 53 (4), 913-916. 
Boyd, J. H., Weissman, M. M., Thompson, W. D., \& Myers, J. K. (1982). Screening for depression in a community sample. Understanding the discrepancies between depression symptom and diagnostic scales. Archives General Psychiatry, 39(10), 1195-1200.

Brown, D. R., Ahmed, F., Gary, L. E., \& Milburn, N. G. (1995). Major depression in a community sample of African Americans. American Journal of Psychiatry, 152(3), 373-378.

Brown, T. M., \& Stoudemire, A. (1998). Psychiatric side effects of prescription and overthe -counter medications: recognition and management. Washington, DC: American Psychiatric Press Inc.

Brownell, K. D. (2002). The environment of obesity. In Fairbum, C. G., Browne, K. D. (Ed.), Eating disorders and obesity (2nd ed., pp. 403-407). New York: Guilford Press.

Bruce, M. L., Takeuchi, D. T., \& Leaf, P. J. (1991). Poverty and psychiatric status. Longitudinal evidence from the New Haven Epidemiologic Catchment Area study. Archives General Psychiatry, 48(5), 470-474.

Brunner, E., Shipley, M. J., Blane, D., Smith, G. D., \& Marmot, M. G. (1999). When does cardiovascular risk start? Past and present socioeconomic circumstances and risk factors in adulthood. Journal of Epidemiological Community Health, 53(12), 757-764.

Burke, G. L., Savage, P. J., Manolio, T. A., Sprafka, J. M., Wagenknecht, L. E., Sidney, S., et al. (1992). Correlates of obesity in young black and white women: the CARDIA Study. American Journal of Public Health, 82(12), 1621-1625.

Burns, N., \& Groves, S. K. (2005). Introduction to statistical analysis. In L. Henderson (Ed.), Practice, nursing and research: conduct, critique and utilization (5th ed., pp. 453-454). St. Louis: ELSEVIER Saunders.

Cancian, M., \& Meyer, D. (2000). Work after welfare: Women's work effort, occupation and economic wellbeing. Social Work Research, 24(2), 69-86.

Carpenter, K. M., Hasin, D. S., Allison, D. B., \& Faith, M. S. (2000). Relationships between obesity and DSM-IV major depressive disorder, suicide ideation, and suicide attempts: results from a general population study. American Journal of Public Health, 90(2), 251-257.

Cawley, J., \& Danziger, S. (2005). Morbid obesity and the transition from welfare to work. Journal of Policy Analysis and Management, 24(4), 727-743.

Center for Disease Control and Prevention. (2007). Overweight and obesity: economic consequences. Retrieved June 27, 2007, from http://www.cdc.gov/nccdphp/dnpa/obesity/economic_consequences.htm 
Chang, V. W., \& Lauderdale, D. S. (2005). Income disparities in body mass index and obesity in the United States, 1971-2002. Archives of Internal Medicine, 165(18), 2122-2128.

Chapman, D. P., Perry, G. S., \& Strine, T. W. (2005). The vital link between chronic disease and depressive disorders. Preventing Chronic Disease, 2(1), A14.

Checkley, S. (1992). Neuroendocrine mechanisms and the precipitation of depression by life events. British Journal of Psychiatry Supplement (15), 7-17.

Cho, M. J., Moscicki, E. K., Narrow, W. E., Rae, D. S., Locke, B. Z., \& Regier, D. A. (1993). Concordance between two measures of depression in the Hispanic Health and Nutrition Examination Survey. Social Psychiatry Epidemiology, 28(4), 156163.

Choi, H. (2002). Understanding adolescent depression in ethnocultural context. Advanced Nursing Science, 25(2), 71-85.

Chung, E. K., McCollum, K. F., Elo, I. T., Lee, H. J., \& Culhane, J. F. (2004). Maternal depressive symptoms and infant health practices among low-income women. Pediatrics, 113(6), 523-529.

Coiro, M. J. (2001). Depressive symptoms among women receiving welfare. Women's Health, 32(1-2), 1-23.

Colditz, G. A., Giovannucci, E., Rimm, E. B., Stampfer, M. J., Rosner, B., Speizer, F. E., et al. (1991). Alcohol intake in relation to diet and obesity in women and men. American Journal of Clinical Nutrition, 54(1), 49-55.

Conway, K. P., Compton, W., Stinson, F. S., \& Grant, B. F. (2006). Lifetime comorbidity of DSM-IV mood and anxiety disorders and specific drug use disorders: results from the National Epidemiologic Survey on Alcohol and Related Conditions. Journal of Clinical Psychiatry, 67(2), 247-257.

Cook, J. A., Cohen, M. H., Burke, J., Grey, D., Anastos, K., Kirstein, L., et al. (2002). Effects of depressive symptoms and mental health quality of life on use of highly active antiretroviral therapy among HIV-seropositive women. Journal of Acquired Immune Deficiency Syndrome, 30(4), 401-409.

Cooper-Patrick, L., Ford, D. E., Mead, L. A., Chang, P. P., \& Klag, M. J. (1997). Exercise and depression in midlife: a prospective study. American Journal of Public Health, 87(4), 670-673.

Corcoran, M., Danziger, S., \& Tolman, R. (2003). Long term employment of African American and whites welfare recipients and the role of persistent health and mental health problems. Women and Health, 39(4), 1-25. 
Crawford, M. J. (2004). Depression: international intervention for a global problem. British Journal of Psychiatry, 184, 379-380.

Crespo, C. J., Keteyian, S. J., Heath, G. W., \& Sempos, C. T. (1996). Leisure-time physical activity among US adults. Results from the Third National Health and Nutrition Examination Survey. Archives of Internal Medicine, 156(1), 93-98.

Crespo, C. J., Smit, E., Andersen, R. E., Carter-Pokras, O., \& Ainsworth, B. E. (2000). Race/ethnicity, social class and their relation to physical inactivity during leisure time: results from the Third National Health and Nutrition Examination Survey, 1988-1994. American Journal Preventive Medicine, 18(1), 46-53.

Culbertson, F. M. (1997). Depression and gender. An international review. American Psychology, 52(1), 25-31.

Danziger, S., Corcoran, M., Heflin, C., Kalil, A., Levine, J., Rosen, D., et al. (2000). Barriers to employment of welfare recipients. Retrieved February 24, 2007 from http://www.psc.isr.umich.edu/pubs/pdf/rr02-508.pdf

Danziger, S., Corcoran, M., Danziger, S., Heflin, C., Kalil, A., Rosen, D., et al. (2002). Barriers to the employment of welfare recipients (02-508). Ann Arbor, MI: Population Studies Center, University of Michigan.

Danziger, S. K., \& Seefeldt, K. S. (2002). Barriers to employment and the "hard to serve": Implications for services, sanctions, time limits. Focus, 22(1) 76-91.

Davidson, M., \& Knafl, K. A. (2006). Dimensional analysis of the concept of obesity. Journal of Advanced Nursing, 54(3), 342-350.

Davis, E. M., Rovi, S., \& Johnson, M. S. (2005). Mental health, family function and obesity in African American women. Journal of National Medical Association, 97(4), 478-482.

DeAngelis, T. (2001, October). Welfare reform and women, five years later. Retrieved July 31, 2007, from http://www.apa.org/monitor/oct01/welfare5.html

de Groot, M., Auslander, W., Williams, J. H., Sherraden, M., \& Haire-Joshu, D. (2003). Depression and poverty among African American women at risk for type 2 diabetes. Annals of Behavioral Medicine, 25(3), 172-181.

Deitel, M. (2003a). The breadth of "obesity." Obesity Surgery, 13(5), 665-667.

Deitel, M. (2003b). Overweight and obesity worldwide now estimated to involve 1.7 billion people. Obesity Surgery, 13(3), 329-330.

Department of Health and Human Services. (2008, March). Physical activity statistics: 2007 state summary data. Retrieved March 30, 2008, from http://apps.nccd.cdc.gov/PASurveillance/StateSumV.asp 
Desai, H. D., \& Jann, M. W. (2000). Major depression in women: a review of the literature. Journal of American Pharmacology Association, 40(4), 525-537.

Dessio, W., Wade, C., Chao, M., Kronenberg, F., Cushman, L. E., \& Kalmuss, D. (2004). Religion, spirituality, and healthcare choices of African American women: results of a national survey. Ethnic Disorders, 14(2), 189-197.

Deurenberg, P., Yap, M., \& van Staveren, W. A. (1998). Body mass index and percent body fat: a meta analysis among different ethnic groups. International Journal of Obesity and Related Metabolic Disorders, 22(12), 1164-1171.

Devlin, M. J., Yanovski, S. Z., \& Wilson, G. T. (2000). Obesity: what mental health professionals need to know. American Journal of Psychiatry, 157(6), 854-866.

Dietz, W. H. (1998). Health consequences of obesity in youth: childhood predictors of adult disease. Pediatrics, 105, 518-525.

DiPietro, L., Anda, R. F., Williamson, D. F., \& Stunkard, A. J. (1992). Depressive symptoms and weight change in a national cohort of adults. International Journal of Obesity and Related Metabolic Disorders, 16(10), 745-753.

DiPietro, L., Dziura, J., \& Blair, S. N. (2004). Estimated change in physical activity level (PAL) and prediction of 5-year weight change in men: the Aerobics Center Longitudinal Study. International Journal of Obesity and Related Metabolic Disorders, 28(12), 1541-1547.

Division of Adult and Community Health. (2006). Alcohol and public health - FAQs. Retrieved February 24, 2007, from http://www.cdc.gov/alcohol/faqs.htm

Division of Nutrition and Physical Activity. (2004). Obesity trends. Retrieved January 31, 2005, from http://www.cdc.gov/nccdphp/dnpa/obesity/

Dixon, J. B., Dixon, M. E., \& O'Brien, P. E. (2003). Depression in association with severe obesity: changes with weight loss. Archives of Internal Medicine, 163(17), 2058-2065.

Dong, C., Sanchez, L. E., \& Price, R. A. (2004). Relationship of obesity to depression: a family-based study. International Journal of Obesity and Related Metabolic Disorders 28(6), 790-795.

Dooley, D., \& Prause, J. (2002). Mental health and welfare transitions: depression and alcohol abuse in AFDC women. American Journal of Community Psychology, 30(6), 787-813.

Drewnowski, A., \& Specter, S. E. (2004). Poverty and obesity: the role of energy density and energy costs. American Journal of Clinical Nutrition, 79(1), 6-16. 
Earle, A., \& Heymann, S. J. (2002). What causes job loss among former welfare recipients: the role of family health problems. Journal of American Medical Women's Association, 57(1), 5-10.

Eaton, C. B., Lapane, K. L., Garber, C. E., Gans, K. M., Lasater, T. M., \& Carleton, R. A. (1999). Effects of a community-based intervention on physical activity: the Pawtucket Heart Health Program. American Journal of Public Health, 89(11), 1741-1744.

Eli, K., Quon, B., Quinn, D. I., Dwight-Johnson, M., Wells, A., Lee, P. J., et al., (2007). Improving treatment of depression among low-income patients with cancer: the design of the ADAPt-C study. General Hospital Psychiatry, 29(3), 223-231.

Erdfelder, E., Faul, F. \& Buchner, A. (1996). GPOWER: A general power analysis program. Behavior Research Methods, Instruments, \& Computers, 28, 1-11.

Everson, S. A., Maty, S. C., Lynch, J. W., \& Kaplan, G. A. (2002). Epidemiologic evidence for the relation between socioeconomic status and depression, obesity, and diabetes. Journal of Psychosomatic Research, 53(4), 891-895.

Fahrenwald, N. L., \& Walker, S. N. (2003). Application of the Transtheoretical Model of behavior change to the physical activity behavior of WIC mothers. Public Health Nursing, 20(4), 307-317.

Faith, M. S., Matz, P. E., \& Jorge, M. A. (2002). Obesity-depression associations in the population. Journal of Psychosomatic Research, 53(4), 935-942.

Farmer, M. E., Locke, B. Z., Moscicki, E. K., Dannenberg, A. L., Larson, D. B., \& Radloff, L. S. (1988). Physical activity and depressive symptoms: the NHANES I Epidemiologic Follow-up Study. American Journal of Epidemiology, 128(6), 1340-1351.

Faubel, M. (1989). Body image and depression in women with early and late onset obesity. Journal of Psychology, 123(4), 385-395.

Fisher, M., \& Gordon, T. (1985). The relation of drinking and smoking habits to diet: the Lipid Research Clinics Prevalence Study. American Journal of Clinical Nutrition, 41(3), 623-630.

Fitzgibbon, M. L., Blackman, L. R., \& Avellone, M. E. (2000). The relationship between body image discrepancy and body mass index across ethnic groups. Obesity Research, 8(8), 582-589.

Flegal, K. M., Carroll, M. D., Ogden, C. L., \& Johnson, C. L. (2002). Prevalence and trends in obesity among US adults, 1999-2000. Journal of the American Medical Association, 288(14), 1723-1727. 
Fontaine, K. R., Redden, D. T., Wang, C., Westfall, A. O., \& Allison, D. B. (2003). Years of life lost due to obesity. Journal of the American Medical Association, 289(2), 187-193.

Foster, G. D., Wadden, T. A., \& Vogt, R. A. (1997). Resting energy expenditure in obese African American and Caucasian women. Obesity Research, 5(1), 1-8.

Frank, L. B., Matza, L. S., Revicki, D. A., \& Chung, J. Y. (2005). Depression and healthrelated quality of life for low-income African American women in the U.S. Quality of Life Research, 14(10), 2293-2301.

Friedman, M. A., \& Brownell, K. D. (1995). Psychological correlates of obesity: moving to the next research generation. Psychological Bulletin, 117(1), 3-20.

Gallagher, D., Visser, M., Sepulveda, D., Pierson, R. N., Harris, T., \& Heymsfield, S. B. (1996). How useful is body mass index for comparison of body fatness across age, sex, and ethnic groups? American Journal of Epidemiology, 143(3), 228-239.

Gazmararian, J. A., James, S. A., \& Lepkowski, J. M. (1995). Depression in black and white women. The role of marriage and socioeconomic status. Annals of Epidemiology, 5(6), 455-463.

Gibson, D. (2003). Food stamp program participation is positively related to obesity in low income women. Journal of Nutrition, 133(7), 2225-2231.

Golden, S. H., Williams, J. E., Ford, D. E., Yeh, H. C., Paton Sanford, C., Nieto, F. J., et al. (2004). Depressive symptoms and the risk of type 2 diabetes: the Atherosclerosis Risk in Communities study. Diabetes Care, 27(2), 429-435.

Golub, E. T., Laka, M., Hagan, H., Havens, J. R., Hudson, S. M., Kapadia, F., et al. (2004). Screening for depressive symptoms among HIV-infected injection drug users: Examination of the CES-D and Back Depression Inventory. Journal of Urban Health, 81, 278-290.

Goodman, E., \& Whitaker, R. C. (2002). A prospective study of the role of depression in the development and persistence of adolescent obesity. Pediatrics, 110(3), 497504.

Gordon-Larsen, P., Adair, L. S., Nelson, M. C., \& Popkin, B. M. (2004). Five-year obesity incidence in the transition period between adolescence and adulthood: the National Longitudinal Study of Adolescent Health. American Journal of Clinical Nutrition, 80(3), 569-575.

Gore, S. V. (1999). African American women's perceptions of weight: paradigm shift for advanced practice. Holistic Nursing Practice, 13(4), 71-79. 
Grant, B. F., Hasin, D. S., Chou, S. P., Stinson, F. S., \& Dawson, D. A. (2004). Nicotine dependence and psychiatric disorders in the United States: results from the national epidemiologic survey on alcohol and related conditions. Archives of General Psychiatry, 61(11), 1107-1115.

Greden, J. F. (2001). The burden of recurrent depression: causes, consequences, and future prospects. Journal of Clinical Psychiatry, 62 Supplement 22, 5-9.

Greenberg, P. E., Kessler, R. C., Birnbaum, H. G., Leong, S. A., Lowe, S. W., Berglund, P. A., et al. (2003). The economic burden of depression in the United States: how did it change between 1990 and 2000. Journal of Clinical Psychiatry, 64(12), 1465-1475.

Gruchow H, Sobocinski K, Barboriak J, and Scheller J. (1985). Alcohol consumption, nutrient intake and relative body weight among US adults. American Journal of Clinical Nutrition,42, 289-295.

Guck, T. P., Kavan, M. G., Elsasser, G. N., Barone, E. J. (2001). Assessment and treatment of depression following myocardial infarction. American Family Physician.64(4), 641-648.

Guo, S. S., Roche, A. F., Chumlea, W. C., Gardner, J. D., \& Siervogel, R. M. (1994). The predictive value of childhood body mass index values for overweight at age 35 years. American Journal of Clinical Nutrition, 59(4), 810-819.

Haas, J. S., Lee, L. B., Kaplan, C. P., Sonneborn, D., Phillips, K. A., \& Liang, S. Y. (2003). The association of race, socioeconomic status, and health insurance status with the prevalence of overweight among children and adolescents. American Journal of Public Health, 93(12), 2105-2110.

Hall, L. A., Gurley, D. N., Sachs, B., \& Kryscio, R. J. (1991). Psychosocial predictors of maternal depressive symptoms, parenting attitudes, and child behavior in singleparent families. Nursing Research, 40(4), 214-220.

Hallstrom, T., \& Noppa, H. (1981). Obesity in women in relation to mental illness, social factors and personality traits. Journal of Psychosomatic Research, 25(2), 75-82.

Hankin, B. L., Abramson, L. Y., Moffitt, T. E., Silva, P. A., McGee, R., \& Angell, K. E. (1998). Development of depression from preadolescence to young adulthood: emerging gender differences in a 10-year longitudinal study. Journal of Abnormal Psychology, 107(1), 128-140.

Hasin, D. S., Goodwin, R. D., Stinson, F. S., \& Grant, B. F. (2005). Epidemiology of major depressive disorder: results from the National Epidemiologic Survey on Alcoholism and Related Conditions. Archives of General Psychiatry, 62(10), 1097-1106. 
Haskell, W. L., Lee, I. M., Pate, R. R., Powell, K. E., Blair, S. N., Franklin, B. A., et al. (2007). Physical activity and public health: updated recommendation for adults from the American College of Sports Medicine and the American Heart Association. Medicine and Science in Sports and Exercise, 39(8), 1423-1434.

Health Resources and Services Administration (2004). Women's health USA 2004. Merrifield, VA: Department of Health and Human Services.

Healthier People Network, Inc. (1991). Healthier People Network Health Risk Appraisal (HPN-HRA, Version 6.0). Atlanta, GA, Healthier People Network, Inc.

Hedley, A. A., Ogden, C. L., Johnson, C. L., Carroll, M. D., Curtin, L. R., \& Flegal, K. M. (2004). Prevalence of overweight and obesity among US children, adolescents, and adults, 1999-2002. Journal of American Medical Association, 291(23), 28472850 .

Heflin, C. M., Siefert, K., \& Williams, D. R. (2005). Food insufficiency and women's mental health: findings from a 3-year panel of welfare recipients. Social Science and Medicine, 61(9), 1971-1982.

Henderson, L.C. (2002). The cultural construction of diabetes mellitus among Oklahoma Choctaw elders and health care providers: discordance between models. Association for Anthropology and Gerontology Newsletter, 23(1), 4-6.

Heneghan, A. M., Silver, E. J., Bauman, L. J., Westbrook, L. E., \& Stein, R. E. (1998). Depressive symptoms in inner-city mothers of young children: who is at risk? Pediatrics, 102(6), 1394-1400.

Hildebrandt, E., \& Kelber, S. T. (2005). Perceptions of health and well-being among women in a work-based welfare program. Public Health Nursing, 22(6), 506-514.

Hill, J.O., Wyatt, H.R., Melanson, E.L. (2000). Genetic and environmental contributions to obesity. Medical Clinics of North America, 84, 333-346.

Hilton, M. E. (1991). The Demographic Distribution of Drinking Patters in 1984. In: Clark, W. B., \& Hilton, M. E. (Eds.). Alcohol in America: Drinking Practices and Problems. (pp. 73-86). Albany, New York: State University of New York Press, 1991.

Hitz, S. (2005). Obesity in America-The Growing Epidemic. Retrieved October 12, 2007, from http://ezinearticles.com/?Obesity-in-America----The-GrowingEpidemic $\stackrel{\text { \&id }=7567}{ }$

Hobfoll, S. E., Ritter, C., Lavin, J., Hulsizer, M. R., \& Cameron, R. P. (1995). Depression prevalence and incidence among inner-city pregnant and postpartum women. Journal of Consulting and Clinical Psychology, 63(3), 445-453. 
$\mathrm{Hu}, \mathrm{F}$. B. (2003). Overweight and obesity in women: health risks and consequences. Journal of Women's Health (Larchmont), 12(2), 163-172.

Istvan, J., Zavela, K., \& Weidner, G. (1992). Body weight and psychological distress in NHANES I. International Journal of Obesity and Related Metabolic Disorders, 16(12), 999-1003.

Jackson, A. P. (2006). The use of psychiatric medications to treat depressive disorders in African American women. Journal of Clinical Psychology, 62(7), 793-800.

Jakicic, J. M., \& Wing, R. R. (1998). Differences in resting energy expenditure in African American versus Caucasian overweight females. International Journal of Obesity and Related Metabolic Disorders, 22(3), 236-242.

James, S. A., Fowler-Brown, A., Raghunathan, T. E., \& Van Hoewyk, J. (2006). Lifecourse socioeconomic position and obesity in African American Women: the Pitt County Study. American Journal of Public Health, 96(3), 554-560.

James, W P T. (2002). A world view of the obesity problem. In Fairburn, C. G., \& Brownell, K. D. (Eds.), Eating disorders and obesity (pp. 411-421). New York: Guilford Press.

Jayakody, R., Danziger, S., \& Pollack, H. (2000). Welfare reform, substance use, and mental health. Journal of Health Politics, Policy and Law, 25(4), 623-651.

Jesse, D. E., Walcott-McQuigg, J., Mariella, A., \& Swanson, M. S. (2005). Risks and protective factors associated with symptoms of depression in low-income African American and Caucasian women during pregnancy. Journal of Midwifery and Women's Health, 50(5), 405-410.

Joffe, H., \& Cohen, L. S. (1998). Estrogen, serotonin, and mood disturbance: where is the therapeutic bridge? Biological Psychiatry, 44(9), 798-811.

Jones, D., O'Connell, C., Gound, M., Heller, L., \& Forehead, R. (2004). Predictors of self-reported physical symptoms in low-income, inner-city, African American women: The Role of Optimism, Depressive Symptoms, and Chronic Illness. Psychology of Women Quarterly, 28 112-121.

Jones-Webb, R. J., \& Snowden, L. R. (1993). Symptoms of depression among blacks and whites. American Journal of Public Health, 83(2), 240-244.

Kaplan, G. A., Siefert, K., Ranjit, N., Raghunathan, T. E., Young, E. A., Tran, D., et al. (2005). The health of poor women under welfare reform. American Journal of Public Health, 95(7), 1252-1258.

Katon, W., von Korff, M., Ciechanowski, P., Russo, J., Lin, E., Simon, G., et al. (2004). Behavioral and clinical factors associated with depression among individuals with diabetes. Diabetes Care, 27(4), 914-920. 
Kendler, K. S., Eaves, L. J., Walters, E. E., Neale, M. C., Heath, A. C., \& Kessler, R. C. (1996). The identification and validation of distinct depressive syndromes in a population-based sample of female twins. Archives of General Psychiatry, 53(5), 391-399.

Kessler, R. B., Berglund, P., Demler, O., Jin, R., Merikangas, K. R., Walters, E. E. (2005). Lifetime prevalence and age-of-onset distributions of DSM-IV disorders in the National Comorbidity Survey Replication. Archives of General Psychiatry, $62,593-602$.

Kessler, R. C., McGonagle, K. A., Swartz, M., Blazer, D. G., \& Nelson, C. B. (1993). Sex and depression in the National Comorbidity Survey. I: Lifetime prevalence, chronicity and recurrence. Journal of Affective Disorders, 29(2-3), 85-96.

Kessler, R. C., Mickelson, K. D., \& Williams, D. R. (1999). The prevalence, distribution, and mental health correlates of perceived discrimination in the United States. Journal of Health and Social Behavior, 40(3), 208-230.

Kohn, L. P., \& Hudson, K. M. (2002). Gender, ethnicity, and depression: Intersectionality and context in mental health research with African American women. Perspectives, 8(1), 174-184.

Kornstein, S. G. (1997). Gender differences in depression: implications for treatment. Journal of Clinical Psychiatry 58, Supplement 15, 12s-18s.

Krieger, N., \& Zierler, S. (1995). What explains the public's health? A call for the epidemiologic theory. Epidemiology 7, 107-109.

Kritz-Silverstein, D., Barrett-Connor, E., \& Corbeau, C. (2001). Cross-sectional and prospective study of exercise and depressed mood in the elderly: the Rancho Bernardo study. American Journal of Epidemiology, 153(6), 596-603.

Kumanyika, S. (1987). Obesity in black women. Epidemiological Review, 9, 31-50.

Kushner, R. F. (2003). The office approach to the obese patient. Primary Care, 30(2), 327-340.

Kushner, R. F., Racette, S. B., Neil, K., \& Schoeller, D. A. (1995). Measurement of physical activity among black and white obese women. Obesity Research, 3, Supplement 2, 261s-265s.

Kushner, R. F., \& Roth, J. L. (2005). Medical evaluation of the obese individual. Psychiatric Clinics North America, 28(1), 89-103, viii.

Langenberg, C., Hardy, R., Kuh, D., Brunner, E., \& Wadsworth, M. (2003). Central and total obesity in middle aged men and women in relation to lifetime socioeconomic status: evidence from a national birth cohort. Journal of Epidemiology and Community Health, 57(10), 816-822. 
Lawlor, D. A., Ebrahim, S., \& Davey Smith, G. (2002). Socioeconomic position in childhood and adulthood and insulin resistance: cross sectional survey using data from British women's heart and health study. British Medical Journal, 325(7368), 805.

Leff, A. (2002). Race, Poverty, and Hunger. Poverty \& Race Research Action Council, 7796, 1-6.

Lemay, C. A., Cashman, S., Savageau, J., Fletcher, K., Kinney, R., \& Long-Middleton, E. (2003). Underdiagnosis of obesity at a community health center. Journal of American Board of Family Practice, 16(1), 14-21.

Lerner, D., Adler, D. A., Chang, H., Lapitsky, L., Hood, M. Y., Perissinotto, C., et al. (2004). Unemployment, job retention, and productivity loss among employees with depression. Psychiatric Services, 55(12), 1371-1378.

Lennon, M. C., Blome, J., \& English, K. (2001). Depression and low-income women: challenges for TANF and Welfare-to-Work policies and programs. Retrieved October 12, 2008 from http://www.researchforum.org/media/Depression410.pdf

Levin-Epstein, J. (2003, April). Welfare, women and health: the role of temporary assistance to needy families. Retrieved October 12, 2008 from http://www.kff.org/womenshealth/loader.cfm?url=/commonspot/security/getfile.c $\underline{\text { fm\&PageID }=14295}$

Liburd, L. C., \& Vinicor, F. (2003). Rethinking diabetes prevention and control in racial and ethnic communities. Journal of Public Health Management and Practice, Nov, Supplement, S74-79.

Link, B. G., \& Phelan, J. (1995). Social conditions as fundamental causes of disease. Journal of Health and Social Behavior, Spec No, 80-94.

London, A., \& Scott, E. (2004). Food security, stability, and change among low income urban women (0503). Retrieved March 30, 2007 from http://ideas.repec.org/p/har/wpaper/0503.html\#provider

Maes, M., Meltzer, H. Y., Stevens, W., Calabrese, J., \& Cosyns, P. (1994). Natural killer cell activity in major depression: relation to circulating natural killer cells, cellular indices of the immune response, and depressive phenomenology. Progressive Neuropsychopharmacology Biological Psychiatry, 18(4), 717-730.

Marano, H. E. (2003). Race and the blues (3025). Retrieved May 25, 2004 from http://www.psychologytoday.com/articles/pto-20030930-000001.html

Martin, P. D., Dutton, G. R., \& Brantley, P. J. (2004). Self-efficacy as a predictor of weight change in African American women. Obesity Research, 12(4), 646-651. 
Mazure, C. M., Maciejewski, P. K., Jacobs, S. C., \& Bruce, M. L. (2002). Stressful life events interacting with cognitive/personality styles to predict late-onset major depression. American Journal of Geriatric Psychiatry, 10(3), 297-304.

McCoy, K. (2003). Widespread depression costs employers billions. Retrieved October 12, 2008, from http://healthlibrary.epnet.com/GetContent.aspx?token=af362d974f80-4453-a175-02cc6220a387\&chunkiid=38871

McElroy, S. L., Kotwal, R., Malhotra, S., Nelson, E. B., Keck, P. E., \& Nemeroff, C. B. (2004). Are mood disorders and obesity related? A review for the mental health professional. Journal of Clinical Psychiatry, 65(5), 634-651.

McGrath, E., Keita, G. P., Strickland, B. R., \& Russo, N. F. (1990). Women and depression: risk factors and treatment issues: Final Report of the American Psychological Association Task Force on Women and Depression. Washington, DC: American Psychological Association.

McLennan, J. (2004). Obesity in children. Tackling a growing problem. Australian Family Physician, 33(1-2), 33-36.

McLennan, J. D., Kotelchuck, M., \& Cho, H. (2001). Prevalence, persistence, and correlates of depressive symptoms in a national sample of mothers of toddlers. Journal of American Academy of Child and Adolescent Psychiatry, 40(11), 13161323.

McTigue, K. M., Garrett, J. M., \& Popkin, B. M. (2002). The natural history of the development of obesity in a cohort of young U.S. adults between 1981 and 1998. Annals of Internal Medicine, 136(12), 857-864.

Mental Health Resource Center. (2006). Depression: depression in women. Retrieved October 12, 2008, from http://www.mentalhealthamerica.net/index.cfm?objectid=C7DF952E-1372-4D20C8A3DDCD5459D07B

Metsch, L. R., \& Pollack, H. A. (2005). Welfare reform and substance abuse. Milbank $Q$, 83(1), 65-99.

Montoya, I. D., Bell, D. C., Atkinson, J. S., Nagy, C. W., \& Whitsett, D. D. (2002). Mental health, drug use, and the transition from welfare to work. Journal of Behavioral Health Services Research, 29(2), 144-156.

Morbidity and Mortality Weekly Report (2002, August). Women and smoking: a report of the Surgeon General (51 RR12). Retrieved January 21, 2007 from http://www.cdc.gov/mmwr/preview/mmwrhtml/rr5112a4.htm 
Morbidity and Mortality Weekly Report. (2005, October). Trends in leisure time physical inactivity by age, sex, and race/ethnicity - United States 1994-2004. Retrieved March 2, 2007, from http://www.cdc.gov/mmwr/preview/mmwrhtml/mm5439a5.htm\#fig2

Morbidity and Mortality Weekly Report. (2007, November). Prevalence of regular physical activity among adults - United States, 2001 and 2005. Retrieved February 24, 2008, from http://www.cdc.gov/mmwr/preview $/ \mathrm{mmwrhtml} / \mathrm{mm} 5646 \mathrm{a} 1 . \mathrm{htm} ? \mathrm{~s} \_\mathrm{cid}=\mathrm{mm} 5646 \mathrm{a}$ $\underline{1} \underline{\mathrm{e}}$

Morbidity and Mortality Weekly Report. (2008, July). State-specific prevalence of obesity among adults --- United States, 2007. Retrieved July 31, 2008, from http://www.cdc.gov/mmwr/preview/mmwrhtml/mm5728a1.htm

Moreland, K., Wing, S., Diez, R. A., \& Poole, C. (2002). Neighborhood characteristics associated with the lcocation of food stores and food services places. American Journal of Preventive Medicine, 22(1), 23-29.

Mulrow, C. D., Williams, J. W., Jr., Gerety, M. B., Ramirez, G., Montiel, O. M., \& Kerber, C. (1995). Case-finding instruments for depression in primary care settings. Annals of Internal Medicine, 122(12), 913-921.

Murray, C. J. L., Lopez, A. D. (1997). Quantifying global mortality, disability, and the contribution of risk factors: results of the Global Burden of Disease Study. The Lancet, 349, 1436-1442.

Murry, V. M., Brody, G. H., Brown, J., Wisenbaker, J., Cutrona, C. E., \& Simons, R. L. (2002). Linking employment status, maternal psychological well-being, parenting and children's attributions about poverty in families receiving government assistance. Family Relations, 51(2), 112-120.

Mustillo, S., Worthman, C., Erkanli, A., Keeler, G., Angold, A., \& Costello, E. J. (2003). Obesity and psychiatric disorder: developmental trajectories. Pediatrics, $111(4 \mathrm{Pt}$ 1), 851-859.

National Cancer Institute. (2005). Tobacco related cancers in women - smoking raises the risk of many cancers. Retrieved December 8, 2006, from http://plan2005.cancer.gov/stories.html

National Center for Chronic Disease Prevention and Health Promotion. (2006). Behavioral risk factor surveillance system. Retrieved February 24, 2007, from http://www.cdc.gov/brfss/about.htm

National Center for Health Statistics. (2006). Obesity still a major problem. Retrieved February 14, 2007, from http://www.cdc.gov/nchs/pressroom/06facts/obesity03 04.htm 
National Institute of Mental Health. (2004). Depression. Retrieved April 9, 2005, from http://www.nimh.nih.gov/publicat/depression.cfm

National Institute of Mental Health. (2007). Women and depression: discovering hope. Retrieved June 27, 2007, from National Institute of Health Web Site: http://www.nimh.nih.gov/health/publications/depression-what-every-womanshould-know/summary.shtml

Nazroo, J. Y., Edwards, A. C., \& Brown, G. W. (1997). Gender differences in the onset of depression following a shared life event: a study of couples. Psychological Medicine, 27(1), 9-19.

Nicklas, B. J., Toth, M. J., Goldberg, A. P., \& Poehlman, E. T. (1997). Racial differences in plasma leptin concentrations in obese postmenopausal women. Journal of Clinical Endocrinology and Metabolism, 82(1), 315-317.

Nishizawa, S., Benkelfat, C., Young, S. N., Leyton, M., Mzengeza, S., de Montigny, C., et al. (1997). Differences between males and females in rates of serotonin synthesis in human brain. Proceedings of the National Academy of Science United States of America, 94(10), 5308-5313.

Office of Disease Prevention and Health Promotion (2001). Overweight and obesity: $a$ major public health issue (16). Retrieved February 13, 2007 from http://odphp.osophs.dhhs.gov/pubs/prevrpt/01fall/pr.htm

Office on Women's Health (2001). Surgeon General's report on women and smoking. African American women and smoking. Washington, DC: United States Department of Health and Human Services.

Ogden, C. L., Carroll, M. D., Curtin, L. R., McDowell, M. A., Tabak, C. J., \& Flegal, K. M. (2006). Prevalence of overweight and obesity in the United States, 1999-2004. Journal of the American Medical Association, 295(13), 1549-1555.

Olson, K., \& Pavetti, L. (1996). Personal and family challenges to the successful transition from welfare to work. Washington, DC: The Urban Institute.

Onyike, C. U., Crum, R. M., Lee, H. B., Lyketsos, C. G., \& Eaton, W. W. (2003). Is obesity associated with major depression? Results from the Third National Health and Nutrition Examination Survey. American Journal of Epidemiology, 158(12), 1139-1147.

Owens, T. M. (2003). Morbid obesity: the disease and co-morbidities. Critical Care Nursing Quality, 26(2), 162-165.

Paeratakul, S., White, M. A., Williamson, D. A., Ryan, D. H., \& Bray, G. A. (2002). Sex, race/ethnicity, socioeconomic status, and BMI in relation to self-perception of overweight. Obesity Research, 10(5), 345-350. 
Palinkas, L. A., Wingard, D. L., \& Barrett-Connor, E. (1996). Depressive symptoms in overweight and obese older adults: a test of the "jolly fat" hypothesis. Journal of Psychosomatic Research, 40(1), 59-66.

Partnership for Prevention. (2005). Straight talk about obesity and health. Retrieved July 18, 2007, from http://www.acsworkplacesolutions.com/documents/ObesitImpactv2.pdf

Parvez, Z. F. (2002, August 15). Women, poverty and welfare reform. Retrieved February 8, 2007, from http://www.socwomen.org/socactivism/factwelfare.pdf

Patt, M. R., Yanek, L. R., Moy, T. F., \& Becker, D. M. (2004). Sociodemographic, behavioral, and psychological correlates of current overweight and obesity in older, urban African American women. Health Education Behavior, 31(4 Supplement), 57S-68S.

Peden, A. R., Rayens, M. K., Hall, L. A., \& Grant, E. (2004). Negative thinking and the mental health of low-income single mothers. Journal of Nursing Scholarship, 36(4), 337-344.

Perdue, T., Hagan, H., Thiede, H., \& Valleroy, L. (2003). Depression and HIV risk behavior among Seattle-area injection drug users and young men who have sex with men. AIDS Education and Prevention, 15(1), 81-92.

Petersen, L., Schnohr, P., \& Sorensen, T. I. (2004). Longitudinal study of the long-term relation between physical activity and obesity in adults. International Journal of Obesity and Related Metabolic Disorders, 28(1), 105-112.

Pi-Sunyer, F. X. (2002). The obesity epidemic: pathophysiology and consequences of obesity. Obesity Research, 10, Supplement 2, 97S-104S.

Pine, D. S., Goldstein, R. B., Wolk, S., \& Weissman, M. M. (2001). The association between childhood depression and adulthood body mass index. Pediatrics, 107(5), 1049-1056.

Poleshuck, E. L., Giles, D. E., \& Tu, X. (2006). Pain and depressive symptoms among financially disadvantaged women's health patients. Journal of Women's Health, 15(2), 182-193.

Polit, D. F., London, A. S., \& Martinez, J. M. (2001). The health of poor urban women: findings from the project on devolution and urban change. New York: Manpower Demonstration Research Corporation.

Polit, D. F., \& Beck, C. T. (2004). Developing a conceptual context (pp. 115-116). In: Margaret Zuccarini (Ed.), Nursing Research: Principles and Methods. Philadelphia, Lippincott, Williams \& Wilkins. 
Pollack, H. A., Danziger, S., Jayakody, R., \& Seefeldt, K. S. (2002). Drug testing welfare recipients--false positives, false negatives, unanticipated opportunities. Women's Health Issues, 12(1), 23-31.

Power, C., Manor, O., \& Matthews, S. (2003). Child to adult socioeconomic conditions and obesity in a national cohort. International Journal of Obesity and Related Metabolic Disorders, 27(9), 1081-1086.

Prentice, A. M., \& Jebb, S. A. (2001). Beyond body mass index. Obesity Review, 2(3), 141-147.

Radloff, L. (1977). Center for Epidemiologic Studies Depression Scale. New York, NY, West Publishing Company.

Radloff, L. (1977). A self report depression scale for research in the general population. Applied Psychological Measurement, 1(3), 385-401.

Ramsey, P. W., \& Glenn, L. L. (2002). Obesity and health status in rural, urban, and suburban southern women. South Medicine Journal, 95(7), 666-671.

Rector, R. S., Warner, S. O., Liu, Y., Hinton, P. S., Sun, G. Y., Cox, R. H., et al. (2007). Exercise and diet induced weight loss improves measures of oxidative stress and insulin sensitivity in adults with characteristics of the metabolic syndrome. American Journal of Physiology, Endocrinology, and Metabolism, 293(2), 500506.

Ren, X. S., Amick, B. C., \& Williams, D. R. (1999). Racial/ethnic disparities in health: the interplay between discrimination and socioeconomic status. Ethnic Disorders, 9(2), 151-165.

Rice, M. C., \& Wicks, M. N. (2006). Assessing the health of women from welfare to work. Association of Women's Health, Obstetrics and Neonatal Nursing, 9(6), 468-472.

Rice, M. C, Wicks, M. N., \& Martin, J. C. (2008). Health risk characteristics of black female informal caregivers on welfare. Clinical Nursing Research, 17(1), 20-31.

Richardson, L. P., Davis, R., Poulton, R., McCauley, E., Moffitt, T. E., Caspi, A., et al. (2003). A longitudinal evaluation of adolescent depression and adult obesity. Archives Pediatric Adolescent Medicine, 157(8), 739-745.

Riley, N. M., Bild, D. E., Cooper, L., Schreiner, P., Smith, D. E., Sorlie, P., et al. (1998). Relation of self-image to body size and weight loss attempts in black women: the CARDIA study. Coronary Artery Risk Development in Young Adults. American Journal of Epidemiology, 148(11), 1062-1068.

Roberts, R. E. (1980). Reliability of The CES-D scale in different ethnic contexts. Psychiatry Researc, 2, 125-134. 
Roberts, R. E., Kaplan, G. A., Shema, S. J., \& Strawbridge, W. J. (2000). Are the obese at greater risk for depression? American Journal of Epidemiology, 152(2), 163 170 .

Roberts, R. E., Strawbridge, W. J., Deleger, S., \& Kaplan, G. A. (2002). Are the fat more jolly? Annals Behavioral Medicine, 24(3), 169-180.

Rodriguez, E., \& Chandra, P. (2006). Alcohol, employment status, and social benefits: one more piece of the puzzle. American Journal of Drug and Alcohol Abuse, $32(2), 237-259$.

Rohrer, J. E., Rohland, B. M., Denison, A., \& Way, A. (2005). Frequency of alcohol use and obesity in community medicine patients. Biomedical Central Family Practice, 6(1), 17.

Rohrer, J. E., \& Roland, B. M. (2004). Psychological risk factors for obesity among women in a family planning clinic. Biomedical Central Family Practice, 5(20), 16.

Romero, D., Chavkin, W., Wise, P. H., Smith, L. A., \& Wood, P. R. (2002). Welfare to work? Impact of maternal health on employment. American Journal of Public Health, 92(9), 1462-1468.

Rosenberg, L., Palmer, J. R., Adams-Campbell, L. L., \& Rao, R. S. (1999). Obesity and hypertension among college-educated black women in the United States. Journal of Human Hypertension, 13(4), 237-241.

Rosman, E. A., \& Yoshikawa, H. (2001). Effects of welfare reform on children of adolescent mothers: moderation by maternal depression, father involvement, and grandmother involvement. Women's Health, 32(3), 253-290.

Rosmond, R., \& Bjorntorp, P. (2000). The role of antidepressants in the treatment of abdominal obesity. Medical Hypotheses, 54(6), 990-994.

Ross, C. E. (1994). Overweight and depression. Journal of Health and Social Behavior, 35(1), 63-79.

Rubin, R. T. (1989). Pharmacoendocrinology of major depression. European Archives of Psychiatry and Neurology Science, 238(5-6), 259-267.

Rumpel, C., Ingram, D. D., Harris, T. B., \& Madans, J. (1994). The association between weight change and psychological well-being in women. International Journal of Obesity and Related Metabolic Disorders, 18(3), 179-183.

Salinsky, E., \& Scott, W. (2003). Obesity in America: a growing threat. Retrieved February 17, 2007 from http://www.4genspec.com/docs/nhpf obesity.pdf 
Sammel, M. D., Grisso, J. A., Freeman, E. W., Hollander, L., Liu, L., Liu, S., et al. (2003). Weight gain among women in the late reproductive years. Family Practice, 20(4), 401-409.

Sanchez-Johnson, L. A., Dymek, M., Alverdy, J., \& le Grange, D. (2003). Binge eating and eating-related cognitions and behavior in ethnically diverse obese women. Obesity Research, 11(8), 1002-1009.

Sanderson, B., Littleton, M., \& Pulley, L. (2002). Environmental, policy, and cultural factors related to physical activity among rural, African American women. Women's Health, 36(2), 75-90.

Schmidt, L. A., \& McCarty, D. (2000). Welfare reform and the changing landscape of substance abuse services for low-income women. Alcoholism Clinical and Experimental Research, 24(8), 1298-1311.

Serdula, M. K., Ivery, D., Coates, R. J., Freedman, D. S., Williamson, D. F., \& Byers, T. (1993). Do obese children become obese adults? A review of the literature. Preventive Medicine, 22(2), 167-177.

Serdula, M. K., Khan, L. K., \& Dietz, W. H. (2003). Weight loss counseling revisited. JAMA, 289(14), 1747-1750.

Sharp, T. A., Bell, M. L., Grunwald, G. K., Schmitz, K. H., Sidney, S., Lewis, C. E., et al. (2002). Differences in resting metabolic rate between white and African American young adults. Obesity Research, 10(8), 726-732.

Siefert, K., Bowman, P. J., Heflin, C. M., Danziger, S., \& Williams, D. R. (2000). Social and environmental predictors of maternal depression in current and recent welfare recipients. American Journal of Orthopsychiatry, 70(4), 510-522.

Siefert, K., Corcoran, M. E., \& Heflin, C. M. (2000). Food insecurity and welfare reform. Ann Arbor, MI: Poverty Research and Training Center, University of Michigan School of Social Work.

Siefert, K., Heflin, C. M., Corcoran, M. E., \& Williams, D. R. (2004). Food insufficiency and physical and mental health in a longitudinal survey of welfare recipients. Journal of Health and Social Behavior, 45(2), 171-186.

Siefert, K., Finlayson, T. L., Williams, D. R., Delva, J., \& Ismail, A. I. (2007). Modifiable risk and protective factors for depressive symptoms in low-income African American mothers. American Journal of Orthopsychiatry, 77(1), 113123.

Siegel, J. M., Yancey, A. K., \& McCarthy, W. J. (2000). Overweight and depressive symptoms among African American women. Preventive Medicine, 31(3), 232240. 
Siegert, R. J., \& Abernethy, D. A. (2005). Depression in multiple sclerosis: a review. Journal of Neurology, Neurosurgery, and Psychiatry, 76(4), 469-475.

Sipkoff, M. (2006). Skeptics abound as demand grows for obesity treatments. Managed Care, 15(1), 16, 18.

Sparling, P. B., Owen, N., Lambert, E. V., \& Haskell, W. L. (2000). Promoting physical activity: the new imperative for public health. Health Education Research, 15(3), 367-376.

Stearns, P. (1997). Fat History: Bodies and Beauty in the Modern West. New York: New York University Press.

Stokes, P. E. (1995). The potential role of excessive cortisol induced by HPA hyperfunction in the pathogenesis of depression. European Neuropsychopharmacology, 5, 77-82.

Strawbridge, W. J., Deleger, S., Roberts, R. E., \& Kaplan, G. A. (2002). Physical activity reduces the risk of subsequent depression for older adults. American Journal of Epidemiology, 156(4), 328-334.

Strickland, P. L., Deakin, J. F., Percival, C., Dixon, J., Gater, R. A., \& Goldberg, D. P. (2002). Bio-social origins of depression in the community. Interactions between social adversity, cortisol and serotonin neurotransmission. British Journal of Psychiatry, 180, 168-173.

Stunkard, A. J., Faith, M. S., \& Allison, K. C. (2003). Depression and obesity. Biological Psychiatry, 54(3), 330-337.

Sullivan, P. F., Neale, M. C., \& Kendler, K. S. (2000). Genetic epidemiology of major depression: review and meta-analysis. American Journal of Psychiatry, 157(10), 1552-1562.

Thurston, R. C., Kubzansky, L. D., Kawachi, I., \& Berkman, L. F. (2005). Is the association between socioeconomic position and coronary heart disease stronger in women than in men? American Journal of Epidemiology, 162(1), 57-65.

Torabi, M., Ding, K. (1998). Selected critical measurement and statistical issues in health education evaluation and research. The International Electronic Journal of Health Education, 1(1), 26-38.

Townsend, M. S., Peerson, J., Love, B., Achterberg, C., \& Murphy, S. P. (2001). Food insecurity is positively related to overweight in women. Journal of Nutrition, 131(6), 1738-1745.

Vander, M., Ward, K., Scarinci, I., \& al, e. (2006). Smoking-related correlates of depressive symptoms in low-income pregnant women. American Journal Health Behavior, 28(6), 510-521. 
Waite, R., \& Killian, P. (2007). Exploring Depression Among a Cohort of African American Women. Journal of American Psychiatric Nurses Association, 13(3), 161-169.

Wang, Y., Monteiro, C., \& Popkin, B. M. (2002). Trends of obesity and underweight in older children and adolescents in the United States, Brazil, China, and Russia. American Journal of Clinical Nutrition, 75(6), 971-977.

Webb, M. S., \& Carey, M. P. (2008). Tobacco smoking among low-income Black women: demographic and psychosocial correlates in a community sample. Nicotine and Tobacco Research, 10(1), 219-229.

Weissman, M. M., \& Olfson, M. (1995). Depression in women: implications for health care research. Science, 269(5225), 799-801.

Whitaker, R. C., Wright, J. A., Pepe, M. S., Seidel, K. D., \& Dietz, W. H. (1997). Predicting obesity in young adulthood from childhood and parental obesity. New England Journal Medicine, 337(13), 869-873.

Wilen, J. M., \& Mounts, K. O. (2006). Women with depression--"You Can't Tell by Looking". Maternal Child Health Journal, 10, 5 Supplement, S183-186.

Williams, D., Yu, Y., Jackson, J., \& Anderson, N. (1997). Racial differences in physical and mental health. Journal of Health Psychology, 2, 335-351.

Williams, D. R., Takeuchi, D. T., \& Adair, R. K. (1992). Marital status and psychiatric disorders among blacks and whites. Journal Health Social Behavior, 33(2), 140157.

Wise, L. A., Adams-Campbell, L. L., Palmer, J. R., \& Rosenberg, L. (2006). Leisure time physical activity in relation to depressive symptoms in the Black Women's Health Study. Annals Behavior Medicine, 32(1), 68-76.

Wolfe, W. S., Sobal, J., Olson, C. M., Frongillo, E. A., Jr., \& Williamson, D. F. (1997). Parity-associated weight gain and its modification by sociodemographic and behavioral factors: a prospective analysis in US women. International Journal Obesity Related Metabolic Disorder, 21(9), 802-810.

World Health Organization (2004). The World Health Report: Changing History Annex Table 3: Burden of disease in DALYs by cause, sex, and mortality stratum in WHO regions, estimates for 2002. Retrieved October 12, 2008 from http://www.who.int/whr/2004/annex/en/

Worley, H. (2006). Depression: a leading contributor to the global burden of disease. Population Reference Bureau. Retrieved March 20, 2007 from http://www.coa.gov.ph/gad/articles/depression_062006.htm 
Wurtman, J. J. (1993). Depression and weight gain: the serotonin connection. Journal Affective Disorder, 29(2-3), 183-192.

Wyatt, S. B., Winters, K. P., \& Dubbert, P. M. (2006). Overweight and obesity: prevalence, consequences, and causes of a growing public health problem. American Journal of Medical Science, 331(4), 166-174.

Wyshak, G. (2001). Women's college physical activity and self-reports of physiciandiagnosed depression and of current symptoms of psychiatric distress. Journal of Women's Health and Gender Based Medicine, 10(4), 363-370.

Yarandi, H. N., \& Gary, F. A. (2004). Mutiple regression: multicollinearity. In Yarandi, H. Yarandi, \& Gary, F. (Eds.), Research methods and applied statistics (pp. 148161). Washington: Substance Abuse Mental Health Services Administration.

Yoon, Y. S., Oh, S. W., \& Park, H. S. (2006). Socioeconomic status in relation to obesity and abdominal obesity in Korean adults: a focus on sex differences. Obesity Research, 14(5), 909-919.

York, D. A., Rossner, S., Caterson, I., Chen, C. M., James, W. P., Kumanyika, S., et al. (2004). Prevention Conference VII: Obesity, a worldwide epidemic related to heart disease and stroke: Group I: worldwide demographics of obesity. Circulation, 110(18), 463-470.

Zhang, Q., \& Wang, Y. (2004). Socioeconomic inequality of obesity in the United States: do gender, age, and ethnicity matter? Social Science Medicine, 58(6), 1171-1180. 


\section{VITA}

Mayola Barbry Rowser was born in Evansville, IN, in 1956. She graduated from the University of Evansville in 1984 in Evansville, Indiana where she earned an Associate of Science Degree in Nursing. She continued her studies and earned a Bachelor of Science in Nursing in 1995 and a Master of Science in Nursing Degree in 1999 from the University of Southern Indiana in Evansville, Indiana. Ms. Rowser entered the Doctor of Nursing Practice program, Psychiatric Family Nurse Practitioner option at The University of Tennessee Health Science Center in Memphis, Tennessee in July, 2002 and graduated in May, 2005. Ms. Rowser enrolled in the PhD in Nursing Program at The University of Tennessee Health Science Center in July, 2005 and will graduate in December 2008. 